COLUMBIA LIBRARIES OFFSITE

HEALTH SCIENCES STANDARD

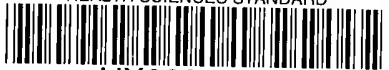

HX00066702

RECAP 
COLUMBIA UNIVERSITY

THE LIBRARIES

HEALTH SCIENCES

LIBRARY

1רC $4+0$ उ8

Colunthia Antuersíty

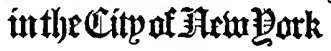

OTallege af

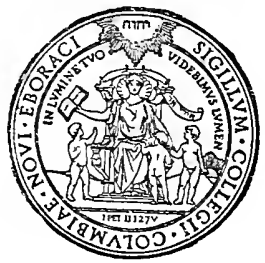

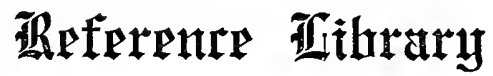

(Btuen byy

Dr. Georqe Mosmer. 

Digitized by the Internet Archive in 2010 with funding from Open Knowledge Commons 
THE CARE OF THE INSANE

AND THEIR

\section{LEGAL CONTROL}




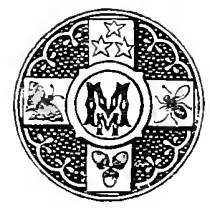




\section{THE}

\section{CARE OF THE INSANE}

AND THEIR

\section{LEGAL CONTROL}

BY

\section{JOHN CHARLES BUCKNILL}

M.D. Lowd., F.R.S.

Follow ard Censor of the Royal College of Physicians; Late Iord Chancellor's Fisitor of I.unatics; a Visiting Fastice of the II aru'ickshire County Lunatic Asylum; and a Gournor of Bethlem Hospital; formerly Acdical Superintendent of the Devon County Lunatic Asylum; Honorary Nenber of the Anerican Association of Medical Superintendents of Asyluns and of the Société Medico-Psychologique of Paris; President of the British Medico-Psychological Association in 1860 ; Lunleian Lecturer on the Law of Insantity in 1878 ; FointEditor of "Brain," and forncrly Editor of "The Foumal of Nedical Science;" FointAzthor of "The Mannal of Psychological Medicine," and Author of "The Mad Folk of Shakespeare," "The Susden Prize Essay on Criminal Responsibility," "Notes on . American Asylums," "Habitueal Drunknness and Insane Drunkards," EG.

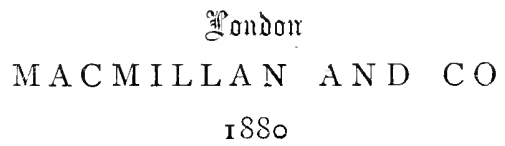


LONDON :

R. Clay, Sons, and Taylor, BREAD STREET HILL, E.C. 


\section{PREFACE.}

THE following pages contain the articles, revised and enlarged, on Lunacy Law Reform, which appeared during the course of last year in the Britis/ Medical Journal. They are reprinted partly in answer to an objection which has repeatedly been made by the proprietors of private lunatic asylums to their arguments, that they were of little weight, seeing that they were anonymous; and partly because the subject with which they deal has been announced by the Government as one demanding immediate legislation. The objection taken to the articles because they were in the first instance published anonymously was perhaps a fair feint to use against them; but their authorship from the first has not been a secret, and as in these pages opinions are expressed which must seem to need the authority of special knowledge, the medical profession at large has a right to be assured by whom they are propounded; and the Author in this republication not only declares his responsibility, but the earnestness and sincerity with which he entertains the opinions thus put forward the result of a very varied 
experience of thirty-nine years, during which he has enjoyed the largest opportunities of observing the care and treatment of the insane in every part of the country, both in public and private asylums and in domestic life. The Author cannot expect that in questions so debatable and debated, and involving so many personal interests as those which he has here discussed, but that his opinions will be warmly controverted, and he is too well acquainted with the vis inertice of established systems to believe that they will be readily adopted. But if they only hasten the inevitable hour when the public will declare that the most helpless and pitiable of their fellow-subjects shall no longer be confined and detained as a profitable private business, and if they only lead this great open profession of medicine to question the right by which it permits a most important class of diseased persons to be sequestered from its care, the publication of these pages will not have been in vain.

The Author owes some explanation to two classes of persons for the freedom with which he has stated his opinions. In the first place he has to express his regret that he has been compelled to include in that which may appear a general censure those medical men who are as honestly engaged in the treatment of mental diseases, even in private asylums, as medical men in any other sphere of their art and science. The Author, well knowing that there are such men, has always felt sympathy for them, and it was of these he was thinking when before the Select Committee of I 877 he declared that he should be very sorry to see all private asylums abolished. But a few personal exceptions ought not to bate the breath of needful criticism applied to a system intrinsically and generally 
bad. And it is improbable that any legislation will interfere with the legitimate work of the true physician. Rather is it likely to reinstate him in his right sphere of dignity and usefulness if he should have wandered from it by becoming the keeper instead of curer of diseased persons. Those physicians who are really skilled in one of the most difficult departments of the medical art, the treatment of mental disease, need scarcely fear that legislation will ever tie their hands as physicians. Nor is it likely that the common or statute law will prevent them from keeping private hospitals for willing and consenting patients. It is in their character of custodians, and in their association with capitalists and speculators in the business of confining and detaining the inmates of these institutions against their will, that physicians engaged in the treatment of the insane must expect to be criticised by their professional brethren and by the public, and controlled by the law and its officers, without much regard to that professional dignity of which they have not themselves been too careful.

The Author also admits the debt of an explanation to the Earl of Shaftesbury and to the Board of Commissioners in Lunacy, over which his lordship has presided since its establishment in 1845 . When we read the well-authenticated descriptions of what lunatic asylums were when Lord Shaftesbury commenced his herculean task of cleansing them; when we think of his steady application to the labour of reforms, and to the more irksome labour of maintaining the good ground gained from relapse into the evil from which it had been won; when we think of the mere routine of official duties in behalf of those who could not repay them even by thanks, 
and of the unofficial work in season and out of season, in the House of Commons and the House of Lords, in offices and committee-rooms, everywhere but in place; and when we think of the genius and eloquence and power of the man who has devoted himself to this life-long labour, it is but very little to say that every one, whether interested or not in the well-being of the insane, must reverence such an example of unweariness in well-doing.

\section{"Præsenti tibi maturos largimur honores."}

But the task which Lord Shaftesbury has carried thus far is one which can never be perfected until the art and science of medicine have reached their extreme limits; and in challenging the interest and co-operation of all who are able to understand the wants of the insane, and to assist in ameliorating their condition, he himself invites criticism of the past and suggestions for the future. This free mindedness with regard to outside criticism is the truest wisdom, and nothing can be more unwise than the opposite feeling, so common in official circles, that it must be right because we have done it, and what you say against the laws which we administer you say against us-the old "fallacy of authority," as it was denounced by Bentham. It is an error to which the least experienced and thoughtful officials are most liable, but a man with Lord Shaftesbury's vast experience and wide grasp of principles, a statesman more than a politician, and above all a social reformer, must recognize that there is no finality in the march of science applied to such a subject as the care and treatment of the insane. The last Parliamentary inquiry 
into the operation of the Lunacy Laws may have been hasty and premature in its inception as it was long drawn out and superficial in its course. But, protracted as it was, the witnesses examined were by no means all those who were necessary for the purpose of obtaining full and true answers to the interrogations of Parliarnent; for persons with the temper of martyrs are scarcely those who are least likely to have been insane; although persons who have been insane and know it are the least likely to come forward publicly after their recovery to complain either of undue detention or of ill-treatment. No one was content, and the subject was not even shelved, although the impression went abroad that such was the intention of the report; the inevitable result being that the feeling of the public has since become more uneasy and distrustful even than before. Nor was this unnatural, seeing that the one thing really proved in the tedious inquiry was the existence of great differences of opinion on the more important questions between Scotch Commissioners and English Commissioners in Lunacy, and between the latter and the Lord Chancellor's visitors. And there seemed to be little consistency anywhere except among the proprietors of private asylums, who defended their interests with courage and ability, and the solidarity generated by a common danger.

The origin, action, and conclusions of this Select Committee, from the terms of its appointment to the comments of the Commissioners in their last report, are singularly loose and illogical, as if every one who touched the subject was bound to become a little incoherent. The reference was "To inquire 
into the operation of the Lunacy Law so far as regards the security afforded by it against Violations of Personal Liberty." But the very object of the Lunacy Law is to authorize violations of personal liberty, under certain circumstances and formalities. Under this strange reference the Select Committee proceeded to investigate, (I) The possibility of imprisonments under the false allegation of lunacy; (2) Of restraint calculated to retard cure; and (3) Of undue obstacles to release when sanity has been restored. They never proposed and they never attempted to investigate the more difficult but vastly more important questions as bearing upon violations of personal liberty, whether harmless lunatics are not unduly deprived of liberty, or whether undue obstacles are not opposed to the release of persons who are almost restored to sanity. They started with that stereotyped prejudice that a lunatic is a lunatic and an asylum the best place for him; and they concluded, "assuming that the strongest cases against the present system were brought before them, allegations of mala fides, or of serious abuses, were not substantiated." That is to say, they did not find what they could admit to be abuses according to the rules they had laid down. The whole community might have influenza, but if cholera and the plague were absent there was no need for anxiety. Upon this conclusion, however, the Commissioners of Lunacy in their 33rd Report published last August, remark that "such language, guarded though it be, is, we repeat, not unsatisfactory to us, on whom necessarily rests much of the responsibility for the due administration of the Lunacy Law," and so for the present the matter is supposed to rest; 
with a few suggestions of change in the law made by the Commissioners, which are certainly not of that radical sort which they "are not disposed to advocate." They are quite satisfied that the "present system of certification affords ample safeguards as well against the admission of persons of sound mind as from the discharge of the insane patients without undue detention." How the system of certification provides for the discharge of patients at all is not explained, but it appears that it does so, and in a manner with which the Commissioners "are quite satisfied." Still the medical certificates are " certainly susceptible of improvement." It has long been the practice of the Commissioners to require that the names of persons furnishing facts indicative of insanity not observed by the certifier himself should be given on the certificate. The Author has pointed out that this most important requirement is merely a regulation of the Commissioners, and that disobedience to it would not invalidate a certificate; and the Commissioners now very properly declare that "we should be glad to have both names and addresses under a statutory requirement in all cases." As to the orders for Reception, the Commissioners suggest the substitution of the word "authority" for "order" They think it undesirable that this authority should be given by a friend, acquaintance, or a servant, unless no relation can be found, which fact should be stated, and they suggest that the authority for reception should contain an undertaking by the person signing it to visit the lunatic either personally or by deputy once in six months. Another alteration is suggested, the need of which the Author was made aware of in his capacity of Visiting Justice to the 
Warwick Asylum, to which institution all the pauper lunatics from the Coventry Union were certified and sent by a comfortable official clique of union officers, namely, the relieving officer, the union doctor, and the union chaplain. The Commissioners propose to erase this blot by making it a condition of the validity of an order signed by an officiating clergyman and relieving officer that notice should have first been given to a justice, and that it should be stated in the order why the justice could not act.

In defence of proprietary lunatic asylums, the Com missioners declare respecting the "incarceration of sane persons, or the prolonged detention for corrupt motives of insane persons who have entirely recovered their reason, under the strict supervision and the safeguards which the Lunacy Acts provide no such abuses are possible." But these assurances do not meet the allegation that "the temptation exists to keep profitable patients longer than necessary," and the assertion that no cases of undue detention were discovered is not easily reconcilable with the evidence. The Commissioners explicitly admit that the keeping of private asylums is a business when they urge that persons so employed "are competing with each other and with the hospitals in a business which, to be remunerative, must be conducted on principles of ordinary prudence and common honesty." No doubt there is a rivalry as to who shall get the patients, but is there any rivalry as to who shall discharge them? A discharged patient is like a dead customer, and the rivalry of cures is an argument which can scarcely be discussed seriously. In the first place the value of the statistics of cures in proprietary asylums is 
problematical, for there is no compulsion to ticket a man rightly whose friends decide upon removing him; and there is no inducement, as in county asylums, to avoid discharging patients as cured lest they should speedily return to betray a blundering diagnosis. What becomes of the patients discharged from licensed houses, who can tell ? Not the Commissioners, certainly, for Lord Shaftesbury says that in one year I3I patients to whom the Commissioners had given leave of absence from metropolitan asylums, " never came back; we never inquired after them; we were glad they did not return to the asylum." [Question 1 I 278]. A pauper patient uncured is almost sure to be brought back to an asylum because he cannot earn his living, but a patient who is removed from a private asylum uncured may remain out supported by his means or his friends. If the Commissioners do not know what becomes of patients discharged on trial from their asylums, still less can they know anything of those who have been ostensibly discharged cured. And if the statistics of private asylums are so unreliable, of what weight is the Commissioners' argument that "every cure becomes the best advertisement of the establishment in which it is effected?" Lord Coleridge upset this argument from the bench by getting a Commissioner as a witness to admit the great desire of the friends of lunatics to keep the calamity secret, a desire which was even augmented in case of cure, and the Commissioners' reply that the number of cures was known does not apply to the language of their Report, which speaks of "every cure that can be shown becomes, in fact, the best advertisement." "That the licensed houses supply at present a social want" may well be admitted 
seeing that no earnest effort has yet been made to "substitute other and better establishments," but the doubt expressed that asylums erected at the public cost "would not be more acceptable to the friends of wealthy patients than the hospitals, which do not receive many lunatics of large fortune," is scarcely worthy of a public board taking a large view of the policy most advantageous for the whole community. If the friends of lunatics of large fortune nolonger had the opportunity of locking up such lunatics in houses competing with each other in a remunerative business, if they should be so prejudiced as to dislike asylums erected at the public cost, they would still have the alternative of employing the lunatic's wealth in placing him in an establishment of his own as a single patient, an alternative which the Lord Chancellor would be very likely to insist upon, unless the lunatic of large fortune was, in some way or other, restrained from his beneficial jurisdiction.

Without considering for the moment that greater evil which arises from "the temptation to keep profitable patients longer than necessary" in houses where a remunerative business is carried on, it is surprising that the Commissioners do not seem to recognize the burthen of excessive payment in behalf of lunatics in private houses which falls upon the inmates and their relatives; for there can be no doubt that the average payments in a hospital are 50 per cent. less than the payments for equivalent accommodation where it can be obtained in a private asylum.

It was urged at the discussion on the Author's paper on Private Asylums read before the British Medical Association that the secrecy which obtained in 
proprietary asylums with regard to their inmates was a great inducement to the friends of lunatics to place them in these institutions; but the Author replied that there certainly was no more secrecy in proprietary asylums than in hospitals for the insane, both institutions being visited officially by governors or visitors, and the officials of the one being as much under the obligation of secrecy as the proprietors of the other, and that one curious inducement not to desire secrecy does not exist in public establishments which is sometimes seen in operation in the private houses, namely, that the presence of some distinguished inmate becomes known as a kind of advertisement. To both places the observations of Lord Shaftesbury apply:-

"Some persons might be afraid that these [hospitals for the insane] would lead to publicity, and destroy the privacy which they now seek. But I really. do not believe that that result would at all take place. I do not see that there would be the slightest publicity greater than there is now. Many persons whose families are afflicted with lunacy think that they are keeping the fact in entire privacy ; but it is an error. If there is an insane relative in any family it is invariably known. The world may not know where he is; but no family ever succeeded in suppressing a knowledge of the fact that there was a mad member connected with it." [Question 556. I 859].

Hospitals for the insane, therefore, such as we have among us at Northampton, Cheadle, Gloucester, Nottingham, Leicester, Stafford, York, Exeter, \&c., with at least equal privacy as regards the individual patients, afford equal or superior accommodation and treatment for half the cost of that to be had in proprictary asylums; and their salaried officers are 
under no "temptation to keep profitable patients longer than necessary." These form a class of institutions so different in most important respects to proprietary asylums that we cannot understand Lord Shaftesbury's opinion that the latter "vie with them perfectly." That any one of them "in the hands of a weak committee might easily be worked so as to become an establishment mainly for the personal benefit of the resident staff" is undeniable, and the suggestions which the Commissioners have made for the improvement of the laws respecting those institutions are highly commendable. One most important suggestion, however, may be added, namely, that the central authority in lunacy should have the power at any time of nominating a certain proporticn of the members of the governing body, and of filling up vacanies occurring in that body which are left unfilled. Moreover an official audit of accounts should be exacted. These remarks apply to the existing hospitals, which have been founded by the benevolent efforts of a former generation, and which do not seem likely to be repeated; and the Commissioners very prudently decline to predict whether Parliament or the country would authorize a compulsory charge on the county rate to multiply such establishments at the present time. In I 859 Lord Shaftesbury earnestly recommended that this should be done, in his admirable evidence from Questions 507 to 562 , but the Committee in their Report, while acknowledging "the great deference which is due to Lord Shaftesbury's opinion," came to the conclusion that "the apprehension of a burthen to be imposed upon the [county] ratepayers would render such an enactment inoperative; and they 
cannot recommend the establishment of them upon a compulsory system."

The Select Committee of I 877 came to a different conclusion, adopting the moderate opinion of those witnesses who, looking forward to the time when there would be sufficient accommodation for all classes of the insane in public institutions, believed that there would be no demand for licensed houses for the upper and middle classes through the spontaneous action of the public in removing the inmates of such houses to the public institutions, and the Committee "suggest that legislative facilities should be afforded, by enlargement of the powers of magistrates or otherwise, for the extension of this system," to wit, of public institutions for the insane of the upper and middle classes. Such appears to be the meaning of the involved paragraph in which this Committee have conveyed their conclusions and suggestions on the most important question, whether or not the licensed houses ought to be left in possession, or suddenly abolished, or gradually suppressed. The verdict is adverse to them, and the sentence is suppression by supercession.

It is of minor importance how the supercession shall be effected; whether by the operation of the magistrates and the county rates, or "otherwise," as the Author believes to be best. But it may be observed in passing that the county-rate scheme did not commend itself to the older Select Committee of very able and practical men. There are many counties in which a hospital for the insane of the middle and upper classes is not at all wanted, either from lack of paticnts or because they already possess an institution of the kind. In others a compulsory measure would be felt to be opprcssive, 
and voluntary legislation would be inoperative. Moreover county hospitals for the insane-would probably be of one type, like county asylums; whereas hospitals established in the first instance, as the Author proposes, by Government, might be, and ought to be, of different kinds and capacities ; some for the insane of small means, others for "those lunatics of large fortune" who so much influence the opinion of the Commissioners in favour of the present system. But whatever the authority and the source of supply fixed upon for the work, it is essential that the legislative enactments should not be of that kind of bastard law which is called permissive, and which cannot in such a matter but lead to delay and mismanagement and disappointment. No one can well be more opposed than the Author to interfering and unnecessary legislation outside the proper functions of Government; but surely if anything beyond the defence of the country and the punishment of crimes does come within the proper function of Government, the provision of means by which persons who have to be incarcerated for long periods shall be properly incarcerated will come within the most stringent limit of right and needful State duty. If the State is right in undertaking the imprisonment of a man who has committed an offence, on what ground would it be wrong in undertaking the imprisonment of a man whose liberty would be dangerous to the community? If lunatics might legally be imprisoned for other reasons than safe keeping, say for medical treatment for themselves, or for the comfort of other persons, the duty of State interference would not be so obvious. But the legal justification being danger, it would scarcely seem to admit of question that the 
State ought to provide officers and places of detention whereby the security of the public may be ensured by restraining the liberty of individuals. Lunatics who, being dangerous to themselves or others, refuse to be forcibly deprived of their liberty, ought only to be confined in State asylums, while space and range enough might be left in licensed houses of the very highest character, which Lord Shaftesbury is so anxious to preserve, for harmless patients who are voluntary inmates. The public are, perhaps, not fully aware of the extent to which the residence of the inmates in two or three of the best asylums is already voluntary. ${ }^{1}$ The proprietor of two of these places has recently published his success in abolishing locked doors throughout his two asylums, the result being that "there have been no attempts to escape, and, what is more curious to remark, those patients who used formerly to stand near the doors on the watch for a chance have now given up the hab:t. Many whose intellect is but slightly or only occasionally impaired, and many others who have been discharged recovered, have expressed the immense sense of relief they have experienced from the change." In conjunction with this open-door system of management, the enlightened proprietor of these private asylums "advocates in every instance where it is possible the plan of voluntary seclusion," i.e. residence. A considerable number of his patients are residents on theirown application; under the proviso that they shall be discharged three days after making another application to that effect, and the system "has been most beneficial in cases in which the mental aberration is only partial," as "the rclations of the

1 Report on Saughton Hall and Balgreen Asylums, I S79. 
patient are necessarily of a more assuring character than in the ordinary confinements under order and medical certificates." "It is in any way the most comfortable method of dealing with a certain class of cases. It certainly fulfils most thoroughly all the conditions of treatment based on non-restraint." Two large asylums for paupers, also in Scotland, are conducted on this open-door system, and the principle has long been acted upon, as far as English laws permit, in the excellent Manor House Asylum at Chiswick. It is interesting to observe that a great authority on the principles of law, Professor Amos, in his recent work, Fifty Years of the English Constitution, explains the anomalies of practice in the law affecting lunatics upon the supposition or legal fiction that a certain amount of assent on the part of the lunatic is attained, or reasonably assumed to the aggressions made upon him for his own protection (p. 460). But when such things are being done and becoming known, how much longer can the authorities uphold the wooden system of treating all lunatics alike? How long will the manufacture of "asylummade lunatics " be permitted to continue for the support of a remunerative business? How long will morbidly sensitive minds be subjected without dire necessity to trials which even the strongest cannot endure without danger and disaster? Lord Shaftesbury, speaking of the number of medical men and attendants who become insane under the strain of associating with lunatics, says, "The Committee can well imagine what it must be to be perpetually in the presence of lunacy, some of them in the most excited state, and some most despondent, and never hardly to pass a night in which they are not disturbed; it has the 
most lowering and most miserable effect upon the nervous system." [Question 7SI.]

Can it be wondered at, if such be the effect upon stout and insensible minds that the "animula blandula vagula" of lunacy, introverted by such associations should shrivel and perish? Even in the vast almshouse establishments where public thrift must deal on the most economic terms with the ever-increasing multitude of our destitute insane, great care ought to be taken that this danger is averted as much as possible by skilful classification and dispersion, and in this direction the Author has long laboured by means of the system he introduced of isolated and cottage wards. But after all a congregation even of pauper lunatics is a great, though doubtless an unavoidable evil, while a system which compasses the herding together of lunatics of large fortune, or even of competent means, for any purpose but the important one of public safety, is but a mouldy method of routine and prejudice. For opulent patients certainly, the smaller the asylum is the less the objection to it, and one would have thought that in the interests of the insane no objection could have been taken to the asylum recently licensed by the Sussex magistrates for four male patients, "well situated in a fine country, and standing in grounds of roo acres, the house containing good and well-proportioned rooms." But the Commissioners "are averse from the multiplication of houses licensed for three or four patients. They supply no urgent demand and cause great waste of public time in the visitation which they entail."

What reception then can the Author expect from the Commissioners for his opinion that for harmless lunatics 
of large fortune, or even of competent means, asylums licensed for two or three inmates, or still better wellregulated domestic life as single patients, are infinitely preferable both for curative treatment and for happiness. Fortunately the Author can point to the single-patient system, as carried out under the authority of the Lord Chancellor, with untold blessings to the great majority of those who enjoy it, and without regard to the great consumption of time which is entailed by the visitation of those single lunatics four times a year by the Lord Chancellor's visitors, and as many times by the committees of the person, whereever the lunatics may dwell.

Thus it will be seen that the Author's scheme of a reformed treatment of the insane of the upper and middle classes comprises: Ist, the establishment of State asylums no more public than the existing institutions, some for the opulent insane for whom asylum restraint is needful, and others for the less opulent insane for whom asylum restraint and the economy of resources is needful. 2nd, the organization of domestic treatment for the quiet and harmless insane as single patients under satisfactory medical management and official inspection. $3 \mathrm{rd}$, the reorganization of the best existing private lunatic asylums and of any new ones for three or four patients, resembling that one in Sussex, which the Commissioners have animadverted upon; the entrance to such asylums to be voluntary, and the detention not to exceed a moderate and fixed period after an inmate has given written notice applying for discharge.

These are no new-fangled notions or visionary. ideas of what might be, but has never been, put to the test of experience. Every part of the scheme has 
been put to the test of trial, and already exists in the most successful practice. The system of State asylums is general throughout the United States and universal in Holland, having in the latter country been made to replace the old bad system of private asylums by the devoted energy of one man, the great physiologist and philanthropist, Schroeder van de Kolk. In Scotland, moreover, a kindred system exists in the excellent chartered asylums of that country. In our own country also State asylums already exist for special classes of the insane : for insane sailors at Yarmouth, for insane Indian servants at Ealing, for persons found insane on trial, at Broadmoor. The second branch of the proposed system exists in excellent organization and success with regard to the single Chancery patients, and with little organization or success under the Commissioners who give single patients one visit a year, even that not being required by the statute. The third branch of the proposed system is already in actual operation and approved success in some few asylums, and partially in others where the system of voluntary boarders is being tentatively carried out ; and one of the positive recommendations of the Select Committee is that the existing restrictions of the law to voluntary boarders in private asylums should be removed. The whole scheme therefore is new in none of its details; it is only new in its method and the proposed extent of its application.

The adoption of this system would carry with it the necessity of large rearrangements, both of classification, including certification, and of official inspection and control. These would, however, seem to be necessary under any circumstances. The present 
system of certification cannot be defended. The public are thoroughly distrustful of it, and the medical profession are so alarmed and dissatisfied that numbers of the leading members of the profession are refusing to certify under any circumstances. And if the Commissoners should continue to dwell in their paradise of contentment it may perchance become depopulated through the operation of a general strike among the doctors.

The rearrangement of official supervision and control is also a necessity which it will be impossible long to postpone. The present system is in the highest degree artificial and makeshift. Every wall in the edifice has a settlement, and every timber is warped. The oldest and highest of the authorities, that of the Queen's Prerogative, does its work well, barring and excepting the law's cost and delay; but the work it has to do is but a small portion of that which it would have to do but for purely artificial distinctions which bring one man in complete possession of one thousand and one pounds under its rule, and leave another in the incomplete possession of a thousand times as much outside its jurisdiction. It cannot be true, and cannot be expected to continue as accepted, that out of 70,000 lunatics in the country only one thousand have a right to that royal protection which was intended in the time of King Edward II. to be thrown over those lunatics whose feudal interests touched the king; if not indeed over all lunatics whom the king as the father of his country was bound to protect. Shall this Magna Charta for the insane dwindle into a solicitor's vademecum in the management of choice properties?

It is to be remarked that the Commission in 
lunacy started in 1845 with the same strength of staff which it now possesses, although the number of insane persons in asylums has increased from $1 \mathrm{I}, 272$ in I844 to $47, \mathrm{I} 78$ in I879. The visitation also has been largely increased, so that, notwithstanding the Commissioners inay have their work more in hand in consequence of the reforms they have effected and the better methods they have introduced, there can be no doubt that their actual work has greatly increased, and that even since I860, when the Select Committee was so desirous to increase the strength of the Commissioners, either by adding to their number or by the appointment of Inspectors to act under their control. The Committee in that Report expressed the "doubt whether it will be in the power of the Board, as at present constituted, effectually to discharge the increased duties to be entrusted to it. But as they collect from the evidence of the chairman that the Commissioners themselves are of opinion that they could do so without any permanent addition either to their number or their staff, your Committee have abstained from recommending, without proof of its necessity, that such additions should be made."

In I 877 Lord Shaftesbury adhered to his opinion. [Question I I,509], "Notwithstanding that the duties are falling more heavily on the Commissioners every year, you would still prefer that they should remain at their present number and not be increased?--For the present I am so. I have just suggested that which would give a very great relief, namely, that the visiting magistrates of every district should visit once or twice a year the single patients in their own districts." Moreover, in his evidence in 1859 
and I 860 Lord Shaftesbury urged upon the Select Committee other alterations of the law, which would have had the effect of giving great relief to the Commissioners, so that they might effectually discharge their increased duties of visiting asylums. These recommendations were that the Commissioners should be relieved from the duty of visiting the insane in workhouses; that in future new licenses should only be granted to asylums within easy reach of a railway station, and that Chancery and single patients should only be permitted to reside within the same accessible localities, and that the Commissioners should be empowered to employ some one for some weeks in the year to finish up any asylum or single case visitation which, under the pressure of business, had not been completed by the Commissioners themselves. None of these recommendations having been adopted either by the Committee or by the legislature, it would appear that Lord Shaftesbury's opinion as to the competency of his Board for the effectual discharge of their duties was qualified by conditions which have not been fulfilled. It has always appeared to the Author that Lord Shaftesbury's great apprehensions that his small and dignified Board might, by any addition to its numbers, be converted into what he calls a noisy parliament, would be groundless under his own strong control or that of any worthy successor; but at the present time the influence of his opinion in this matter has secured the great advantage of leaving the ground open for a new and more efficient arrangement.

Lord Shaftesbury has served through two lunacy periods, from I 828 to 1845 , which may be called the period of abuse, and from 1845 to the present time, 
which may be called the period of reform. From the near future another period must commence which may be called that of reconstruction. But it seems impossible to believe that the care of the insane can continue to be controlled by the present entanglement of authorities, always costly, and sometimes conflicting; the old authority of the Queen's Prerogative, the new authority of the Commissioners in Lunacy, the ubiquitous authority of the magistracy, and the rising authority of the Local Government Board and the guardians of the poor, expressing itself in Caterham and Leavesden, and in Mr. SclaterBooth's Local Government Bill, for the present withdraw11. A commission is not usually considered a permanent arrangement, and this one in particular, established to deal with temporary evils, stands between two very powerful opposites-the old authority over lunatics with property, and the new one, claiming, and certain to obtain, power over lunatics with none. The consideration of the latter point must be deferred to a more convenient season, but seeing that in the combination of pauperism with lunacy the former element is unquestionably the more weighty and pressing one, it would seem clear that the control of the care and maintenance of pauper lunatics must eventually pass into the hands of that central authority which presides over the pauper class generally, and that the guardians of the poor, more or less assisted, guided, and checked by the magistracy, must be permitted to have an active share in the administration of the laws affecting those destitute persons who are insane. When this impending change is completed it will be quite needful that the Local Government Board should comprise persons well 
acquainted with lunacy and the needs of the insane; and no persons could be more appropriately chosen for this responsible office than some of the gentlemen who now hold office as Commissioners in Lunacy. It will not be difficult to consolidate the laws affecting destitute persons who are insane, and to place their execution under the authority of the Local Government Board thus strengthened.

The advisability of this change being admitted, it will be difficult to make any show of good reason why all other lunatics shonld not be placed under one authority, and that of the Queen's Prerogative exercised by the Lord Chancellor and the Lords Justices being the oldest, the most powerful, and the most adapted to comprehensive enlargement; there can be little doubt that this is the one which ought to absorb the other.

The Queen's Prerogative in Lunacy is exercised by the Lord Chancellor and the Lords Justices, by the Registrar in Lunacy and his staff, the Masters in Lunacy and their staff, and the Visitors in Lunacy and their staff. The cost of the three offices, including pensions, but excluding interest on cost of offices in the Courts of Justice, is as follows:-

Registrar in Lunacy, £2,217.

Masters in Lunacy, $£ 12,805$.

Visitors in Lunacy, $£ 8,3 \mathrm{I} 7$.

The cost of the Commissioners in Lunacy is $£$ I 8,169 , making altogether a total of $£ 41,508$.

This total, however, does not include any portion of the salaries of the Lord Chancellor and the Lords Justices, although in estimating the whole cost of the central authority in Lunacy it ought to do so. Neither does it include any portion of the cost of 
the Local Government Board, although that Board and its officers are engaged in the care of pauper lunatics not in asylums. Neither does it include the cost of the medical officers and clerks employed by the visitors of proprietary asylums, nor those costs of the visitation of county asylums which fall upon the county rates. A very large proportion of the visitation of lunatics, both public and private, is discharged by the unpaid magistracy, but if the costs of the above-mentioned duties, which are not gratuitous, were to be estimated, and added to the abovementioned total for the public offices as the whole cost, a total would be arrived at which would probably commend itself as quite a respectable amount even for the efficient discharge of such an important duty as the supervision of the manner in which the insane of all classes are treated and maintained. The system whereby an asylum may be visited at the same moment by the Lord Chancellor's Visitors, the Visiting Commissioners, and the Visiting Justices, is not economical of public time and money. The two former authorities especially are, to say the least, placed in an unmethodical and unthrifty relation to each other. The Author, in his evidence in 1877 , refused to admit that there was an antagonism or jealousy between the two Boards of Chancery Visitors and Commissioners, but he was compelled to admit that they were not at all co-operative, and when pressed he referred to an instance in which he. had found a Chancery lunatic very badly treated in a private lunatic asylum. In order to obtain speedy redress, and as there was no Committee of the Person to whom to complain, he wrote to inform the Commissioners in Lunacy of the facts; but those gentlemen, 
instead of exerting their own powers, thought fit to remit the complaint to the Lord Chancellor, which the visitor could more properly have done himself. The result was a rebuke from the Chancellor for irregular proceedings. So much the Author had to confess to the Select Committee, who had the right to question him. While feeling himself under the restraint of an old official not voluntarily to mention any circumstances to illustrate his opinions, he is at least at liberty to express the opinion that the two Boards, as at present organized, are not only nonco-operative, but that the two systems, though not the Boards, are antagonistic.

Under one system no interference with the personal liberty or the civil rights of any subject is even attempted until after a judicial investigation in which the liability to error is rather in the excess of caution and forbearance. Under the other system any one of the Queen's subjects may be deprived of his liberty, captured, confined, and detained, by the proprictor of a licensed house or his servants upon the order of any person whatsoever, either a British subject or an alien, either an adult or an infant, either a relative or a stranger, either an equal in social rank, or a menial substitute; the only conditions being that he has seen the alleged lunatic within one month of making the order, and that this is supported by the certificates of two men qualified to practise and practising the medical profession.

Under one system, no person's liberty and civil rights are interfered with unless he has been found by a competent tribunal of unsound mind, and unable to manage himself and his affairs. Under the other sjstem this question is not ra:sed, but any person can 
be indefinitely imprisoned who, in the opinion of two medical men, is a lunatic, or idiot, or person of unsound mind, and "a proper person to be taken charge of and detained under care and treatment."

Under one system, a scheme or method of the lunatic's maintenance or mode of life, regarding even minute details, is drawn up in the Master's office and approved by the Lords Justices, and a lunatic with a property of fifty-one pounds a year in possession enjoys the privilege of having it expended to the best advantage under the careful direction of the highest legal authorities in the realm. Under the other system there is no power nor endeavour to provide any system of maintenance or mode of living, and the immediate heir of the largest property may be confined at the lowest rate in the poorest possible asylum.

Under one system, a lunatic's property is effectually protected from designing and dishonest persons, and he cannot marry or enter into any contract. Under the other system there is no such protection, although many persons with mental infirmity have been incarcerated in asylums for the purpose of preventing improper expenditure or undesired dispositions of property. But it does not appear that even confinement in an asylum is any real protection, or that the circular of the Commissioners in Lunacy forbidding the proprietors of asylums to permit their lunatic inmates to sign cheques, deeds, or other documents affecting property, is anything but a well-meant official action, but quite unsupported by any legal authority, and therefore quite invalid.

Under one system, the lunatic is allowed to enjoy the largest amount of personal liberty which is 
consistent with his own personal safety and that of the public. Under the other system the lunatic's personal liberty is often restrained to prevent civil acts which are not dangerous, and which are not void, but only in his case voidable.

Under one system, the Lords Justices place the personal charge and care of the lunatic in the hands of the most suitable person they can discover, passing over in this respect the nearest relatives if they are unfit for the duty. They require these Committees of the Person to visit the lunatic, wherever he may be, at least once every three months, and to make a report of the lunatic's condition and treatment every six months. Under the other system no one in particular has charge of the lunatic, and no relative or friend is required to visit him, although a lunatic lady may be detained in an asylum, even without the knowledge of her husband, until she dies. What power there is remains with that casual person who signs the order.

Under the one system, the visitors of lunatics are required to report to the Lord Chancellor as to the mental state and bodily condition of each individual lunatic at each visit ; to declare whether or not everything is done which can be done for his welfare; to recommend any change which may seem advisable; and if he has recovered, to report his recovery forthwith. Under the other system, the visiting Commissioners are not required to speak to, much less to examine, every lunatic. They consider that in "a large asylum there are very few cases indeed that require personal conversation. It is right to see them, and sce that they are in good bodily condition and properly taken care of, but as to communication with 
them, the larger proportion of them are wholly unfit for it ; they are not open to anything of the kind." [Question II 329, I 859.] As to the diagnosis and report of a'patient's recovery, "no Commissioner would venture to give an opinion if he were sent for on a sudden, merely saying 'that a patient had recovered, and we want your opinion as to whether he should not be discharged.' " [Question 4I3, I860.]

Under the one system, $34^{\circ} 6$ per cent. of the lunatics are under home treatment in private dwellings, and $65^{\circ} 4$ per cent. in asylums. Under the other system, 5.9 per cent. only of the private patients are under home treatment in private dwellings, and $94^{\circ} \mathrm{I}$ per cent. are confined in asylums.

Finally, the one system, rooted in the foundations of the English constitution, is consistent with, and a part of, the law of the land, and it is presided over by the chiefs of the law, who are entrusted with power to make necessary orders and regulations having the force of Acts of Parliament, and the subordinate officers are compelled to act up to, but within the strict limits of, their duty. But the other system is a thing of yesterday, or, more strictly speaking, it is thirty-five years old. It is a Commission established to remedy certain abuses which it has remedied, and which otherwise must have been remedied in some other manner. It is established upon statutes which have been so interpreted as to sanction the incarceration of harmless and quiet lunatics in direct opposition to the common law. Beyond the letter of the statutes it is devoid of power, although modifications in the statutes can be made from time to time to suit the system. [Question I I245.] The officials of the system have, nevertheless, been 
compelled to let some powers entrusted to them lie dormant for years, and to assume others which they do not possess, and they have had to make various proposals for large and fundamental changes of official duty. Can there be a doubt which of these two systems is best worth preserving? In reality there is no choice, for either the present wasteful system of opening one furrow with two ploughs must continue, or the old Prerogative authority must absorb the Conmission, for the reverse proceeding is clearly and absolutely impracticable. The Commission, on the other hand, would be easily and beneficially absorbed into the Lord Chancellor's system, some of the present members of the Commission being transferred to the old Prerogative authority, enlarged and empowered to inspect and protect all insane persons who are not paupers. A serious attempt to realise this idea, with its counterpart relating to pauper lunatics, would no doubt have been quite beyond the reference of the Select Committee, but would it not be worthy of the great Lord Chancellor who has put his hand to the amendment and consolidation of the lunacy laws? The Author earnestly prays that he may be favourably induced so to consider it.

The great injustice and suffering which to a large extent is inflicted upon harmless and quiet lunatics who are confined in asylums without need, is an arraignment of the present system which can only be answered by a great change. Individual instances of such suffering would appeal more forcibly to the public sentiment than any assertion of the general fact, and Lord Cairns himself has taught the lesson, when, in presiding at the Literary Fund Dinner last year, to illustrate the difficulty of eliciting 
sympathy by abstract descriptions, he appealed to Sterne, who, failing to get near enough to the misery of imprisonment by describing it in the abstract, drew the Captive in his immortal sketch. And so the orator proceeded to describe the captive as he might be seen "wasted with long expectation and confinement, counting the dismal days and nights he had spent, lifting for a moment his hopeless eye, and casting it down in despair, and going on with the work of his affliction." And Lord Cairns proceeded, "If I could show you an individual case, if I could put before you a man of genius, cultivation, and learning, of a sensitive and honourable spirit, devoted and toiling in his profession, and making it the support of himself and of those dependent upon him, and if I could show you such a one struck down for a time by one of those calamities to which we are all subject in health or means;" and if instances of lunatics were permissible the great statesman might have perfected his simile from that circle of sorrow and suffering. He might have said, If I might in these days show you such a man under circumstances resembling those of Sterne's captive, I should have to take you to the lunatic asylum, and point out that cultivated and sensitive gentleman, deserted by his friends, who seldom give themselves any trouble about his condition, perpetually in the presence of lunatics, which has the most miserable and most lowering effect upon the nervous system, under the control of rough men of menial station, hired at a cheap rate, who use coarse language to him and push him about, [3253-3279, I877], wasting with long expectation and confinement, counting the dismal days and nights, hopeless 
and in despair;-thus, he would have painted a picture so touching that he must have moved his audience to a height of pity and resolve that no pains should be spared to limit and confine such misery within the strictest bounds of unavoidable necessity, to prevent the slightest addition to the anguish often inseparable from mental disease, to liberate all insane captives whose freedom would not be dangerous, and to surround those who remained with every safeguard of disinterestedness, humanity, and public responsibility. 


\section{CONTENTS.}

I.

Difference between the inmates of the old mad-bouses and the modern asylums-The former containing only obvious and dangerous cases of lunacy, the latter containing great numbers of quiet and harmless patients whose insanity it is often difficult to determine . . . . . . . . . . .

II.

The need of public interest in the management of asylums-The tendency of officialism to maintain existing methods-The difference of duty of the Commissioners and the Visitors of lunatics-Universal complaint of bad treatment in asylumsThe English Gheel of opulent lunatics, and the comparative happiness of insane persons under domestic care-The inefficient visitation of single patients-Nervous patients-Official views opposed to medical interests . . . . . . . . . .

\section{III.}

Certificates of insanity and orders of detention-Contrast between those required for a pauper and a not pauper lunatic, the former, less needful of stringency, being the most stringent-Objections to the jealonsy of medical men which is shown in forbidding them to act in consultation-Objections to the certificates being the same for all kinds of lunatics in all kinds of treatment-Suggestions for their reform . . . . . . 
IV.

Medical certificates should only be evidence upon which magistrates should act-Needful limitations of power of confinement - Power of confinement by relatives-Medical visitation of single patients-Committees of the person-Objections to the order of detention-Objections to the power of capture and confinement given to proprietors of asylums and their servants -Objections to unlimited power of relatives-Advantages of the Scotch procedure-Necessity for magisterial action in the confinement of all lunatics . . . . . . . . . . .

\section{V.}

The legal justification of confining insare persons is dangerCases of Nottidge $z$. Ripley and Fletcher $v$. Fletcher-Commissioners' opposition to the laws of the courts-Commissioners' reasons why insane persons, not dangerous, should be confinedCommissioners not reporting to Lord Chancellor of lunatics with property not duly protected-Commissioners' objections to inquisitions-Casus omissus of law rezarding lunatics dependant upon opulent relatives-Scotch definitions of a lunatic . . .

VI.

Dr. Conolly's denunciation of proprietary asylums, also Lord Shaftesbury's-Commissioners' satisfaction with these places in IS 47 -Their account of mi-doings in them in IS 75 -Cominissioners' neglect of medical considerations-Lord Shaftesbury's evidence in IS 59 and in IS 77 -Opinions of Lord Ashley, Mr. Lutwidge, Mr. Gaskell, Mr. Wilkes, and Mr. Campbell •

\section{VII.}

Memorandum to the Lord Chancellor respecting proprietary asylums-Opinions respecting asylums and do.me-tic treatment of Lord Chancellor's visitors-Necessity of more individual inspection of lunatics in asylums-Recovered patients sometimes unduly detained in asylums-Motives for placing patients in asylums-Dr. Mitchell's eridence thereupon-Proposed remoral of quiet cases into domestic life . . . . . . . . 


\section{VIII.}

PAGH

The two projects of reform, Mr. Dillwyn's by buying up proprietary asylums, and Lord Shaftesbury's by establishing competing hospitals at the public expense-Objections to purchase of asylums-Proprietary asylums mostly in bad sites, and of bad construction-Different kinds of proprietary asylums . .

\section{IX.}

The best remedy the establishment of State asylums for the upper and middle classes-Memorandum to the Lord Chancellor on State asylums for Chancery lunatics-Extension of this project -Estimate of numbers to provide for, and of cost-Proposed Parliamentary Commission to establish State asylums . .

$\mathrm{X}$.

Dr. Maudsley's opinions on indiscriminate locking up of insane persons in asylums, on the discomforts of asylums and the tyranny of attendants-Dr. Blandford's opinion that many insane persons are infinitely happier out of asylums, and ought to ve removed from them-The late Dr. A. Sulherland's statistics of cure under domestic treatment-Mr. Percival's and Dr. Lockhart Robertson's opinions of domestic treatment-This treatment does prevail in the initiatory stages-Carried on by general practitioners-Exceptions in suicidal and dangrerous patients-Absence of medical treatment in asylums-Chronic harmless patients and Chancery cases in domestic life . .

\section{XI.}

Grounds on which the medical profession is interested in the management of asylums-Tendency of recent laws to sequester the insane from the care of the medical profession generallyDifference between ownership in a business and professional engagements-Misleading analogy between the fees of medical men and the profits of asylum proprietors-The late Mir. Wakley's opinion of proprietary asylums--Impriconment for private profit authorized by no other Engrish law-Difficulty of 
ascertaining the treatment of patients or their recovery in proprietary asylums-Some asylum physicians honourable and disinterested-Medical certificates ought to be statements of evidence merely-The: civil power alone ought to order confinement-Commissioners ought not to be administrators in, aud inspectors only beyond, metropolitan district-Two central lunacy anthorities should administer the law severally relating to destitute and not destitute lunatics-The Board of Commissioners in Lunacy should cease to exist, the Commissioners being distributed between the Local Government Board for the supervision of destitute lunatics, and the Lord Chancellor's Iunacy offices for the supervision of all other lunatics . . 


\section{CARE OF THE INSANE}

AXD D MELR

\section{LEGAL CONTROL.}

I.

"THE FASHION OF THE TIME HAS CHANGED."

"WATCH what main currents draw the years," says the Poet Laureate ; and one of the strongest now observable is surely, the reform of domestic institutions, which are judged to be inadequate in their working to the humanity, or justice, or economy of the age. It matters not greatly who are the ins and who are the outs of office when the current of opinion sets steadily in the direction of some change which the public conscience demands in the laws regulating the treatment of any class of the community. The change will have to be made.

For years past, signs have not been wantingindeed, he who runs may read them without glassesthat the public conscience has been tender and sore as to the customs and laws which the sane majority has sanctioned for what is called the care and treatment, but to speak more truly for the custody and 
control, of that which is still fortunately the insane minority of the people. The early history of this rnatter, even within the present century, is so ghastly and disgraceful, that it may be passed by on the same plea which Macaulay used, to excuse himself for ignoring the early history of the country, namely, that it is one of kites and wolves. Yet the horrible disclosures of the Parliamentary Committees which sat in 1815 and 1845 may be referred to in evidence of the pressing necessity which cried aloud for the earlier legislative enactments. The statutes still bear deep traces of this haste to remedy urgent evils : and this is a point which is well worthy of consideration at the present time. It was like opening an abscess before it was mature, and the wound has become erysipelatous. Perhaps it is not quite correct to say that the legislation was premature, but certainly it was adapted for a very different state of things from that which now exists, and it came to occupy the place of larger and better measures. In these days a big, ripe, uncomplicated abuse has become a rarity, and almost always the legislative doctor has to adapt his remedies to a combination of the disease and the results of previous treatment. This is emphaticaliy the case with lunacy abuses, which, having their original seat in the great ignorance and frequent brutality of the old-fashioned madhouse-keeper, have been modified, under the treatment of the lunacy laws, into the milder but far more complicated difficulties of the existing complaint. Institutions for the insane have grown to be what they are under the sanction and protection of the law. Our fathers called them Madhouses, and never dreamed but that people obviously mad, and for the most part maniacs, would alone be incarcerated 
in them. We call them Licensed Houses for the reception of the insane, and many of them are called Retreats, as if residence in them were for the most part voluntary. And the change of name is not unjustified by the change which has taken place in the thing named. We have some accounts of the kind of inmates who filled the few madhouses which existed before the alleviating action of the lunacy laws. It may be that, in rare instances, the rude iniquity of the times might have led to the incarceration of a ruffian who was not mad; but outrageous madness was the rule, and the detention of patients after they had become tranquil and harmless was against the rule. Nowadays, our numerous asylums swarm with a motley crowd of persons of weak mind or low spirits; with tranquil and reasonable persons said to be liable to excitement; with persons said to have suicidal tendencies if they are not always under supervision; with paralytics and epileptics, and with persons in various stages of mental decay; no doubt all of them, with very rare exceptions, persons of unsound mind, but not madmen or lunatics, or even insane persons, as our fathers understood these terms.

Disease of the brain, causing mania, probably produced very much the same symptoms, if let alone, before I845, as those which it produces now. It was interfered with at that date by means of chains and fetters; it is often interfered with now by the administration of hydrate of chloral and bromide of potassium, and other narcotic and depressing remedies. But the different treatment of maniacs will not account for the difference existing between the old dens and the -new asylums. That can only be the result of a widcly 
different class of inmates, after the largest allowance has been made, as in all justice it ought to be made, for the tranquilizing result of greater care, skill, and humanity. But the point is this-that the law providing that madmen, dangerous to themselves and others, shall be secluded in madhouses for absolutely needful care and protection, has been extended in its application to large classes of persons who would never have been considered lunatics when this legislation was entered upon. Since I 845 , medical science has discovered whole realms of lunacy, and the nicer touch of a finikin civilization has shrunk from the contact of imperfect fellow-creatures, and thus the manifold receptacles of lunacy are filled to overflow with a population more nearly resembling that which is still at large. When recognizable lunacy was painted in glaring colours, there was little need of painstaking investigation. There is more need for it now that delicate tints of mental unsoundness indicate the "proper persons to be taken charge of and detained under care and treatment," such care and treatment really meaning imprisonment and control ; for of late years the face of authority has been set hard against care and treatment of insane patients out of asylums. Care and treatment do not now mean the watchfulness and efforts of medical men as directed to the cure of other diseases, but they rrean the abstraction of a most important class of diseased persons from the wide and catholic interests of the medical profession, to be relegated to the custody, control, and profit of privileged persons, a large proportion of whom do not belong to the medical profession. The situation is entirely altered. The old brutalities have become rare and exceptional under the régime of the Commissioners, 
and instead thereof another evil has been evolved, and the asylum system in its whole vast extent has encompassed an ever-increasing multitude, numbers of whom might well be enjoying moderate freedom and comparative happiness in their own homes. This, in truth, is the incandescent centre of "the most burning question of the day," as Mr.E. A. Millar, Q.C., calls "the law affecting the custody and control of lunatics," in his very able address on jurisprudence, read last year before the Social Science Congress. This is the conviction so deeply impressed upon the public conscience, that it has refused to be smoothed out, even by the labours of the Select Committee of the House of Commons.

It is remarkable, but has not perhaps been remarked, that almost all the argument which has been put forth in defence of the present most defective system of admission into asylums is grounded upon the assumption that great speed is necessary for the purpose of securing the early and curative treatment of acute cases. It is urged, not without reason, that if "the law's delay," as it was known to Hamlet and is not unknown to us, be allowed to intervene before the incarceration of a lunatic, a precious period of curable disease may be for ever lost ; and if any considerable proportion of the unfortunates committed to detention in asylums were recent and curable cases, the argument would to that extent be valid on condition that curative treatment were systematically employed in private asylums.

On this supposition, the greatest possible facility for the committal of lunatics to asylums may be advocated; and any medical man on the Register as ignorant of lunacy as he may be of the higher mathematics may 
still be authorized to certify away the liberty of the subject in the most dainty cases of mental diagnosis. Formerly, any man calling himself a medical man might do this, but his action was almost always confined to acute cases, the nature of which might easily have been understood by a constable, churchwarden, or any other Jack-in-office, and was, therefore, likely to be right and useful. But, if it be true that nowadays a large proportion of persons committed to asylums are not obviously and glaringly mad, it would follow that persons alone who are conversant with mental disease ought to be allowed to testify to their condition; and if, further, a large proportion of persons committed to asylums are not acute but chronic cases, not, therefore, in any immediate need of curative treatment, it would seem also to follow that the above plea for immediate and facile action without the intervention of the law's delay is not capable of being sustained. 
THE PREROGATIVE OF ASYLUMDOM.

WHAT is really the matter with those lunacy laws which may be found in Mr. Fry's seven hundred and seventy-one closely printed pages, and which, in their relation to the liberty of the subject, have undergone what purports to be a thorough investigation, the record of which may be found in the thick folio of a recent Blue Book? Mr. Phillips sees little else than perfection in them, and a "great change for the better in the management of asylums" since I 862, "due to our (the Commissioners') activity to some extent, and to the strong public opinion which is always bearing upon the management of asylums." "The public look after these matters much better than they used to do in former times." "I think all inquiry is good." These are gracious admissions on the part of the Commissioner, and should reconcile him to the undiminished anxiety which the public and the profession still manifest in the administration of the lunacy laws, and especially in the management of proprietary asylums. There is a common and natural tendency on the part of officials to become attached to the laws under which they live and move and have their being. 
It is not the good workman who finds fault with his tools; but the employer surely may both criticise them and the work they effect. The tradition of the Commissioners in Lunacy has always inclined towards the detention of the insane in asylums, and the tradition of a public office is a very persistent force. They were appointed, in the first instance, to control the misdeeds of asylum-keepers, and their supervision of asylums still comprises almost the whole of their statutory duty. They do, indeed, pay an annual visit to a number of single patients certificated; but this duty is self-imposed, and it may be said that, if asylums do not exist for the Commissioners, at least Commissioners exist for asylums. Therefore, it is not wonderful that almost all the testimony emanating from the Commissioners' office, which has been given before the Select Committee of Commons in 1877 , has had an obvious bias towards the maintenance of that system under which, since the Committee in 1859 , the roll of lunatics in asylums (pauper and private), had increased I 5 per cent., while the total lunacy in the country during those seventeen years had only increased 76 per cent., the admissions into asylums rising from $4^{6} 6$ per annum per 10,000 of the population in 1866 to $5^{\circ} 9$ in $1875^{\circ}$.

On the other hand, the tradition of the Lord Chancellor's lunacy offices is opposed to the incarceration of any lunatic in an asylum for whom due protection and the enjoyment of life can be provided outside. This tradition, no doubt, has come down from very ancient times; but modern practice has maintained it, and the experience of to-day justifies the liberty which our forefathers, amid all the abuses of the time, granted to lunatics, who were not frantic or dangerous. The 
example of Chancery lunatics in domestic life would surely make any man conversant with it question the wholesale need of asylum restraint, and its influence was well expressed by Dr. Lockhart Robertson before the Select Committee, in his reply to Question I,O9 I : "Has the opinion you have formed, that it is desirable to remove as much as possible patients from asylums, been based upon the knowledge which you have acquired since your appointment as Lord Chancellor's visitor?-Most wonderfully. I could never have believed that patients who were such confirmed lunatics could be treated in private families in the way that Chancery lunatics are, if I had not personally watched these cases."

The statute requires the Lord Chancellor's visitors to visit, see, and report upon every Chancery lunatic in domestic treatment four times a year, and every one in an asylum only once a year. As there is usually more than one Chancery patient in an asylum, the visitation of such a patient generally entails no travelling and little trouble; whereas his removal to domestic treatment often imposes upon the visitor a long quarterly journey. The law, therefore, offers a strong personal inducement to the Lord Chancellor's visitors to accumulate their wards in asylums, and it is in the teeth of this unintentional bribe to opposite action that the Lord Chancellor's visitors so far encourage domestic treatment, that one-third of their lunatics may be found in mansions, farm-houses, and cottages in such enjoyment of life, that the luxuries of the most showy asylum would be misery to most of them. No doubt some Chancery lunatics under domestic care are ill chosen for it, and others are placed amidst unfavourable surroundings and with unfit guardians. 
The visitors have less power than ought to be given to them, in determining what lunatics need the restraint of asylums and those for whom domestic care is suitable. The affections, the prejudices, and often the selfishness, of relatives interfere too much. Still, there is a broad selection both of patients and of places and persons fitted for their treatment; or, to speak more accurately, there is the power of unfavourable report, which in most cases results in right selection-the selection of the fittest and of the richestalthough this latter is by no means a constant quality, so that the foot of the visitor treads the threshold of the palace and that of the hovel. In a favourable instance, the visitor reports that a Chancery lunatic in an asylum would be secure and happy in domestic life; to which he may, perhaps, be able to add, that the probability of recovery also would be increased; and if the change be made, the visitor follows it with his criticism and responsibility, seeing what good or harm he may have done, and trying by his advice to augment the one or to annul the other. This is a very different system to that which the defective state of the law compels the Commissioners to pursue towards patients for whom asylum life may seem to them no longer desirable. Question I I,278 indicates this difference: "We gave leave of absence during the year 1876 in the metropolitan licensed houses to 614 persons: of these, I 3 I never came back. We never inquired after them; very glad they did not return to the asylum." In this manner "a great amount of liberation is effected." The Commissioners have not the power to remove a patient who is convalescent but not cured, or any other suitable case, from an asylum into domestic care, nor would they have any practical 
control over his treatment if it were done. Were it otherwise, it is to be hoped there would be a vast addition made to that Gheel of Lord Chancellor's lunatics-scattered, indeed, but existing in our midst, with which the Belgian institution cannot compare,a system which, imperfect as it is, solves the problem of making the lives of many lunatics comfortable, secure, and, as far as their sad malady will permit, contented, and, strange to say, on the whole, happy. What a comment is their condition upon that fearful but undeniable statement of Mr. Cave (in Question 9,660 ), and the painful reply to it, which amounts to a confession that, with all the improved treatment which the Commissioners have been able to compass, the lunatics under their supervision suffer under a general and miserable sense of injustice. "There is," said the Right Hon. Chairman of the Select Committee, "an almost universal complaint made by lunatics of bad treatment in asylums. I suppose you hardly ever find any who do not fancy that they did suffer unjustly while they were confined in an asylum." "Almost every insane man," says Mr. Phillips in reply, "thinks he is sane, and everything connected with his detention as an insane man he looks upon as wrong."

Every unprejudiced person conversant with asylum life will endorse Mr. Cave's assertion. Every one acquainted with domestic treatment will feel assured that Mr. Phillips's explanation only applies to asylum lunacy, and that it is, to a great extent, the misery of imprisonment which begets the strong sense of wrong. The aversion which most lunatics have to asylums is no doubt not altogether a rational sentiment. But, if we reflect that, with what mind he has left, a lunatic 
feels the stigma of detention in an asylum; that, moreover, the restraint of limited quarters and narrow bounds is irksome to him; that he resents the inevitable association of distasteful companions, perhaps not more insane than himself, but different, and therefore offensive; and, if he be a man of culture and position, that subjection to the men who for low wages accept the duties of attendants, is often felt by him to be unspeakably degrading; and that to all this may be added the conviction that he is deserted by those who owe him personal care and tenderness,-we shall scarcely need to follow Mr. Phillips in attributing all his complaints and his sense of wrong to insane conceptions. To the lunatic under proper care in domestic life everything is changed. He need feel no brand upon him; he is a member of an English home circle of sane people who, even in the exercise of a wise selfishness, must strive to make him contented, and who often, by the mere habit of geniality, do make him happy. When patients and guardians are suitable, even the meagre comforts of a cottage home, which would compare badly with the whitewashed spruceness of a workhouse ward, become precious to the weary and wasted mind to which rest and a modicum of sympathy are worth more than all else which a spoiled life can hold. Errors and omissions are of course excepted; for even among Chancery patients some few are neglected and ill-treated, and some are in domestic life who are ill-chosen for that sphere. But many lunatics are very child-like; and a striking illustration of this subject may be drawn from the beneficial change which has in various places been effected by the system of boarding-out workhouse children, who in the workhouses have "a leaden 
hue and sickly look, with inert, cowed, sullen, and morose temperaments," and in whom, according to the testimony of Sir William Johnston, formerly Lord Provost of Edinburgh, such a change is wrought, that " there was hardly a face we could recognize, so healthy, hearty, and changed were they by having breathed the free air and exercised both their bodies and minds amidst their companions in the country." "The unmerited stigma of workhouse-boy does not attach." "The moral gain cannot possibly be estimated." (See The Boarding-Out System in Scotland. By William Anderson. Menzies and Co.) Nothing is more hateful to an adult Englishman than to live in an institution. Passing by life in gaols, and even in workhouses, as too harsh a comparison, what has broken up the great national almshouses of Greenwich and Chelsea, but experience of the feeling that Englishmen would rather be pinched in a cottage than pampered in a palace, if the latter implied a crowded life in common.

Of course, it is understood that the domestic care of lunatics requires constant and careful supervision. Ignorance and indolence are too common in the world not to endanger the good treatment of such helpless beings as lunatics, even by their natural friends and relatives; and when the duties of guardianship are discharged by paid agents, watch and guard against the temptations of selfishness ought, on principle, to be as strictly maintained when a patient is kept for profit as a single patient in a private residence as when he is detained for profit in a licensed house. The liability to detention after the need for it has altogether passed is indeed greatly diminished in the private residence, and the mischief of it diluted ; for, as a rule, 
the single patient is sane or insane in the eyes of his little world, from which the asylum patient is hidden; and if the former, he being at large be held under certificates somewhat longer than need be, the restriction of liberty is little felt, whereas needless detention in an asylum is the source of profound wretchedness.

If "patients are put away at a distance to live only with attendants" and subjected to the appearance only of supervision, neglect and cruelty are indeed the probable result; but this is not what is now understood by the domestic care and treatment of the insane. Of the 460 single patients visited once a year by the Commissioners, it would indeed be sanguine to believe that the treatment is always satisfactory; for the Commissioners have no statutory obligation to visit them at all; they have no statutory powers to interfere with their treatment when they do visit them ; and, except by means of an order obtained from the Lord Chancellor, they cannot even procure the liberation of any of them whom they find to have recovered or not to be insane. The weary work of visiting these 460 single patients, even once a year, by the Commissioners was the subject of urgent complaint to the Select Committee; and it was somewhat naïvely suggested that in the country, where the visitation of one such patient often involves the labour of a day and a journey of thirty or forty miles, it should be performed by the justices, who are unpaid, and who get much of the labour and little of the credit of lunacy work throughout the country. When he is wanted, there are few things to which the justice of the peace is not deemed competent, but when he is thought to be superfluous his defects appear. Thus, he is said to be the proper person to undertake the visitation of all the single 
patients in the country; and yet he is unfit to sign the order for admitting a private patient into an asylum, because he is by no means equal to the deputy-sheriff of a Scotch county, but only "the common magistrate of the county who sits in petty sessions, a man of comparative inferiority." He has to deal with all the difficult cases of private lunacy, the wandering lunatics, the lunatics not under proper care and control, the lunatics neglected or improperly treated; but to sign or countersign the everyday papers of private asylum lunacy-for that height of responsibility it is declared that his social status and his mental capacity do not fit him.

The real visitation, however, of single patients under certificates is the statutory visit and report once a fortnight of a medical man ( 8 and 9 Vic. c. I0O, s. 90). This enactment forms the only substantial protection of single patients from ill-treatment; and it is one of which the profession has the right to be jealous, for it forms its last hold upon a vast class of diseased persons which has for the most part been removed without intention from the immediate care and cognisance of the profession. And this last stronghold also is being undermined; for, by the statute of I 862 , Chancery lunatics, who were formerly subjected to it, were withdrawn from it by an alteration of the law which the Lord Chancellor's visitors have been known greatly to regret. Furthermore, strict adherence to this enactment is not always encouraged by the Commissioners, who sometimes recommend, in cases of doubtful fitness, that their powers should be invoked to remit this fortnightly visitation. When a legal Commissioner recommends the remission of the fortnightly medical visits to a 
single patient suffering from general paralysis, whom he has seen in a tranquil period, it is, no doubt, because he cannot foresee that within a fortnight the patient will be in a state of maniacal excitement or recurring convulsions. But this is only a small instance of the officialism which overrides the profession in lunacy matters. Let the profession-that is, the members of the profession-ask themselves whether they are willing wholly to resign the treatment of mental disease into the hands of officials and a class of licensed men who carry on the business of boarding lunatics, of which class only 66 per cent. belong to the profession, many of them no doubt, in spirit and in truth, but many others in such a sense that their medical qualities are hidden under their great economical and financial abilities. Let the members of the profession at large reflect upon what it really means to surrender all guidance and treatment of disease affecting the mind; the influence in society and influence in families which they lose thereby; the difficulty of treating many bodily diseases if they be warned off the mental preserve ; the impossibility of keeping the bounds, or even of knowing them. The weight of a great opinion was given to the Select Committee, that constantly "lunatics are kept in unlicensed places under the name of nervous patients"; and it was suggested "that all persons taking nervous patients should notify that to the Commissioners, and the Commissioners should then come down and see whether the patient was a nervous patient or a lunatic. If he were a nervous patient, he would be left where he was; if a lunatic patient, he would be put under certificate." There is excellent sense and undoubted truth in these remarks 
from the official point of view; but let the profession reflect upon what they may come to mean in the future, if no stand be made for the rightful position of the profession in the treatment of all kinds of disease. The visiting physicians of asylums have been elbowed out of existence; the insane members of the richer classes have been accumulated in institutions, where they have become the property of capitalists; and the single patients, residing lawfully under certificates in English homes, and the frequent visitation of medical men in ordinary practice, are regarded as if they were rebels to the great prerogative of asylumdom. 
WHY, THIS IS A CERTIFICATE.

IF any one of common sense could be quite ignorant of the lunacy laws which hang over his head, and were asked upon what kind of formality it would seem to him right that a man should be deprived of his liberty on account of unsoundness of mind, he would be very likely to commence his reply by laying down the broad principle that, such necessity being conceded, all subjects of the Queen ought, in such a matter at least, to be dealt with alike. But, if he were told that this would be inconvenient, because, the great bulk of insane persons being maintained out of public funds, there was the greatest possible inducement not to deprive them of their liberty for one moment longer than was absolutely needful, while the remainder, being persons of private means, were liable for various reasons to be deprived of their liberty without absolute need for such a step, he would, no doubt, be inclined to say that, in the former case, the conditions might be formal, but in the latter, every security which a careful investigation could afford ought to be taken. 
But if he were told that this principle was reversed in practice, and that a destitute lunatic could not be confined in a public institution, under the charge of public officials, and maintained there out of public funds, except upon the intervention of the officer who administers these funds, and the order of a magistrate, while a rich lunatic could be locked up in a private place of confinement upon the order of any person, who might be an alien, an infant, or a man of straw, with whom the owner of the place chose to make a pecuniary agreement, the man of common sense would not be unlikely to conclude that, "for ways that are strange," our legislature at least equaled that of the "heathen Chinee." If the forms of admission for a private patient and those for a pauper patient were mutually interchanged, some reason might be assigned for their difference. It might be thought right that two medical men instead of one should testify to the necessity for care and treatment which would be a public burthen, while the sanction of public officials should be invoked for an incarceration contrary to the spirit of the laws, and liable to be imposed from unworthy motives. If the form of admission of a private patient be examined, a strange structure it will be found. The two certifying medical men, whose action ought to be united thought in counsel, like the head of gold, are made to stand apart, like the thighs of brass; but the feet of clay on which the image rests is clearly the order "of the undersigned," who may be anybody.

On what intelligible ground should the "physician, surgeon, or apothecary" in actual practice, personally examine the patient "separately from any other medical practitioner"? It seems, if one thinks of it, 
a strange embodiment of jealousy and distrust ; for in other instances where the opinions of two or more medical men are required, the opposite course is taken in order to secure the great advantage of combined observation. When, in any other form of disease, it is desired to confirm the opinion of one medical man by that of another, what would be thought of the wisdom of a proposal that each man should examine the patient separately? When medical men examine a patient together, they usefully check each other, and are of the greatest mutual assistance in observing correctly, and estimating rightly, the symptoms of disease, a consideration of the greatest importance in cases of mental disease, whereof the main symptoms are words spoken by the patient, which often convey a different meaning to the minds of different people. If the lunacy laws had not been imbued with distrust of the medical profession, they would never have contained an enactment abrogating all the advantages of medical consultation. Rather would they have enacted that the examination should be a joint one, the opinion concurrent, and the report thereof, or certificate, mutual.

When the patient has been got into an asylum, a different estimate of joint examinations is adopted; for no patient can be discharged out of the asylum, by the Commissioners, except upon a joint examination made by two of them, repeated at an interval of not less than fourteen days, and a concurrent opinion upon the point at issue. If it were as easy to get a man out of an asylum as to get him into one, the forms of admission would not, perhaps, be so important as they are; but when the exit is hedged in with legal difficulties, the entrance ought surely to 
be guarded with an equal amount of care and forethought; and this hindrance to that most useful practice of consultation and mutual action which prevails in the medical profession ought, for one thing, to be removed.

The next point which attracts attention in these forms is that strange conjunction of ideas upon which the theory of private lunacy law seems to be based, namely, that a person who is a lunatic, or an idiot, or a person of unsound mind, is also always a proper person to be taken charge of and detained under care and treatment. There are really three ideas jumbled in this part of the certificate, as if they were correlative, namely, unsoundness of mind, care and treatment, and detention; whereas the things themselves are quite distinct, separable, and independent. Unsoundness of mind may, and ofren does. exist, without the need of any "care and treatment ;" and even when care and treatment are required for it, there is very often not the slightest necessity for detention.

It is, to say the least, very remarkable that no distinction is made in the form of admission between the person of unsound mind who only needs common care and a little kindness in domestic life, and the lunatic who needs to be detained in an asylum under lock and key.

With regard to the first of these notions, whatever the interpretation clause of the statute may say, there is a distinction made by common assent between a lunatic and a person of unsound mind. A person whose mental faculties are simply enfeebled by disease or natural decay, is of unsound mind, but it would be quite wrong to call him 
a lunatic; and yet nineteen out of twenty of the admission-papers which the Commissioners accept for the detention of people in lunatic asylums, simply affirm that such persons are of unsound mind. But this condition, which would suffice to justify care, and even a little control, in domestic life, is surely insufficient to justify detention under lock and key in an asylum. The second amendment, therefore, which seems needful in the certificate-so called probably because it so often asserts things which are not certain-is to require the reporting medical signatories to distinguish, with some degree of definition, the kind of mental disease which they have found; or at least whether it be lunacy, or idiocy, or unsoundness of mind; whether it be disease, or defect, or decay. And this would lead up to a third and most important amendment of what must appear, to any mind unpossessed with the lunacy creed of the day, a great and palpable error of the existing form, namely, the omission to require the medical examiners to report what kind of care and treatment they consider needful. At present, these professional reporters, whose opinion is registered with nice precision, have to give exactly the same form of certificate for an imbecile youth, residing with his mother, with money in his pocket, and whose property, under trustees, helps to keep the house, but who needs no more treatment than a little loving care and guidance, as that certificate which they must give to the homicidal or suicidal lunatic, or the raving maniac, for whose safe keeping a special building and a staff of skilled attendants would seem to be needful. A more roughand-ready scheme could scarcely have been devised than these indiscriminating medical certificates. The 
same for the asylum, the hospital, and the home; the same for the lunatic, the imbecile, and the infirm of mind. They were devised, and have been most effectually used under the idea of bringing them, that is, the insane population, into the asylums, with an equal misunderstanding, of medical science and social right.

Therefore the third amendment which is needed to convert these formal certificates into something like medical reports worthy of confidence, and drawn with the purpose of guiding action, would be to require that they should indicate the kind of care and treatment which, in the opinion of the reporters, is needful in the particular case. They ought at least to distinguish between care and treatment in domestic life and care and treatment in an asylum, for the difference between the two is enormous; and a medical man who has given a well-intentioned certificate, under the belief that it would be used as a justification for gentle control in the former, is liable to find it utilized for imprisonment in an institution. But, even beyond this broad distinction, it would seem to be reasonable and right that the medical men upon whose report the liberty of an Englishman is about to be restricted should have the power, and should bear the responsibility, of indicating the particular persons to whose care and treatment, or (to get rid of an ambiguous euphemism) to whose control they would be willing to subject their patient. There are asylums and asylums, as there are homes and homes; and merely to say "Let him have care and treatment" is just as vague as to say "Give his medicine in some convenient vehicle," which, as the story goes, may mean a wheelbarrow. 
When a physician, having given a certificate for the home-treatment of some weak-minded creature, finds him put into asylum-durance upon it, he has a great right to complain. But also, when the physician recommends care and treatment, surely it ought to be care and treatment of which he has some knowledge; and, if it be personal care, as in insanity it mostly is, then he ought to be able to specify the care of some person or persons whom he knows. A medical man who would send a patient to the seaside, without saying whether it was Bournemouth or Scarborough which he would recommend, would be careful and judicious in comparison with one who would think that he had done his whole duty by blindly signing papers capable of such various interpretations and use as the existing lunacy-certificates. The medical man may have given his certificate for what he thought an urgent but temporary purpose of treatment in a particular institution which he trusts, and, by the system of transfers, under the same papers his patient may be made to go the round of asylums so long as his life lasts or the lunacy laws endure. No wonder that it was stated before the Select Committee that the best men in the medical profession were more and more in the habit of refusing to sign these certificates of lunacy. It is not from fear of consequences to themselves that they do this; for to these they are no more liable than the operating surgeon or obstetrician, if they use due skill and diligence. But the reason is, that these know what they do, while the certifier in lunacy does not know. The remedy for this great evil is, that the certificate or report upon a lunatic or a person of unsound mind should be explicit in its recommendation of the 
particular place and persons by whom the care and treatment should be applied, and that it should only be available for the one purpose for which it was granted. That is to say, it should be competent and necessary for the certifying medical men to testify in writing, according to duly prescribed form, that, in their opinion, $\mathrm{N}$ or $\mathrm{M}$ being a lunatic, it would be right for him to be placed in an asylum, which they should name; or that, $\mathrm{N}$ or $\mathrm{M}$ being a person of unsound mind, it would be right for him to be placed under the care of certain private persons whom they should name. And it ought certainly also to be competent to them to name a period during which such certificate ought to run and not longer; for it is clearly wrong that a medical man cannot place a mental patient under legal care and treatment without the feeling that, on account of some small remains of his present malady, he may be consigning him to a prolonged detention. No medical man who reflected upon what he was doing could perform such an act without twinges of conscience and tremors of self-respect; and, if these forms be not modified in the liberal spirit of professional consultation and report, it needs no miraculous gift of prophecy to foretell that, discredited with the profession at large, they will become more and more the perquisite of hack certifiers-hangers-on upon the asylum system.

Another essential amendment of the present forms is that the grounds for detention in an asylum, and even the grounds for control under domestic care, should be stated by the medical men who recommend either the one or the other to be employed.

Custommblindness (which is worse than colour- 
blindness, because it blurs the outline of things as they are) often leads official people to associate unsoundness of mind with detention under care and treatment as correlative, if not identical, conditions; but with the general public it is not so, and still less with the medical profession, and still less again with that of the law.

With regard to the medical men who are responsible for advising detention in an asylum, it is but just that they should be allowed the opportunity of stating the reasons upon which they give so momentous a professional judgment. With regard to the patients, it is most unjust that such a judgment should be passed upon them without the grounds of it being stated, and submitted to some authority capable of revising it. With regard to the public, it is most unsatisfactory that a great secret power should be exercised over its liberties without a clear explanation of its necessity being put on record in each instance. And, therefore, it would appear to be imperative to a proper certification of a lunatic for detention in an asylum, that the reasons for which such detention is needful should be fully stated upon the face of the documents, and distinguished from the facts which simply indicate lunacy. It may be that the late Chief Baron, adopting the dictum of the eminent counsel who is now the Lord Chief Justice of England, expounded the law in the case of Ncttidge $v$. Ripley and Another on lines which would require a broad and liberal interpretation. But, notwithstanding the pamphlets of expostulation which it produced, the above is still a leading case in the matter, and a judicial precedent; and it cannot be doubted that no person of unsound mind may by common law be rightfully confined.in 
an asylum, if it can be proved that he is perfectly manageable, safe, and harmless in the enjoyment of his liberty. The opposite conditions would seem to include all legal justification of what is called care and treatment in an asylum; but, however this may be, the deficiency of the present forms in omitting all mention of the reasons for detention, and the absolute need of amending them in this respect, must be apparent to every open mind. But even what may be called the milder recommendation of the medical reporters, the detentio mitior of domestic life, ought not to be given without the statement of the reasons upon which it is founded. What is meant by care and treatment even of a single patient in domestic life is, of course, control. The smooth words are a mere blind, and, if an imbecile or a person of unsound mind needs no control, which includes protection, he needs no interference of the authorities with the management of his person, whatever may be the case with that of his property. What are the specific facts observed by the reporting medical men which should justify detention in an asylum, or those which should only lead to the milder control of domestic care, it scarcely comes within the scope of these articles to indicate. They are the proper subject of the diagnosis of insanity with reference to treatment. There are, however, some few cases of insanity، in which the symptoms are so far concealed or intermitting, that it may become needful for the reporting medical men to avail themselves, win corroboration of their own observations, of facts communicated to them by others; and, in such cases, in amendment of the present forms, it would seem to be desirable that the statements made by other persons to the medical men. 
should be signed by the persons who make them; and that they should be so made and signed with the knowledge that the superior authority, by whom the validity of the paper must be determined, has the power to require them to be verified by statutory declaration. In this manner a great amount of loose, inaccurate, and untrustworthy statement would be eliminated, which greatly discredits the present system of hearsay evidence. To put the proposition in other words, the statute now requires that the certifying medical man shall specify the facts upon which he has formed his opinion, "and shall distinguish in such certificate facts observed by himself from facts communicated to him by others; and no person shall be received into any registered hospital, licensed house, or as a single patient, under any certificate which purports to be founded only upon facts communicated by others" (I6 and I7 Vic., c. 96, s. I0). The Commissioners do indeed require that the name or names of "others" communicating facts shall be stated in the certificate; but this is merely an official regulation, and not a statutory requirement. The strict effect of the statute is that the certifying medical men may be satisfied with the merest modicum of fact observed by themselves, supplementing it by hearsay evidence from persons whose names even they are not required to supply. They are thus placed in the position of weighing the bearing and trustworthiness of unattested statements, which is quite a wrong one for them to occupy. But if their informants were required to sign their statements, with the knowledge that they might immediately be called upon to swear to them, the position would certainly be altered for the better. 
There is a curious enactment ( 16 and $\mathrm{I} 7$ Vic. , c. 96 , sec. I2), as to what medical men may not sign certificates-namely, no father, brother, son, partner, or assistant of the proprietor of the asylum to which the patient is sent; and, in the Amendment Act of I 862 , any person receiving a percentage, or otherwise interested in the payments, is also excluded, but nothing is said of a father-in-law, or a brother-inlaw, or a cousin, or of female medical relatives. The omission of the father-in-law has been peculiarly unfortunate. It would perhaps be better to leave disabilities of this kind to the determination of a regulating authority, whose action should precede and not follow the use of the document.

What that authority should be, must be discussed in another article. At present, the medical certifiers are but the servants of the man who signs the order; who may himself be a servant, or even, as Mr. Percival suggested to the Select Comnittee, an infant (Question 337). He may be a phantom or a tyrant, a delusive name or a mischievous reality; and it was fully admitted by the Commissioners that he could not be maintained in his present position unless power were given to them to depose him and to nominate his successor. It would be much better that the revolution should be thorough and effected by law. 


\section{IV.}

THE POWER OF THE KEIS.

If the reforms suggested in the last article were adopted, the present bald certificates might be exchanged for trustworthy medical evidence, and the pretence of independent examinations, well known to lunacy doctors, and well described by one who had suffered from it (Minutes of Evidence, Questions 92 I 5 and 9216$)$, whereby a few questions are put while first one doctor and then another disappears for a moment behind a side-screen, would pass into well merited oblivion. If these reforms were adopted, the demands for a public inquiry in each case of subjecting an insane person to detention or to control, which have lately been rife in the criticisms of the lay press, would probably be discontinued; especially if this medical evidence were used as evidence only, and as the needful foundation of magisterial action, and if this reform were accompanied by such other reforms of the lunacy law and its administration as would appease the well-founded fears of the public, that harmless insane persons are sometimes incarcerated upon inadequate grounds or for unreasonable periods. 
It is, of course, understood that the common law will justify a medical man for restraining and controlling a patient who is delirious from fever, wounds, poison, drink, or any other cause including insanity, his defence being that he has used due skill and diligence in the necessary exercise of his art. This is the justification for the needful restraint of a madman for a limited time for purposes of care and treatment under the common law. But the statute law introduces limitations to this right, namely, limitations as to number and as to profit, so that not more than one insane person can be detained under care and treatment except in certain places licensed for this purpose, and so that not even one insane person can be received and kept for profit in any place whatsoever, unless certain forms be observed. The statute law does not forbid, prevent, or punish the continuous restraint of a lunatic who is not actually neglected or ill-treated, and who is under what may be deemed care and control, unless he be received and kept for profit. There is no law to prevent a Mr. Rochester from locking up his mad wife in the attic of his mansion with a keeper, as described in Fane Eyre, But if he had confined her alone and in a state of nudity in a cellar, clearly the law would have reached him, for she would have been neglected and ill-treated, and not have been under proper care and control; and how it was that a metropolitan magistrate recently failed to deal with the instance of this latter kind, which was referred to by one of the honourable members of the Select Committee, it is difficult to see. Whether any person like Mr. Rochester should still be allowed to make a private oubliette for a mad member of his family, is 
very questionable. The recommendation of the Select Committee, that confidential reports of confirmed lunatics under restraint in private families or religious houses should be sent to the Commissioners, would be of no value, unless associated with visitation. The first and primary question would seem to be, whether every insane person who is deprived of liberty ought or ought not to be under the supervision of the State. The Earl of Shaftesbury answered this question, before the Select Committee on Lunatics, I858, with statesmanlike caution (Questions 304305). "I do not say whether it would be right or wrong. I do not think it desirable to introduce our powers into a strictly private house; if a husband have charge of a wife in his own house, or a wife have charge of a husband, or parents have charge of children, or children of parents, I do not think that public opinion would allow of any intrusion in such cases."

The statute, however, takes no cognisance of propinquity of blood in this matter; and a mother cannot receive and keep her insane son for a profit, except under certificates and order. It is profit and not kindred which rules the action or abstention of the State, and profit is often a difficult thing to prove. A considerable improvement, therefore, of the statute would seem to be offered by the simple adoption of Lord Shaftesbury's views, making certificates unnecessary for the care and control of the insane by the relatives whom he names, but requiring them with the accompaniment of sufficient State supervision whereever an insane person is kept by any other person. And this law, thus simplified, ought to be administered impartially, so as to give no occasion for such 
invidious remarks as the following one made by the Fournal of Mental Science for April, I 879, page 48 . "The Commissioners take credit," says this writer, "in their annual reports, for the zeal with which they hunt out these cases; and the institution of a criminal prosecution in a 'sensational' case, from time to time, serves to foster public appreciation of their activity and usefulness."

With the above doubtful exceptions, no single lunatic ought to be detained or restrained without medical certificates for more than a brief and fixed period. In recent and sudden cases, one certificate might be allowed to suffice for a short time, until the consultation and regular report of two medical men and the magistrate's order could be provided. The transmission to the central authority of the latter, followed and completed by the fortnightly visitation and report, as at present fixed by the statute, should be the only protection against statutory penalties.

In the case of a single patient under certificates, there surely need be no order, either of a magistrate or of any other person. The medical visitation and report ought to protect the person controlling a single lunatic only against prosecution under the statute, but not against civil proceedings for damages. If that most unhappy section of the Lunacy Act I 845 (Section 99) be repealed, the medical report, the fortnightly visitation and report, and the common law of action for damages, would be sufficient to protect single cases under domestic care. These domestic cases ought to be considered as especially under medical treatment and supervision, and, as a rule, there should be neither magistrate's nor any 
other person's order for such treatment. In many cases, however, it would be a vast improvement upon the present system to give to the Commissioners, or to the central lunacy authority of the future whomsoever it may be, the power of appointing a relative or friend or other person to hold towards the private patient, either in domestic care or in asylum confinement, the same position, not as the man who signs the order, but as the Committee of the Person of a Chancery lunatic-a person appointed and removable by the authority, a suitable and proper person for the charge, who would undertake to visit the patient periodically, to report on his condition, and to carry out the reasonable recommendations of the authority as to care and treatment. Many single cases and asylum cases also would need no such person-simple, easy, and tractable cases, short and curable cases, and others undefinable; but, in prolcnged and difficult cases, requiring careful consideration and painstaking, the substitution of a Committee of the Person who would undertake to visit and to exercise efficient supervision, under good official control, for the man who signed the order, would be an incalculable improvement.

When domestic care and medical supervision and treatment, implying some control but not much, are insufficient for the requirements of the case, and the patient has to be made an asylum lunatic, the sanction for that which no disguises can make anything less than the loss of liberty by imprisonment ought surely to be that of the State speaking through one of its public seriants. Medical opinion must still, no doubt, be the main reason for detention, though considerations of the public safety which are 
not medical may buttress it; but, for the welfare of the patients, the liberties of the people, and the dignity of the profession, it must be conceded that the interested or delusive sanction now afforded by the order of detention must be supplanted by something of more authority. The Commissioners in Lunacy, indeed, plead for the status quo; it is not easy to discover wherefore, seeing that the Commission is overladen with that most burthensome kind of responsibility, the management of people over whom it has little power, of whom these signatories of orders for asylum detention form a mutinous body, in which each man shirks or fights for his own hand. The proprietor of a licensed house has a more intelligible reason for upholding the man who signs the order, seeing that generally he is the other party to a business agreement ; and, if the proprietor sometimes accepts a man of straw as the ostensible person with whom he contracts, he may be trusted to look behind him to some one else who is tangible and solvent. But the public want some one else who is solvent in moral responsibility, which cannot be assumed of the man who signs the order.

If the Commissioners had arrived at the well-considered conviction that the present system was really good in principle, they would probably, at least in the metropolitan district, where their powers are practically unlimited, have submitted it to reasonable regulations. They would not have permitted people to be detained in asylums under their rule, under the orders of men living on the other side of the world, or of servants of the family, or of innkeepers, of lawyers' clerks, and other casual people whose position and character afford no guarantee for the right use of 
their great powers. If in any way dissatisfied with the admission-papers the Commissioners can order the discharge of the patient, and with this power in their hands they have actually amended the statutory admission-papers by their regulation as to the requirement of the names of "other" persons communicating facts which indicate insanity. It is not that the unregulated system has worked well, for in many instances it has worked grievously ill ; for if, to the credit of the medical profession, it can truly be said that the instances in which persons who are not insane have been received into asylums are exceedingly rare, it can scarcely be denied that, owing to the ignorance, negligence, or selfishness of persons who sign the order, or of those who instigate them, imprisonment in asylums is often needlessly imposed, and is often wrongfully prolonged upon improper objects.

The power of caption, which the order confers upon the owner of an asylum and his servants, is another invasion of the liberty of the subject which is a great scandal. The statute relating to pauper lunatics provides for their conveyance to the county asylum by the proper official. The order of the sheriff in Scotland provides for the conveyance of both pauper and private lunatics to the asylum; and in neither case has the medical superintendent any power over a lunatic until he has been duly received and admitted into the institution. But in England the statute gives the power of caption of any private lunatic to the owner or superintendent of any licensed house or hospital, or to his servants; so that, for seven days after the order and certificates are signed, the owner of an asylum or his servants may search for, seize, 
and convey, bound hand and foot if need be, any private lunatic from Carlisle to Penzance. No wonder that this "taking" of private lunatics has from time to time afforded incidents which have shocked the public sentiment of humanity, decency, and right. The enactment under which it is practised is a wonderful example of what the English public will bear when the sufferers are a small and helpless class and many powerful interests are engaged in keeping things quiet. The power and protection conferred upon the proprietors of asylums and their servants by the ninety-ninth section of the Lunacy Act of 1845 is without parallel in anything else remaining in the Statutes at Large. It makes one wonder in what age and country we are living; for it not only authorizes a private man to receive, as a matter of profitable business, any lunatic or alleged lunatic of whom certain papers have been signed, and to detain him "until he die or be removed or discharged by due authority," but against all civil actions for "taking, confining, detaining, or retaking" such an alleged lunatic, it gives him the right to plead such order and certificates if correct, as a justification. Surely some judicial sanction ought to be essential before such protected powers are acquired by private people over the liberties of the least of the Queen's subjects. Surely the question must arise in all fair minds, whether such powers ought to be conferred upon private people under any circumstances or sanction whatever. Gracious amenities and benignities of life in a free land! Did any one, savouring your sweetness, ever consider the full meaning of the sentence passed upon the liberties of Englishmen in the harsh lines of this enactment, without a shudder at what may be done 
with impunity under the ægis of legalized injustice? The common law of the land, laid down in repeated and unquestioned judgments by the greatest judges, is, that no one but a dangerous lunatic shall be locked up in an asylum; but this enactment of 1845 has for a generation made private war upon the liberties of the innocent and the helpless, who are no more dangerous than children, no more in need of imprisonment than the deaf and the blind. Whatever else be done or left undone in lunacy law reform, the charter of private imprisonment contained in 8 and 9 Vic., c. roo, sec. 99, must be repealed, and all insane persons who are harmless restored to the full possession of the common-law rights of Englishmen.

But those lunatics who are not harmless must be still sent to asylums by authority. A medical opinion and report are not an authority for such detention. Would it be right and expedient to constitute the order of relatives and friends, under regulation and definition, such authority? or would it be best to place the power and responsibility upon the shoulders of the magistrate? The sentimental argument in favour of the action of near relatives in this matter is, of course, extremely strong, and no one would wish to run counter to the domestic affections in so great a calamity as madness in a family. But the arguments in favour of the existing order, which were urged upon, the Select Committee, were not founded upon such unstable ground as sentiment, which, in the face of the law for pauper lunatics and the certainty that domestic vice must be reckoned upon to take its turn with domestic virtue in the dealings of relatives with lunatics, could not be 
maintained. The voice of affection is as potent in the homes of the destitute as in those of the rich, and yet in the former it is overruled by that of the magistrate. The bias of affection would in all classes tend to retain harmless cases of insanity under the home roof-tree. The bias of the evil brood of bad passions would be to immure them in the concealment of an asylum ; to get rid of trouble; to diminish expense ; sometimes to have freedom for misconduct. There would be no hardship felt by a loving relative that the action of the magistrate relieved him from a most painful duty. There might be annoyance felt by a selfish or vicious relative that the action of the magistrate interfered with a heartless exercise of authority. In the pleadings for the relatives to sign the order, the great value of their responsibility before the law was urged; but it was forgotten that neither husband nor wife can bring actions for damages against each other, and that actions between parents and children would be difficult and scandalous; and that regard to future rights of procedure on the part of a lunatic would, on this argument, exclude the nearest relatives from the signatories of the order. Under this view of the value of the order, any substantial householder would be preferable to a near relative. The governors of Bethlem and of other hospitals for the insane do, in fact, require the endorsement of the statutory forms by substantial householders, in view of certain responsibilities-removal, burial, etc. In point of fact, therefore, the sentimental argument for the maintenance of the power of relatives to inflict imprisonment upon their relatives is a sentimental argument and nothing more; nothing more, unless when it is something worse-the desire to possess a 
power for selfish purposes, or the foolish and feeble desire of secrecy and concealment.

The framers of the Scotch lunacy law, who, coming after their English compeers, have had the opportunity of avoiding some of their mistakes, gave a wide berth to this private power of imprisonment; and over the border, therefore, the friend or relative who desires to place a lunatic in an asylum, having obtained medical certificates of his insanity and that he ought to be placed in an asylum, has to petition the sheriff, upon whose order the lunatic is conveyed to the asylum and detained there. The Scotch lunacy law, and the way in which it works, can be best studied in the adinirable evidence of Dr. Mitchell, one of the Commissioners. To Question 9,872 he says: "Under the Scotch laws, the procedure for authorizing the admission of patients into asylums rests on the idea that the step is one which involves a loss of personal liberty ; accordingly, in Scotland, the persons who can authorize admission of any patient into an asylum are persons who are entrusted with the power of taking away personal liberty for other reasons than lunacy." That is the principle, and, no doubt, the sound and constitutional one. Dr. Mitchell proceeds to explain that the petition to the sheriff must be accompanied by two certificates granted by registered medical men, bearing that they have separately examined the patient and found him, first, a lunatic, and secondly, a proper person to be placed in an asylum. The sheriff may refuse the petition for a great variety of reasons, and often does so, "dealing with the petition as he deals with any other petition which prays him to exercise an authority conferred upon him by the State." Dr. Mitchell further states : "It naturally forms a feature of such a procedure 
which rests upon such an idea, that it is exactly the same whether the person to be admitted is in affluent circumstances or is a pauper; whether he is to be placed in a private or a public asylum. This uniformity of procedure in regard to all classes of asylums and all classes of patients is an important feature in the Scotch law, and it appears to me that it is a feature which cannot be absent from any lunacy laws which are sound. On this procedure, more than ninetyseven per cent. of all lunatics in Scotch asylums have been admitted. I believe that it satisfies the public, who do not find it cumbrous, or a hindrance to the early and quiet treatment of patients; and I also believe that the contentment of many patients is promoted by a knowledge of the fact that it has been necessary for their friends to obtain an order from a high public functionary for their admission into, and their detention in, an asylum. Many patients feel that they have been taken to an asylum against their will ; that they are kept there against their will by force of necessity. They feel this to be imprisonment, and talk of it as imprisonment; and it satisfies them, to some extent, to know that their personal liberty has not been taken away without an order from a sheriff, to whom they can appeal, and to whom they do appeal sometimes with success." The evidence both of Dr. Mitchell and Sir James Coxe makes it clear that the sheriffs do exercise their functions in this matter, not ministerially, but judicially; and, therefore, it is only open to criticise the system as it is thus administered. The Earl of Shaftesbury did so criticise it (Question I $I, 605$ ), on the ground that such a judicial act would exonerate the medical certifiers, the man who signed the order, and the man who received the patient; so 
that however bad the papers might have been, it would take from the patient the right of legal redress when he obtained his liberty. The whole thing was endorsed by the magistrate, and must pass as unquestionable. But, notwithstanding his lordship's deep and far-reaching knowledge of lunacy matters, we must venture to question the correctness of his law on this point. Of course, the man of the order and his responsibilities are superseded by the Scotch system ; but the judicial act of the magistrate would scarcely exonerate medical certifiers who had not used due skill and diligence, neither does the English method lay any legal responsibility upon them if they have exercised these qualities. And, with regard to the man who admits the patient, it is certain, from the Scotch evidence, that he is liable to action for damages if the formalities of admission be not strictly observed.

It is difficult to conceive the poss:bility of drafting a statute by which the hand of common law could be more tightly bound from giving redress for questionable confinement in an asylum than the existing one; "the man in the street" who, perhaps, had signed the order, being the only target left to be shot at. But Lord Shaftesbury's earnest desire that an injured man should have his remedy is a precious promise of reform in this direction. Every one who has been falsely shut up as a lunatic, private or pauper, ought to have his civil remedy untrammeled. The action of the magistrate ought to cover nothing more than the reception of the lunatic, and his detention for such time as might reasonably be deemed sufficient to ascertain his mental state. If wrongfully detained after this time, the pauper even ought to have his remedy for damages inflicted malâ fide against the 
visiting justices, who can sue and bc sued through their clerk. The private patient in a hospital for the insane ought to have his remedy against the governors through suit also against their clerk. The private patient confined in a licensed house ought to have his remedy against the proprietor and licensee.

Another argument used by Lord Shaftesbury was, that the Commissioners could not overrule admissionpapers which had been endorsed by a magistrate; but surely his lordship underrates the powers of his Board, seeing that the Commissioners have provided themselves with the power of ordering pauper lunatics under a magistrate's order to be discharged from county asylums, sane or insane, if the papers be not formally correct. In any matter on which Lord Shaftesbury feels strongly about lunatics, there is sure to be in his view some sound reason founded in good sense and humanity; and in this instance it seems to be his objection to the interference of the civil power with the medical treatment of the insane. [Questions I I5-24.] But it seems an inevitable necessity, this connection of lunacy with the police and with the magistracy. In their own domain, what are the Commissioners themselves but magistrates in the daily discharge of the police functions of civil government regulating the treatment of the insane? With regard, indeed, to their principal and original functions and powers-namely, the governance of licensed houses in the metropolitan district-the Commissioners find their exact analogue in the Boards of Visiting Justices appointed at Quarter Sessions to be the governing bodies of licensed houses in the provincial counties. When it is considered that throughout the country 38,87 I lunatics are under the immediate care and 
control of the magistracy, confined under their orders in county and borough asylums, and that, out of the 4,645 private lunatics in licensed houses, 2, 169 are also under the immediate care and control of the magistracy in the provinces; when it is also considered what onerous and delicate duties are imposed by the law upon magistrates with regard to private lunatics who are neglected, or not under proper care and control, or are wandering, and in other matters of lunacy law too numerous to mention,-one would have thought that the Commissioners would have eagerly desired the aid and assistance of that most important and influential body of Her Majesty's subjects and servants to whose faithfulness and diligence the primary administration of the law is confided : its aid and assistance in no new direction, but simply in extending their present duties to sufferers from a calamity so great that it needs no increase from the influence of class legislation.

Therefore abolish the man who signs the order ; and in the case of a private, as of a pauper patient, let it be signed by the magistrate, not ministerially, but judicially. The statute ought to declare, and the form to ensure, that the magistrate shall feel himself called upon to form a real judgment upon the evidence placed before him, and to require, if need be, its amendment either in form or substance. In Scotland, the magistrate-that is, the sheriff-depute-does not personally examine the patient, dealing with the case upon the testimony alone; while in England the magistrate is required personally to examine a pauper patient. The difference in practice may probably arise from the circumstance that the duty is performed by one official in each Scotch county, whereas in England it is confided to a considerable number; so that in the one 
case personal examination would cause great delay and inconvenience, and in the other none. Certainly the English practice appears the more commendable ; for, in a matter so purely personal, the personal examination would seem to be of high value. In Chancery lunacy, the Master, sitting as a jucige, must see and examine the alleged lunatic at the inquisition; and on writ of supersedeas, the Lords Justices themselves personally examine the man who has recovered. The Commissioners in Lunacy, on the other hand, neither see their lunatics on admission nor on discharge, and many private lunatics pass through their confinement in licensed houses without ever seeing either magistrate or commissioner. 
INSANE AND NOT DANGEROUS.

THE import of admission-papers, or as they might more correctly be called commitment papers, can only be appreciated by a full understanding of the detention and confinement which they involve. If asylums were really hospitals, insanity a brief disease, and no continuous restraint of personal liberty required in its treatment, it is not obvious that commitment papers would be at all needful. But the less that asylums are hospitals, and the more they are places of prolonged confinement and restraint, the more imperative is the necessity that commitment to them should be guarded by the action of recognized authority; and the more facile the imposition of restraint, the greater the safeguards ought to be that it shall not be unduly prolonged.

There are three distinct questions to be considered in this relation, namely, (I) the kind of people who may be committed to asylums; (2) the condition of their release; (3) the restraint to which they may be subjected.

On the perusal of medical writings on lunacy and 
the evidence given by officials in lunacy before Parliamentary Committees, one cannot fail to be impressed with the great importance which is attached to detention in asylums as a means of treatment of disease. The one great argument in favour of facile confinement is, that the speedy treatment of mental disease may thereby be provided. This idea so pervades these expressions of opinion on this subject, that it appears to be assumed that the main and primary object of confinement is the treatment of disease. But, strange as it may, perchance, appear to many well-instructed medical men, this assumption has no legal foundation whatever. The purpose of the law, as expounded by the judges of the law without exception, looks not in the slightest degree to the treatment of disease as authorizing and justifying the confinement of an insane person. The sole purpose of the law is to provide for the safety of the public and the individual. Safety is the one sole object which the law of England recognizes as the aim and purpose of confining the insane. Where there is no danger, there can be no legal justification of confinement; and, without doubt, any harmless and safe person, however insane, would be entitled to damages for confinement in an asylum, even if by such confinement he had received the greatest medical benefit in regard of his disease. The damages might be so small as to be represented by the smallest coin of the realm, but to damages on the point of law he would be entitled.

In the case of Nottidge $v$. Ripley and another, this principle was laid down as unquestionable law. At this trial, for the detention of a lady who was admitted to have been suffering from insane delusions, 
the Lord Chief Baron, in summing up, said: "As to the plea of justification-namely, that the plaintiff was a lunatic, and not capable of taking care of herself, and was in such a state of mind as to be likely to injure herself and other persons, and that it was in consequence of being in that state that they had put her in a place of safety-that plea was not made out. Now, he was bound to say that the law was correctly laid down by the learned counsel who had just sat down " (Mr. Cockburn, now Lord Chief Justice), "namely, that if the jury considered upon the evidence, that the lady was not in such a state as to be dangerous to herself and others, then the plea to that effect not having been made out, the verdict ought to be for the plaintiff upon that issue. The defendants were not in any way justified in adopting the course they had taken, unless the jury should think that the plaintiff was of unsound mind and dangerous to herself and others. If the jury should be of opinion that the plaintiff was not in that state of danger, it was clear that the verdict upon the second plea must be for the plaintiff. There could be no doubt that, if the lady was not insane and dangerous, a most unjustifiable outrage had been committed upon her by the defendants in their own persons. They might have instituted an inquiry by Commission; but they had not done so; and, therefore, they had made themselves liable to such a verdict as the jury might think fit to impose upon them." The verdict was for $£ 50$ damages, the jury expressing the opinion that the defendants had not been actuated by any unworthy or mercenary motives. (The Times June 27 th, I849.)

In the proceedings in Fletcher $v$. Fletcher, January 
I 8th, I 859, which were still more important, because it was a case of argument on demurrer before the Judges of the Queen's Bench sitting in banco, under the presidency of a future Lord Chancellor, this principle was broadly reaffirmed. In this argument, the real issue was the somewhat technical one as to whether the plea was admissible that the person who had been confined in an asylum had conducted himself as a person of unsound mind, \&c. ; whereas it was successfully contended that the plea ought to have been that he was of unsound mind. The argument pro was conducted by Mr. (now Justice) Lush, who maintained that, "at the common law, to be a valid justification, it must be alleged and shown that the person confined was a lunatic, and dangerous." Mr. Bovill, who argued the demurrer contra, did not deny that this was the law. Chief Justice Campbell said: "By the common law of England, it is only a person of unsound mind, and dangerous to himself or others, that may be restrained of his liberty by another. Such is taken to be the law from the case in Bro Abr, down to the last case on the subject." Justice Wightman said: "At common law, any one taking up another as a lunatic, in order to justify himself must show that he was a dangerous lunatic." Justice Crompton and Justice Hall concurred. References were made to many previous judgments, especially to Elliot $v$. Allen, in which it was admitted by the learned judges that "the law was assumed to be undoubted on this point." (28 L. F. R., I34.)

This important argument before the full Court of the Judges of the Queen's Bench, in which the law of the land with regard to the confinement of lunatics has been most rccently declared on the 
highest authority, has been somewhat remarkably passed sub silentio by the Commissioners in Lunacy; although in the former less important instance, above quoted, of a jury trial, the ruling of the judge excited both official, medical, and legislature remonstrance; the first, in a letter to the Lord Chancellor from the Commissioners in Lunacy, ordered to be printed by the House of Commons, Ist August, I849; the second, in a published remonstrance to the Lord Chief Baron by Dr. Conolly; and the third in remarks made by Lord Monteagle and Lord Brougham in the House of Lord's. The substance of all these attacks upon the exposition of the law by one of its chiefs, is, that obedience to the law would be exceedingly inconvenient, inasmuch as, "amongst the many persons confined as being lunatics, those who have already proved themselves to be dangerous are comparatively few in number" (Commissioners" letter) ; or, to repeat the words of Lord Monteagle, "the great majority of persons detained in custody in lunatic asylums were no more dangerous to themselves or others than any noble lord who was in the habit of addressing that House." The statute law is silent on the subject of a lunatic being dangerous or otherwise, except in the statement appended to the order of admission. In this statement, the person giving authority for the confinement of a lunatic is required to state whether the lunatic is suicidal or dangerous to others. It would be interesting and important to know the proportion of admission-papers which contains the statement that the lunatic is dangerous.

It will have been observed that Lord Chief Justice Campbell and the puisne judges who concurred with him declared that no person of unsound mind who 
was not dangerous could legally be either taken up as a lunatic or restrained of his liberty or confined. This declaration of the law, therefore, covers not only the taking, but the detaining and confining of insane persons; and therefore it would appear that, even if a person be originally taken up as a dangerous lunatic, if he should afterwards become not dangerous, his further detention will be illegal. (Note p. 57.)

This opinion was very positively expressed by the judge in the Nottidge case, in the examination of one of the Commissioners who was a witness. "The Lord Chief Baron said : Mr. Milne, was this lady in such a state of mind as to be dangerous to herself and others ?-Mr. Milne: Not so far as I was aware of. Not so far as I know.-Lord Chief Baron: If she were not so, then how was it that you kept her in this asylum for seventeen months?-Mr. Milne: My lord, it was no part of my duty to keep her there. I was only to liberate her if I saw good and sufficient reason for adopting that course.-Lord Chief Baron : It is my opinion that you ought to liberate every person who is not dangerous to himself or others. If the notion has got abroad that any person may be confined in a lunatic asylum or a madhouse who has any absurd or even mad opinion upon any religious subject, and is safe and harmless upon every other topic, I altogether and entirely differ with such an opinion, and I desire to impress that opinion with as much force as I can in the hearing of one of the Commissioners." (See note, p. 57.)

It would be curious to ascertain how many patients the Commissioners have recommended to be discharged who have not recovered, and for what reasons they have ever done so. In their letter to the Lord 
Chancellor above referred to, the Commissioners, having admitted that the dangerous lunatics are few, state that the far greater number confined in asylums consist of "(I) those who are sent into lunatic establishments for the purpose of treatment, with a view to the alleviation or cure of their malady; (2) those who from disease of mind are incapable of selfgovernment, and who therefore require at certain periods (perhaps generally), the most careful supervision and control; and (3) those who are incapable of taking care of themselves and their affairs, and are likely, therefore, to sustain serious injury if left at large and unprotected."

On the necessity of the treatment of harmless patients in private lunatic asylums, an opinion divergent from that here indicated may certainly be entertained. Any comment upon the second category of harmless patients may fairly be excused on the ground that it is not possible to understand what kind of harmless patients are indicated as those who, being "incapable of self-government," "require the most careful supervision and control." The third category, of "those who are incapable of taking care of themselves or their affairs," is as vague as it is wide ; but if for such incapables some kind of club-life be desirable, as tending to the increase of comfort and the decrease of cost-then at least let it be some legalized form of association dissociated from all the opprobrium and misery of asylum detention in company with dangerous lunatics.

Outside of the legal justification, therefore, the Commissioners maintain that an insane person, not dangerous, may be confined in an asylum for treatment, for supervision, and for care, but, as it would 
seem, on condition that, if released, he would be "left at large and unprotected," and deprived of treatment, supervision, and care. In a subsequent page, the Commissioners declare that they will promote the liberation of a patient of weak mind, who "appears to be perfectly harmless," "if he have a comfortable home, or friends disposed to receive or protect him and his property from injury; but where this is wanting, the Commissioners do not think themselves justified in removing the patient from the shelter of an asylum, and leaving him at large and unprotected." The consideration is thoughtful and humane, but it is forced upon the Commissioners by the shortcomings of the statute. There are few patients who can be safely discharged, even from the warm wards of a general hospital, into the east wind of the street. If the Commissioners could lead their patients to something like a home, where care and protection would be provided for them, the fear of discharging patients not dangerous for the reason assigned would be removed. It must, however, not be forgotten that the common law limiting the confinement of lunatics to those who are dangerous applies to their confinement in any place and to any restrictions upon their liberty, and that strictly a man may not put his hand upon the shoulder of a lunatic who is not dangerous without committing an assault, or lock him in his bedroom without false imprisonment. That such a law cannot be executed is obvious. It is smothered in its own absurdity as regards the proper treatment of the insane at horne, and only on account of its application to patients detained in asylums is it important from its direct antagonism to the operation of the statutes. It expresses the lawyer's view of interference with the 
insane, founded upon the facts of life when society was young and simple, in opposition to the doctor's view of what must be done to prevent mischief among the tender and complex interests of modern life. In the spring-time of the common law, a great lawyer or doctor who had become insane might not be dangerous if he were not violent; but such a man at the present day, who went about town babbling, not of green fields but of family secrets, would certainly not be harmless. The Commissioners, in their letter, have made the mistake of adopting the word harmless as the opposite of the legal term dangerous, which it is not. A man is not harmless who is mischievous or in any way injurious or harmful to himself or others; but it by no means follows that a man not harmless must be dangerous. By this term dangerous, the lawyers mean liable to inflict physical, not moral, injury. By this limitation of the term dangerous to physical danger, the antagonism of the common to statute law is rendered the more absolute, and the necessity of new enactments to reconcile the two laws the more imperative. Indeed, the common law, the statute law, and the royal prerogative in lunacy matters are in such a hopeless state of entanglement, that it would seem that nothing short of codification can possibly succeed in loosening and smoothing out their knotted intricacies and confusions.

It will be observed that all the above arguments apply only to insane persons having or enjoying property. The confinement of destitute persons of unsound mind rests on quite a different footing. Their welfare must be combined with considerations of public thrift and convenience. But the well-being of an insane person who has property surely ought not to be made 
by official authority dependent upon the disposition of friends to receive and protect him and his property from injury. Neither is it so left when the law is obeyed. A lunatic of property who is at large may remain unprotected through default of his friends. But a lunatic under cognisance of the Commissioners cannot remain with property " not duly protected," except by inaction of the Commissioners, whose bounden duty it is to invoke the jurisdiction of the Lord Chancellor. The reasons they give for withholding the exercise of their statutory powers in this respect is that "proceedings by commission are, generally speaking, advisable only where the insanity is likely to be of a permanent character, and the property of the lunatic is of such a nature as to require them." Moreover, they object that these proceedings are costly and public. But it is to be remarked that the Lords Justices, acting with the Lord Chancellor under the sign manual, are the appointed judges of the propriety of commissions ; and that the Commissioners have the simple duty imposed upon them of reporting to the Lord Chancellor that the property of any person alleged to be, or detained as, a lunatic is not duly protected or the income not duly applied for his benefit. The words relating to the application of the income were added in the later statute.

$(8$ and 9 Vic., c. 100, s. 94 ; 16 and 17 Vic., c. 70, sec. 54.)

The Commissioners conclude their objections to commissions of inquiry by the remark that "It is obvious that the finding of a jury is in no case essential in order legally to justify the confinement of a person of unsound mind." This is quite true, in so far that very few commissions are held before juries; but it 
is not correct, save and except for dangerous lunatics, that the finding of a commission of inquiry is not essential to legal detention. The Lord Chief Baron was perfectly right in declaring that a commission of inquiry ought to have been held on Miss Nottidge ; and a large proportion of the harmless patients in private asylums are in the same position as the one in which that lady was illegally placed. Many are the devices to evade the law: illegal payments by trustees to unauthorized persons; illegal authorities to receive rents, extorted from insane persons ; illegal transactions of bankers, conveniently ignorant of their customers' mental state; but, above all, powers of attorney acted upon, if not given, after the insanity. The number of insane persons of property who ought to be under the Lord Chancellor's well-informed protection, but whom the Commissioners leave in the unprotected shelter of asylums, is very large. Surely it would not be a great thing, and would be a most useful one, for the Commissioners to require information of the property of all persons detained and taken charge of as lunatics, and to report thereupon to the Lord Chancellor, who through his registrar and medical visitors would make inquiries as to their due protection. As an instance, it was stated in evidence at a recent trial that a gentleman with an income of $£ 4$,000 was confined in a metropolitan asylum upon a stipend of $£ 360$; and, seeing that his wife admitted that she had expended $£ \mathrm{I}, 000$ a year, or thereabouts, in millinery and jewels, it might be thought that he and his property were not duly protected. A speedy and handy proceeding in Chancery for the protection and utilization of the property of persons whose insanity promises to be of short duration is one of the crying 
needs of the lunacy law; but it is a bad expedient for legal officials to let the law entrusted to them be dormant because it is costly and cumbrous.

Besides those dangerous lunatics who may be legally confined under the common law and the statutes, and those Chancery lunatics who may be legally confined under the authority of the Lord Chancellor, there is a residuum of not dangerous lunatics having no property who are maintained by relatives who have means to do so. Under the canons of construction, the lunacy statutes may possiby be held to justify the detaining and taking charge of such lunatics notwithstanding the prohibition of the common law. This may be the case, and it certainly is the fact that they are so detained; but it is impossible that this vast gapthis huge casus omissus-should be allowed to continue, throwing more than a doubt upon the legality of the detaining, and taking charge under the strictest obedience to the forms of statute, of any insane person who is not either dangerous or found lunatic by inquisition.

\section{NOTE.}

P. 51. A similar question arose even with regard to pauper lunatics on the first operation of the Scotch Lunacy Statute in I858. The Board of Supervisors for the Relief of the Poor, differing from the new Board of Lunacy, as to the definition of the statutory term "lunatic," took the opinion of the following eminent counsel thereupon, namely, John Inglis, James Moncrieff, and George Ross, Esqrs. Their joint opinion ran as follows :-

I. "We are of opinion that the words of the statute require, in the definition of a lunatic, unfitness to be at large as regards either the individual's own personal safety and conduct, or the personal safety and 
property of others. The two elements in each alternative of the definition must be combined. But these may often be unusually developed as to one of the elements only which necessarily implies danger as regards the other. In other words, unless the unfitness as regards conduct also threaten personal danger to the individual himself, or the unfitness as regards the property of others also threaten danger to the persons of others, the definition of the statute will not be satisfied."

2. "We are of opinion that paupers who from weakness or fatuity of mind are unable to manage their own affairs, are not comprebended under the definition of the word. lunatic given by the statute." -Appendix to First Report of Commissioners in Lunacy for Scotland, page II 9 .

The legal difficulty of placing insane paupers, not dangerous and therefore not lunatics, in asylums was songht to be removed by the interpretation clause of the Scotch Lunacy Act of 1862, by which it was declared that a Iunatic was any lunatic idiot or insane person certified to be a Iunatic by two medical men. The remedy, however, has overshot the necessity; for now it is maintained that even a dangerons lunatic is not a lunatic until after he has been certified. 
"Every lunatic asylum should be the property of the State, and be controlled by public officers." Such was one of the maxims in which the late Dr. Conolly epitomised his Suggestions for the better Protection and Care of the Insane, when, after five years of experience as" "Inspecting-Physician of the Lunatic Houses for the County of Warwick," he wrote his first eloquent, humane, and thoughtful work on insanity. Dr. Conolly grounded his maxims of reform upon facts which he adduced and summarised in the following conclusions: "That the present regulations regarding the insane are at once inefficient for the protection of the insane themselves, and dangerous to the public; that it results from them that some are improperly confined, and others improperly at large ; that, whilst the eccentric are endangered, those actually mad are often allowed a dangerous liberty; that the public are dissatisfied, and medical men harassed and perplexed." "Other evils arising out of the present manner of providing for lunatics are, that they are often confided to persons who are unacquainted with bodily and 
mental disorders, and who neglect such treatment as might conduce to recovery; that it is the interest of such persons to keep patients under their care who ought not to be so confined; that, by associating lunatics with lunatics, the general chances of recovery are much diminished."

A considerable reform has taken place in the regulations regarding the insane since the above important opinions were published, but not the less are "the public dissatisfied and medical men harassed and distressed "; for the evils of neglected curative treatment, of interest in unnecessary confinement, and of the chances of recovery diminished by associating lunatics with lunatics, have greatly increased in their dimensions, though they have doubtless diminished in their intensity.

Nothing which Dr. Conolly ever wrote does more credit to his head and his heart than these opinions on a subject that was destined to make his name famous; early opinions, it is true, and published before advancing years and personal interests had made him indulgent to the evils he had denounced, and induced to say, like another great reformer, reclining upon his well-earned laurels, "Rest and be thankful."

Another name illustrious on the roll of benefactors of the race of men must also be cited. It is scarcely possible to discuss any question in lunacy without reference, tacit or expressed, to the actions and opinions of the Earl of Shaftesbury. Before the actions of such a man, while still among us, criticism must be dumb, lest a temperate account may sound like adulation. But his opinions, which must to a great degree be those of his Board, challenge that 
criticism of disputed questions which his liberal mind will freely accept. If he have given a somewhat different estimate of the demerits of proprietary lunatic asylums, in his evidence before the Select Committee of I877, from that which he gave before the Select Committee of 1859 , his lordship's candid and reasonable explanation of the fact must be fully and frankly accepted-namely, that, owing to the constant vigilance of his Board and to the numerous changes which have taken place in the persons who own proprietary asylums, there has been a considerable improvement in the condition of these places during the eighteen years which intervened between his earlier and later evidence; an improvement, however, which his lordship declares would not endure if his Board were to "relax their vigilance ever so little," for if that be done, "the whole thing will speedily go back to its former level."

Lord Shaftesbury takes great credit to the Commissioners for the vigilance with which they have exercised their authority over the proprietary asylums, and for the change which has taken place in their condition; so that the evidence given in I 859 could not be fairly given at the present day. It is natural that the Commissioners should exalt their office, and be content with the excellent work they have done with diligence and faithfulness in the public interest, rejoicing over the improvements they have been able to effect, even if they do so painfully feel that the edifice of these reforms is a house built upon the sand. But would it not be more wise to construct stable foundations than to sustain and adorn a structure which will speedily go back to its former level, unless it be maintained by unrelaxing vigilance? Would it not be 
well, in so vast and varied a task as the supervision of the insane, forgetting those things which are behind, and, reaching forth to those things which are before, to be a little less content with imperfect and precarious achievement? There is a passage in the Commissioners' second Report, published in 1847 , under the title of a Further Report, the consideration of which may lead to the reflection that, in a long journey, under a task of grave responsibility, fitting halting-places for self-congratulation are few and far between. In this paragraph, the Commissioners say: "We are now desirous of satisfying your lordship, as far as we are able, that whatever defects may still be found in lunatic establishments, the amount of improvement that has taken place of late years in the accommodation and comforts provided for the insane has been great and general." Without comment upon the real condition of lunatic establishments when this comforting assurance was conveyed to the Lord Chancellor, it is enough to state that it was made when the Commissioners were unconsciously only commencing the great work before them. Perhaps their estimate of its progress towards completion, as it may be gathered from the evidence of $\mathrm{I} 877$, is equaily premature. Perhaps the Commissioners would have been more wise toward the public and more just to themselves if, before the Select Committee, they had repudiated the unmerited position of apparent defenders of imperfect laws, and if, while they still have with them the great chief to whose opinions no Government can refuse deference, they had shown a comprehensive forethought of the legislative requirements of the insane.

It would, however, be most unjust to the Commis- 
sioners to assume that, because they did not condemn the proprietary asylums before the Parliamentary Committee, they are satisfied with their condition from their own point of view. Their Report published in I 875, pages 39 to 50 , contains an array of "occurrences in these houses deserving of particular notice," which proves that, however great the changes from a worse state may have been, the present condition of all kinds and varieties of proprietary asylums is far from satisfactory to the official mind. Proprietary Asylum No. I, they report, "has been greatly improved by the erection of a larger hall for recreation." In No. 2, "the internal condition has not been amended satisfactorily, too little attention being paid to necessary repairs and alterations." In No. 3, "we have found cause to suggest that an assistant medical officer be appointed." In No. 4, "a good deal has been done, though more remained to be done, to improve the condition of this house as to decorative repair and the renovation of the bedding." In Nos. 4, 5, 6, 7, and 8 , transfers of licence are noted. In No. 9, "we have had to express our dissatisfaction at the frequent changes which have taken place in the post of assistant medical officer, several appointments having been manifestly made of gentlemen possessing but little professional experience. We hope, in our next report, to be able to state that effectual means have been taken to establish a proper system of constant observation of the suicidal and epileptic patients." In Nos. IO, II, I2, changes in the licence are recorded. In No. 13 a gentleman of advanced years committed suicide by hanging; "due vigilance had not, in our opinion, been exercised." In No. I4, "improvements have been made in the buildings." 
In No. I 5, a lady committed suicide under arrangements which the Commissioners designate as "simply delusive, and ought never to be relied upon as safe." In No. I6, "a demented patient, aged 76, in feeble health," was stated by his son to have been "illtreated and severely injured." Appended [to the son's letter] was a certificate of a medical man, testifying to "several wounds, bruises, and bed-sores upon the person of the patient." After " a careful inquiry, we came to the conclusion that there was no evidence to support a charge of intentional ill-treatment, or even of gross carelessness ; but we were far from exonerating those concerned from all blame." In Nos. I7, I8, and I9, changes in the licence are recorded. In No. 20, "we were unable again to report favourably; most of the rooms require renovation as to paint, paper, and furniture." In No. 2 I, "the proprietor has not applied for the renewal of his licence." In No. 22, it was found that Dr. - had "very wrongly neglected to make proper entries in the medical visitation-book as to seclusion." In No. 23, change in licence: In No. 24, the male division and also the state of the bedrooms, "unfavourably noticed last year, was found to be satisfactory." A death by suicide is reported, "the arrangements made for the supervision of this patient were culpably lax." In No. 25 , a death by suicide occurred, but the coroner's jury exonerated all persons from blame. In No. 26 , "more frequent and efficient visitation of the wards by night" is recommended. In No. 27, "we have found cause to complain of the deficiency of attendants; the arrangements being unsuitable for the reception of suicidal, violent, and dangerous cases, it would seem proper to confine this licence to the 
reception of patients of the quiet and harmless class!" In No. 28, "the dining-rooms and other parts of the house are unsatisfactory;" there is "a want of proper attendants." In No. 27 the licence has been dropped. In No. 29, "the conduct of this house had for some time been unsatisfactory to us. An inquest was held here on the housekeeper of the proprietor; she died of hæmorrhage after childbirth, in circumstances discreditable to the proprietor, etc. ; licence was not renewed." In Nos. 30, 3I, and 32 , changes in licence are reported. In No. 33, "we urged that the practice of bathing two patients in the same water ought to be discontinued." In No. 34, a suicide by hanging is reported; the coroner's jury attached no blame to any person. In No. 35 (Midland Idiot Asylum), "from deficient water-supply, want of furniture, rough state of grounds, we found it impossible to report as to fitness for occupation;" "this is essentially a charitable institution." In No. 36 , "the suicide of a gentleman gave rise to a prosecution, at our instance, of the attendant on whom the chief blame appeared to rest." In No. 37, "the condition has for some time past been reported as extremely unsatisfactory. Much renovation is required, but the proprietor is reluctant to carry out any of the improvements necessary to place this house in a fit state for the reception of patients."

When it is considered how large a proportion of these "occurrences in these houses deserving of particular notice" have reference to the renovation and decoration of the buildings, to "paint, paper, and furniture," it must be admitted that the condition of these houses as buildings does not, on the whole, 
appear, from this recent report of the Commissioners, to be satisfactory and reassuring. But if so much "more is expended upon them by the proprietors" as receptacles and residences, while these comments have to be made, what must have been their condition beforetime? "Very bad indeed;" as Lord Shaftesbury admits. With the exception of a comment on one asylum, as to several appointments of inexperienced medical officers, there is not one remark, throughout the above long list, of a medical or quasi-medical character; and all reference to the objections above quoted from Dr. Conolly, to the system of proprietary asylums, are conspicuous by their absence.

If the Commissioners had embarked upon the task of investigating the qualifications of the proprietors with regard to their acquaintance with bodily and mental disorders; to their employment or neglect of such treatment as might conduce to recovery; to their detention of lunatics who ought not to be confined in asylums; and to the diminution of the chances of recovery by the association of lunatics with lunatics, what might not then have been the list of "occurrences deserving of particular notice" within the course of the official year? There is no comparison between the importance of those things which ought to have been done and the things stated to have been left undone. (See note, p. 74.)

In the early years of the commission, wide and scientific views of medical hygiene and medical treatment were to be found in the Reports, worthy of such able and eminent physicians as Dr. Turner and Dr. Prichard; but of late the medical spirit has been drowned in the flood of official duty, and it is in vain 
now that we look for any signs of the consideration of lunacy questions from a medical point of view. It is to be hoped that some day the commission will return to its allegiance to medical science, without which it can neither lay the sure foundation nor crown the edifice of its reforms. We shall then have accounts of a very different character, not upon the "paint, paper, and furniture" of receptacles for the insane, but upon the curative treatment of patients in hospitals for the insane, and of convalescents and outpatients, and of mental disease dealt with generally with the intent and purpose of curing or abating it. But, whatever may have been the changes of fact for the better in the state of proprietary asylums, as distinguished from that of their inmates, from that condition when, after the commission had been at work for more than a quarter of a century, it was "very bad indeed," the principles which Lord Shaftesbury denounced remain unchanged, and unchanged they must remain so long as human nature retains its imperfections. The vigilance of the Commissioners cannot alter the bias of nature, and it was upon arguments grounded upon this persistent influence his lordship denounced the detention of insane persons in private establishments for the profit of the proprietors. A republication of the whole of his evidence would be too long for these pages; but it is impossible to conceive anything more weighty and convincing than his argument against "that vicious principle of profit" which he denounces."Half of the provisions [in our Lunacy Acts]" he says, "are made to enable the Commissioners to fight against the selfishness of persons who open these asylums. When a certain diet, for instance, 
is prescribed, what security is there that that diet is given? We know that a certain course of medicine is necessary, but what security is there that that course of medicine is undergone by the patient? And it is, therefore, in their power to retard the cure of their patients indefinitely, and the temptation is inordinately great, and it is more than human nature can ordinarily stand." [Question 504.]

"If a patient is manifestly cured, then the discharge must take place; but what I say is this, that it is in the power of the medical superintendents [of private asylums] not to hasten the cure, but to retard the cure; and there are many remedies that they will not give, and there are things that may be done that they will not do." [Question 505.] "With regard to the attendants in those houses, the principle of profit keeps down the wages, and the attendants in them have not the highest qualifications." [Question 506.]

Lord Shaftesbury takes care to include under his condemnation the keeping of insane patients for profit either as the inmates of licensed houses or as single patients; and it is clearly the unprofessional remuneration for boarding a patient at which he strikes, not at fees or payments for professional services. It is at this business of keeping lunatics, and not at the professional relation of medical men with the insane and its legitimate remuneration, at which he directs his severe and weighty censure.

Indeed, on this point he states emphatically, "I have been told that I entertained most undue suspicions of that great [medical] profession. I have no suspicion of them as medical men ; but my suspicions are of the medical men only when they are proprietors 
of lunatic asylums into which patients are taken for profit. I am perfectly ready to admit that there are some of the best men in that department of the profession that one can meet with. I am perfectly ready to admit that there are a great many medical proprietors who now, under the operation of this Act, are governed in a great measure by their own good feelings, and they have brought their houses to a very great degree of excellence ; but even the very best of them must be under this influence of the profit to be made out of the patients." [Question 494.]

On reading the above extracts of evidence, not the strongest in expression, given in 1859 , one cannot be surprised that his lordship's sense of the great and various improvements he specified, which under the advice of his Board have been made in the condition of proprietary asylums, should have led him to declare in I 877 that, "so far as the evidence I gave in 1859 is concerned, I should not give it now." His view of the principle of profit, however, seems to have undergone but little modification, although it is now recognized more as the feeling of the public.

"There exists a principle and desire of profit ; and, so long as there are licensed asylums on any great scale, the public will always conceive that the principle of profit will of necessity predominate." [Question I 1,357, I 877 .]

Mr. Dillwyn: "Your lordship's opinion is that it greatly depends upon, administrative action to correct or counteract the-vicious principle [of profit] which is ever striving to reassert itself?" Lord Shaftesbury : "I think it does, unless you can introduce such a system as to make the hospital system universal, then to some extent the principle of profit is eliminated; 
and I should be very glad to see it, and I only wish to retain a certain number of [licensed] houses which, as I said before, will then be of the very highest order." [Question I I, 509.]

But, why is the principle of profit, the great motive power of the world's work, so mischievous in its application to the care and control of the insane? Why should not a lunatic be kept for profit as freely as a child at a boarding-school, or a sane adult at a boarding-house? Lord Shaftesbury sees that there is a wide though general distinction to be drawn.

Mr. Dillwyn: "You still condemn the principle of it as strongly as ever?"- "Yes; as applicable to this particular form, this subject-matter of lunacy. I know many persons will say the principle of profit enters into a great number of pursuits and professions; no doubt it does, but there is something very peculiar in the condition of lunacy, something specially demanding more than ordinary care." [Question $I I, 506$.

This "something," which led John Stuart Mill to declare that an insane person should everywhere be regarded as a proper object of the care of the State, is his dependence, his helplessness, and his incapacity to give evidence regarding himself. A child also is dependent, but the love of parents for their children is so general that it forms one of the broadest foundations of social order. Yet, the control of parents is not unlimited, as the Factory and Education Acts prove. Moreover, children are not imprisoned in schools for unlimited periods, neither are they incapable of giving testimony which is accepted as reliable regarding themselves. Towards lunatics, on the other hand, the affection of relatives 
is too often in abeyance, and the patients are "altogether abandoned" to the care of others. Lord Shaftesbury gave very strong evidence on this point in 1858 , urging upon the Committee that the thirtysixth clause of the Act of 1828 , which had somehow dropped out of the subsequent Act, should be reenacted, by which clause the person under whose authority a private patient had been confined was compelled to visit the patient "once at least in every six months during his confinement." [Question 226.] See note, p. 74 .

The Lord Chancellor exacts such visitation from Committees of the Person every three months; but there is no law or regulation respecting the individual visitation of patients in asylums who are not under the Lord Chancellor's care. If they are not "altogether abandoned," "the friends very seldom do come," and the only visitation to which they have a legal right is that official inspection when the whole regiment is reviewed and each rank and file looked at in his turn. Even the correspondence of patients in private asylums is restricted. "I dare say that very often they are prevented from writing to their friends in a way that is really cruel and unjust." [Question 224, 1859.] If the friends were to visit, as many of them do, there is no certainty in such asylums that they would be able to obtain any accurate information of the treatment of the patient, since even the Commissioners declare their inability to do so. "We have the power in the licensed houses to fix the dietary, and we often have done so ; but whether they observe it is a difficult thing to say. And there is an evil again, as a profit is to be made out of tine whole matter; when our backs are turned, how do 
we know what they will do?" (Question 402.) When the friends do visit, which is "very seldom," and "very seldom that they give themselves any trouble about the condition of the patient, the proprietor would take care to trim up the room, put the patient on a clean shirt, and make his relatives believe that he was fairly kept." [Question 9I3.] All these things thus stated by Lord Shaftesbury to the Select Committee of 1859 may, no doubt, be much better now than they were at that time, as they might have been much better, according to the Commissioners, at that date than they were in 1847, when the second self-satisfied Report of the Commissioners to the Lord Chancellor was made; yet there is no assurance that the improvement is permanent, but, according to Lord Shaftesbury, quite the contrary. "You think, if the vigilance of the Commissioners is relaxed ever so little, things would relapse into their old form ?" "I think so [said his lordship]; and I look not only to the vigilance of the Commissioners, but to the vigilance of the public. I want everybody to be alive to the matter." [Question II, 507, I877.]

It ought to be needless to point out that Lord Shaftesbury's evidence in 1877 was not inconsistent with that which he gave in 1859 . Indeed, he said expressly in 1877: "I entertain all the opinions I then [in I 859] entertained in respect both of licensed houses and hospitals; but I should be very sorry to see an enactment that prohibited licensed houses altogether." [Question II,352.] There are few, if any, wide interests respecting which a great variation in the detail of evidence would not be rendered needful by the lapse of eighteen years. But the principle which underlies Lord Shaftesbury's testimony of both dates remains, 
and the conclusion drawn is identical. This further cause of variation ought not to be overlooked, that the Select Committee of 1877 was appointed to inquire into the lunacy laws so far as regards the security afforded by them against violations of personal liberty; while the Select Committee of I 859 was appointed to inquire into the operation of the lunacy laws generally. The questions being different, the answers might be expected to vary. In this later inquiry, the reference might be considered to show that suspicion unjust to the work of Lord Shaftesbury and his colleagues was entertained, and to forebode hostile changes in the law. In the earlier inquiry, a considerable change in the law was anticipated as needful, and it was his lordship's duty to indicate the principles on which these changes ought to be made. That he did so with uncommon courage, knowledge, and perspicuity, is known to all who have studied the Blue Book which his evidence mainly has redeemed from oblivion. In many respects, his opinions therein expressed were adopted in drafting the new statutes of 1862 ; although as respects proprietary asylums, on which subject he spoke more strongly than on any other subject, his opinions were not adopted by the legislature. His earnest recommendation that hospitals for the well-to-do insane should be established at the public cost was not adopted; nor were such obviously just, needful, and easy regulations as the one above referred to respecting the visitation of lunatics by their friends, nor that one respecting the renewal of certificates after a patient had been detained in an asylum for three months. [Question 20I.] Lord Shaftesbury's opinions in 1859 were perhaps in 
advance of the time. There might have been what he calls a "temporary exhibition of feeling on the part of the public," but the wind of public opinion had not filled the sails of legislative resolve; now there are signs that it will blow steadily, though it may not be a trade wind. To a great extent Lord Shaftesbury has himself been the Æolus, for there can be no doubt that his opinions, cloud-compelling or dispersing, have shaped the thought of the present day : thought which is becoming anxious in its agreement with his earnest desire-" I look to the vigilance of the public; I want everybody to be alive to the matter." But good law, well administered, leaves the public mind at rest; and it is the defect of law in unsettled countries which compels men to form vigilance committees.

\section{NOTES.}

P. 66. Mr. Lutwidge, in his evidence before the Select Committee in I 59 , franlily declared that the Commissioners were not in the habit of interfering in the course of medical treatment which insane patients in asylums undergo. It is no part of their duty, and they take no formal action about it, although with reference to treatment generally, such as diet, restraint, lodging, and so forth, they do talie action. Also they offer advice as to such general treatment, but not as to physic. [Questions 2106 et seq.]

P. 7I. It may be well to support the above opinion, even of so high and pure an authority as Lord Shaftesbury, upon the leading principle which ought to be the foundation of all proposals for change in the detention of the insane.

On the 6th of June, I 845 , Lord Shaftesbury, then Lord Ashley, said, in the House of Commons, "Our present business is to affirm that poor lunatics ought to be maintained at the public charge. I entertain, myself, a very decided opinion that none of any class should be received 
for profit; but all, I hope, will agree that paupers at any rate should not be the objects of financial speculation." At the present time, however, I, I Io pauper lunatics are still confined in proprietary asylums as objects of financial speculation.

In $1857 \mathrm{Mr}$. Gaskell and Mr. Campbell, two of the English Commissioners in Lunacy, acting in conjunction with Lord Monteith and Sir James Coxe as Her Majesty's Commissioners appointed to inquire into the state of lunatic asylums in Scotland, reported to Her Majesty as follows:- "Where economy on the one hand and profit on the other are in undisguised operation as the main motives of conduct, there can be no doubt that pauper lunatics in licensed houses are exposed to the danger of privation and neglect," (p. 125). In $1858 \mathrm{Mr}$. Wilkes and Mr. Lutwidge, other two of the Commissiones in Lunacy, acting as Her Majesty's Commissioners of Inquiry into the state of lunatic asylums in Ireland, reported to Her Majesty, "It cannot but be observable in a private asylum how limitedly the patients' wants seem to be discerned when they are not absolute necessities; how little the agreeable is studied where it is not the essential; and how strong the tendency must be to restraint, since the opposite system, if carried out, will necessarily require an increased number of attendants, at increased cost, and therefore diminished profit, to the proprietor. In fact, without seeking to reproach any, we fear it must be confessed by all, that where profit is the aim, it will too generally be pursued to the prejudice of those from whom it is derived. With these views we would desire to see institutions established for the reception of that class of lunatics whose social position places them above receiving support from public funds, or seeking to be maintained by private charity, and yet whose humble means will not admit of their being placed, as single patients, where funds as well as friends will not be wanting to ensure their comfort," (p. 32).

Mr. IV. G. Campbell, the Commissioner, again expressed his opinion in evidence before the Select Committee in I860, "I am fully aware of the defective and very unadvisable arrangement of having a licensed house for the detention of insane persons, because the treatment of the insane involves the detention of the person. The fact of a person receiving another for profit, and having the power to de rive him of his liberty, is, I think, a most objectionable arrangement."

The Commissioners have expressed doubts and foretold difficulties as to the best method of providing a remedy for this most objectionable arrangement, but they do not appear to have deviated from the great principle which, in the above term:, they have so strongly emphasized. 


\section{VII.}

PROPRIETARY ASYLUMS.

IN the Appendix to the Minutes of Evidence given before the Select Committee on the Lunacy Laws, 1877 , will be found a table showing the proportion per cent. of private patients under the Lord Chancellor and under the Commissioners in Lunacy in England and Wales who were respectively in asylums or in private dwellings in the year 1875 , from which it appears that of the Lord Chancellor's lunatics $65^{\circ} 4$ per cent. were in asylums and 34.6 in home-treatment in private dwellings. Of the English Commissioners' lunatics, 94. I per cent. were in asylums and 5.9 per cent. in home-treatment. The remarkable difference existing between the proportion of private patients under different authorities who are retained in asylums or under home-treatment in private dwellings cannot be accounted for by the greater wealth of the Lord Chancellor's lunatics. Many of the Chancery patients are persons of slender means; indeed, Dr. Lockhart Robertson, in reply to the inquiry whether the payment in asylums was not larger in the case of Chancery lunatics, said: "I do not know that it is larger. The 
Chancery lunatics are not a rich class. No; I should think the payment was about the average." [Question 879.] But there can be no doubt that, owing to the great cost of proceedings in the Lord Chancellor's offices, inquisitions are frequently delayed so long as hopes of recovery appear to exist ; and that, consequently, the average character of the malady in Chancery lunatics is more chronic and incurable than in certificated lunatics.

But neither the property nor the chronicity of the Lord Chancellor's patients can account for the wide difference existing being the $34^{\circ} 6$ per cent. of those who are in home-treatment, compared with the 5.9 of the Commissioners' patients who are in home-treatment. The real cause of the difference is referable to the different opinions which appear to be entertained in the two lunacy offices as to the care and treatment of the insane. The opinion of the Commissioners, expressed in their reports and their evidence passim, and even more emphatically by the above figures, is, that the care and treatment of the insane in asylums is to be preferred to their care and treatment at home or in private dwellings. The chiefs of the lunacy department of the royal prerogative-namely, the Lord Chancellor and the Lords Justices-influenced partly by the traditions and practice of their office and partly by the opinions of their subordinate officers, take a different view of the question, which is forcibly expressed in the fact that the proportion of their lunatics under home-treatment is six times as great as that of the Commissioners' lunatics. The Lord Chancellor and the Lords Justices have given no evidence of their opinion beyond this fact, for which they are ultimately responsible. The opinion, however, 
of the secondary officials of the department may be gathered from a memorandum submitted to the Lord Chancellor, and to be found in the second Appendix to the Report of the Select Committee. This memorandum from the Board of Visitors to the Lord Chancellor, after referring to a previous memorandum having reference to the condition and treatment of patients in a particular asylum, assured his lordship that "thirteen years' working of this Act has led the visitors to the conclusion that the one yearly visit to the asylum patients is insufficient for the due protection of these patients; while, on the other hand, the quarterly visits to the patients in private dwellings is as much in excess of their requirements." It is further stated that "the Chancery lunatics in private dwellings are quiet and harmless cases of dementia and imbecility of many years' standing, and whose habits and mode of life change little year by year; and they and their guardians are, from long intercourse, equally well linown to the visitors. On the other hand, the Chancery patients in asylums are more recent cases, and hence more likely to recover than those in private dwellings, while in the inferior private asylums they are more liable to improper treatment. It is obviously a greater hardship that a patient in an asylum, if recovered or if improperly treated, should remain under such conditions for any length of time from want of visitation, than if such patient were in a private dwelling. As a matter of fact, these patients frequently complain to us that they are so rarely visited, and are thus deprived of opportunities of obtaining redress for their grievances. We are thus led respectfully to subrnit to the Lord Chancellor this suggestion: that the visitation of all the Chancery 
lunatics be equalized," etc. Signed, "W. N. Nicholson, Chairman of the Board."

In this remarkable memorandum, the visitors appear to commit themselves definitely to the following opinions : I. The "quiet and safe" Chancery patients are, as a rule, taken care of in private dwellings, where their treatment is so satisfactory to the visitors that an official visit once a quarter is considered to be in excess of the requirements for their due protection, notwithstanding that the Chancery single patients are exempted from the fortnightly visit and report of a medical attendant, to which single patients under certificates are subjected. 2. Lunatics are more liable to improper treatment in the inferior private asylums than they are in private dwellings. 3. The recovery of a Chancery lunatic, detained in an asylum, is liable to be overlooked for a considerable time until the annual examination of the visitor be made. 4. The sufferings of a person in an asylum, either from illtreatment or from detention after recovery, are obviously greater than those which would be endured under similar circumstances in a private dwelling. 5. Where there is a deficiency of visitation, the right course to adopt is to increase it, and not to transfer the duty to some other body.

It would be interesting and important to know in what the improper treatment of Chancery patients in asylums, referred to by the visitors, mainly consists. The reports of the visitors are secret under the statute; but the substance of them is conveyed to the Committees whenever recommendation of improved treatment is made in them. The visitors do not exercise any control over the conduct and management of asylums; and, therefore, it may be supposed that 
their reports do not frequently refer to the architectural and upholstery business of asylums. They have not even to consider and report upon the condition of their patients collectively in any asylum, but upon the state of mind, condition of body, the treatment, comfort and enjoyment of his means, of every individual patient, and to declare in each case that nothing more can be done for the well-being of each patient than is done; or, in case of inability to make such a declaration, they are compelled to report to the Board the grounds of their dissatisfaction. As regards the welfare of the individual lunatic, and especially as regards his protection from needless confinement, it may well be that the single visit of the Lord Chancellor's visitor may be of more value than the multipled visitations of officials who mainly regard the lunatics in a mass, who visit the patients rather than each patient, and the asylums rather than the patients. It is no injustice to the Commissioners to say that their onerous and varied duties prevent them from giving that minute attention to the mental condition and the treatment of each patient under their supervision, which would be needful if they had to make a report upon the mental and bodily state and the requirements of each patient. Whenever cases of doubt and difficulty are brought under their notice, they may spare no pains. They do frequently grant private interviews to patients who request them, and who are fit subjects for such interviews; and they also grant interviews not private with almost any patients who make the demand, and who, as a rule, are the most captious and querulous and troublesome inmates of every asylum. But under this plan, a depressed, a reserved, or a convalescing patient, who has not 
regained the strength and boldness of health, is extremely likely to be overlooked, although he is exactly the patient whose removal from the unsanitary surroundings of an asylum is most needful for his perfect recovery. There is a tide in the affairs of madness which, seized at flood, leads on to fortune, the precious fortune of health; neglected, all the life is spent in shoals and shallows. This is no poetical hyperbole; for, in all sobriety of statement, it may be affirmed that, in most cases of insanity, there is a time when an entire change of surroundings effects the happiest change in the mental state-sometimes resulting in perfect recovery, oftentimes resulting in permanent improvement. If this state be overlooked, it passes into one or other of the chronic forms of insanity, and the last state of that man is worse than the first. It might be that the proprietor of a private asylum would say to the visiting Commissioners: "Here are some patients who have not recovered, but they are so much improved that they would be likely to recover under domestic care, which their ample means can liberally provide. They are reserved and retiring, but, if you will examine them, I think you will advise their removal." It might be that the proprietor of a private asylum would thus aid the Commissioners in the discharge of their most important duties; and in those instances where the proprietor of an asylum is more a physician than a man of business, such cases might be and are so dealt with, without the aid of the Commissioners. But, in default of such disinterested action, the transitory nisus of returning sanity is exhausted, and these unhappy people remain until they die "asylummade lunatics." 
The detention in asylums of patients who have absolutely recovered is not a common occurrence. For many reasons, a sane person is not a welcome inmate in a proprietary asylum. He is almost certain to be a keen and hostile observer- " a chiel amang ye takin' notes"- or at least a troublesome and persistent claimant for his liberty. Recovered patients are much more frequently detained for a while in county asylums, and with good reason; for the prolonged detention there is almost sure to be for the patient's own benefit, or for the public interest and safety; and the superintendent, feeling himself placed above the suspicion of corrupt motives, is not afraid to exercise a large discretion. But recovered patients are sometimes met with in proprictary asylums, if the examination of the patients be made in such a manner that the state of mind of each patient be ascertained. The Author, in his evidence before the Select Committee, stated that, while he was the Lord Chancellor's visitor, he had met with five cases of persons who were detained in asylums under the imputation of insanity a considerable time after they had recovered, although, with one exception, they were not originally put into the asylums while sane. [Questions 1,771, 1,890, 1,891.] If five such cases could be found by the Author from among the five-hundred Chancery patients, the average number which he visited in asylums, the total number of patients detained under the imputation of insanity when they were recovered among the four thousand six hundred patients in proprietary asylums might be forty-six, which would not be an altogether insignificant matter, although it is fully admitted that this evil is but a small one compared 
with the magnitude of that other evil of detaining in asylums unsuitable patients who have not recovered. This is the great evil at which public opinion should strike, notwithstanding the shield of authority which has been thrown over it. It is upon this wrong that the proprietary asylums thrive, and it is this wrong which the Select Committee ought to have searched, no: like a pocket of hops by a square inch of sample, but by an examination of the bulk-by a thorough investigation, which it never attempted. The reference to the Committce was to inquire into the operation of the lunacy laws so far as regards the security afforded by it against violations of personal liberty. What greater violation of personal liberty can be conceived than to imprison a man in a lunatic asylum kept for profit by a private proprietor, unless such imprisonment is lawful and necessary ; lawful not only according to doubtful interpretations of the forms of statutes which omit to state the law, but according to the great common law of the land; necessary not for the convenience of relatives, but for the safety of the public and the protection of the patient?

It cannot be too much insisted upon that the allegation against the proprietors of private asylums is not that of mala fides in taking, detaining, and confining persons of sound mind as lunatics; but that they detain persons of unsound mind, whose confinement within their walls is unnecessary and unlawful. Very curiously, the Select Committee do not appear to have had their attention directed to the common law, since they have assumed throughout the inquiry that the whole of the lunacy law was contained in the ragged tesscllation of statutes which they superficially examined. The law of confinement, 
therefore, is not to be found in the Blue Book. The necessity of confinement even is but sparingly alluded to; the assumption throughout the inquiry seeming to be that patients who had not perfectly recovered were rightly detained; and hence it was, as the Committee reported, that "much of the evidence amounted to little more than complaints of hesitation among superintendents and relatives to believe in the perfect recovery of patients."

With one remarkable exception, there is nowhere to be found in this Blue Book on violation of liberty any attempt to account for those abundant instances of it in which patients who are not dangerous are incarcerated in asylums. The exception occurs in the evidence of Dr. Mitchell, the Scotch Commissioner [Questions 9,927 to 9,936]; and applying for the most part to the detention of patients in Scotch chartered asylums under the sheriffs' order, which is so much less open to suspicion than their detention in private establishments, that it will lose nothing in the weight of its candid admissions by comparison with the English practice. Dr. Mitchell observes: "I, scarcely require to say that a large number of patients are sent to asylums neither in the hope of cure nor to promote their happiness and well-being ; they are sent to promote the comfort of other people, or as a matter of convenience. It is not intended to injure patients who are thus sent; on the contrary, care may be, and generally is, taken to secure for them every reasonable comfort and advantage. I do not allude to this because I think the motive for such removals necessarily bad; on the contrary, I think it often good; it springs occasionally from nothing more than a sense of justice to the healthy, whose prosperity and 
comfort may be destroyed by the presence among them of an insane relative. . . The determination of whether an insane relative ought or ought not to be sent to an asylum often depends upon considerations apart from the mere existence of insanity, apart even from its character. These considerations of convenience, however, may be carried so far as to be unjust to patients whose insanity is but slightly marked, and who feel the restraints of an asylum very irksome. Ordinary mental enfeeblement is now more frequently certified to be lunacy than formerly. There is a change in this subject, both on the part of the community and of medical men."

"I frequently saw patients, during one visit to a county, at home and provided for under private care ; a year elapsed, and on going back I found that those patients had been removed to asylums. The reasons I was interested in knowing. There might be a change in the patient's condition, but tlat was seldom the reason. It much more frequently happened, the cases being chronic cases, that the removal was due to some change which had occurred in the domestic arrangements, some one's death, or perhaps the loss of money, or perhaps even the acquisition of money. The reasons were extremely various, but they were not generally reasons which related to the patient's own condition or his insanity. They were often, I thought, good and sufficient reasons. I frequently thought that, on the whole, it was an advantage to the patient that he had been removed. At other times, I thought that, with a little forbearance, and with a little attempt to adapt the new circumstances to the patient's case, the old arrangements might have been undisturbed." 
Dr. Mitchell having stated his opinion that the legitimate grounds for sending a patient to an asylum were either that he was dangerous, or that he was likely to be cured by being sent there, or that he needed such special care as cannot be given out of an asylum, replied to the Chairman's remark, "That opens the door to a very wide question, as to whether persons who might be taken care of elsewhere ought to be sent to asylums?"- "Yes, I feel that; and I think that the fact that this wide field [extended view of insanity] prevails is a reason for greater care in supervising the admissions to asylums so as to prevent the undue detention of persons whose happiness would be greater out of asylums."

Chairman: "The degree of inconvenience which might be experienced by friends owing to the presence of a lunatic would be a question which would admit of most varied interpretation?"-_Yes; I think so."

Sir Trevor Lawrence: "Is it not in your opinion the case that the vast majority of Iunat:cs would be, or, at all events, would consider themselves, happier outside the asylum than inside?"--Dr. Mitchell: "I think there are very few people who find asylum life pleasant."

In vain may the evidence of the English Commissioners and their thrty-three annual reports be searched for information and opinions of this character, but the action of the Lord Chancellor and of the Lords Justices does indicate their perception of the rights of the insane in contrast to the convenience of their relatives and their appreciation of the value of domestic in comparison with asylum treatment; and the evidence of the Lord Chancellor's 
medical visitors fully supports and justifies the action of their chiefs.

Dr. Robertson says: "One-third of the certified lunatics might be spread over the country, but the other two-thirds require asylum treatment, and I thought for those public asylums ought to be provided." [Question I, I I 9.]

Dr. Crichton Browne says: "I hold two-thirds to be about the proper proportion of dangerous cases and lunatics requiring asylum treatment. I should think nearly two-thirds do require asylum treatment." [Question I, 305.]

It has already been shown that, as regards Chancery lunatics, a somewhat larger proportion than a third is already spread over the country, and the remarks of Dr. Robertson are obviously intended to apply only to certified lunatics in proprietary asylums and hospitals for the insane who are not Chancery lunatics. The residue of private certified lunatics who would be left in private asylums after pauper and Chancery lunatics and that one-third of cases who are asserted to be improperly detained being deducted, the diffculty of providing for the residue would not be a formidable one; and that it ought to be so reduced can scarcely admit of doubt. The detention of pauper lunatics in private asylums is an admitted abuse solely due to default of the authorities. The detention of Chancery lunatics in private asylums and hospitals would be terminated by the establishment of the special institutions which have been so strongly recommended by the Lord Chancellor's visitors; and the discharge into domestic care and control of that proportion of asylum inmates which the highest authorities declare unsuitable for 
asylum treatment is a measure of justice and humanity which cannot be long delayed. When this emancipation has taken place, the care and treatment of the remaining patients could be provided for in various ways, the consideration of which must be considered in another chapter. 


\section{VIII.}

"UNDER WHICH KING, BEZONIAN ?"

THERE are two rival projects before the public for the transferrence of asylums for the rich from the hands of private proprietors to those of salaried officials. The first, which may be called the competing project, has been most ably advocated by the noble Chairman of the Board of Commissioners in Lunacy, and consists in the establishment at the public expense of hospitals for the insane, the competition of which, it is assumed, would abolish the bad proprietary asylums and improve the better ones, so that only private asylums of admitted excellence would remain. The second, which may be called the purchasing project, is the intention of a Bill now before Parliament, introduced by Mr. Dillwyn, Sir George Balfour, and Mr. Herschell, Q.C., by which it is proposed to enact that justices of the peace may purchase proprietary asylums in their several districts, with moneys raised upon the county or borough rates. Strong arguments may be employed for the principle of each of these projects. For the latter, it may be said that it would be the more 
simple and speedy; that, if the large sum of money requisite for its completion were easily available, it would at once cut the knot of a perplexing social difficulty, and that all persons claiming vested rights would obtain due compensation, and that, if the purchase were made compulsory, as it would need to be, the reform would cover the whole ground of the abuse, and the rescue of the insane from private proprietors be complete. For Lord Shaftesbury's less ambitious project, it may be argued that it would be far less costly to the public; that, being less hasty in its operation, it would be less liable to deviate from prudent and wise methods, and that it would allow any portions of the proprietary system viable through exceptional excellence to survive. These arguments are certainly not so striking as those in favour of the rival project; but, on the other hand, the objections and difficulties will, on examination, appear to be far less insurmountable.

The first and greatest objection to the purchasing project is that, with a certain number of exceptions, proprietary asylums are not worth purchase. There are scarcely half a dozen proprietary asylums which could, by any expenditure of skill and money, be converted into moderately good hospitals for the insane. The remainder of them are quite incapable of such conversion from various causes. Most of them are altogether too small for such conversion, and are placed on sites far too narrow and inconvenient. Some of the largest of them are in the midst of towns and cities. Not a few of them consist of ancient buildings, inconvenient to use, expensive to repair, and utterly inadequate to supply those conditions of comfort within doors, and of free movement 
out of doors, which the customers of the public would undoubtedly exact, and which the public would feel bound to supply to the well-to-do inmates of its own institutions. Consider what it is thought right to give to a pauper patient in a good county asylum in the way of house-room, fittings, and grounds, with that which another patient receives for three or four times as much payment in one of the shabbier private asylums, and the idea of converting proprietary into public asylums will appcar impracticable. If some benevolent Peabody were to buy them up-the proprietary asylums-and make a present of them to the nation, the only possible thing which the nation could do with them would be to sell them again for what the sites would fetch, and expend the proceeds as far as they would go in the erection of such buildings as the public could feel its conscience justified in using for the detention against their will of innocent persons accustomed to the pleasures and luxuries of life. In only a small number of instances have proprictary asylums been constructed for their purpose, and these instances have, for the most part, been conspicuous failures. When it is considered that the object of the architect appears to have been the erection of a pretentious building, and then to arrange it in such manner that it would be most profitable to its possessor in the letting of separate or associated apartments, it may easily be seen that such a construction would not be a good investment for the public as a hospital for the insane. But with these few exceptions, asylums have not been built for their purpose, but consist of old mansions, or of adventure schools which have not survived the development of public school competition. Some of them have been converted into 
really good buildings for private treatment, more of them are moderately good, but the great majority are hopelessly inconvenient in construction, gloomy in occupation, and costly to keep in repair. It is not needful to say what ought to be done to any authority who should authorize the purchase of buildings of the latter class with public money for conversion into hospitals. Even the sites would be most undesirable for purchase. Most of them are far too small, and many of them are in the midst of torwns and cities, and worth up to $£ 2,000$ an acre for building purposes; a lock up of capital which may well answer the purpose of a private asylum proprietor, but which would be quite unjustifiable on the part of the public, even if there were no objection to the use of a minute oasis in a desert of bricks and mortar for the confinement of innocent people at this time of day, when convalescent hospitals for the poor, and public schools for the needy, are deported into the glorious lifegiving freedom of the country. Proprietary asylums, considered as buildings, rub along as private speculations, doing more or less good under more or less difficulties; but the acquisition of them as a whole for the purpose of conversion into public hospitals would be as wise as if the Government had bought up old merchant-ships for conversion into oceangoing steamers. Modern machinery might have been thrust into them, but would never have fitted into them, and they would have been spoiled for the old work and useless for the new. A part from the purchase of the buildings, fittings, plant, furniture, and grounds, the purchase of the goodwill of these proprietary asylums must be considered; and the first reflection which suggests itself is, that to purchase 
with public money the goodwill of a good institution may not be needful, while to purchase the goodwill of bad institutions would be absurd. Some compensation may be right and expedient for abolishing even a bad institution, but to call a payment of this kind the purchase of a goodwill is a contradiction in terms.

Proprietary asylums differ so widely from each other, that no information can be gained by considering this part of the question in the abstract, and it would be inconvenient to study it in the particular. But the whole class of such asylums may be divided into sub-classes, of which kinds may be given, not representing any particular institution, but representing a group; and in this manner the question may, perhaps, be considered with the probability of coming to a right conclusion. First, there are those asylums which are instruments in the hands of true physicians for the cure of mental disease. Outside members of the profession have free access to patients in asylums of this kind, and often advise in their treatment. There is a free and most wholesome readiness of exchange of patients between the asylum and home life, into which the care of the asylum physician follows them. The patients, therefore, are very far from feeling that they will remain in the asylum "until they die;" nor is their liberty restrained, while they remain, more than is absolutely necessary for their safety. After having been discharged, they are frequently not unwilling to return. Consequently, the place has very little of the air of detention about it, and the inmates are not depressed but free spoken, in comparison with the sullen people one meets with in othęr asylums. They are patients 
less than captives. The greatest distinction ought to be drawn between the true asylum physician and the mere asylum proprietor. The worth of the goodwill of such a place is in the heart and brains of its possessor; and to purchase the asylum under the idea that its real value would be acquired, would be as futile as to buy Joachim's fiddle in the expectation of getting his music. Such an asylum must be and ought to be a survival under any change in the law. Then there are asylums of another kind, which belong to liberal-minded and sensible persons, who are satisfied with the responsibilities of ownership and content with a good return from capital invested or property bequeathed, and depute the best agents to be obtained by careful selection and handsome salaries to discharge the duties of management. The medical superintendents, with full powers, do the best they can for the welfare of their patients in every respect. The result is that such asylums obtain repute, and are generally furnished with their complement of inmates. The sale of such asylums to the State would be a perfectly honest and feasible transaction, but it might only be desirable to expend public money in such a manner in order to prevent those lapses which arise upon changes in the ownership of such property, Under the continuance of good management, such asylums might survive competition. Another kind of asylums generally represents the unfavourable aspect of the business element, although it is not alleged that any one asylum presents all the features of the class. In asylums of this kind, every art is used to attract patients, and every device employed to keep them. There is often a great deal of show and tinsel about these establishments, and the proprietors exhibit to 
visitors the pretty things which ought to make patients happy, were they not a perverse generation, apt to discover the motives which rule these places, and to feel intensely that they are captives and not patients. Moreover, the purpose of these places being to receive much and expend little, the attendants are poorly paid and of bad quality, the food is common, and the service mean. No amount of beer and tobacco will smooth the troubled waters of discontent among gentlemen who feel themselves not only captives for a sordid purpose, but unsphered from their social rank by poor and low surroundings. Escapes, or attempts to escape, are of course frequent, and when the friends propose removal, every method of hindrance is used. In asylums of this kind, the unwelcome indications of approaching recovery are frequently overlooked or disputed. To purchase the goodwill of such asylums would be wasteful and unwise, for what could the public do with them?

Another kind of asylums consist of the large cheap asylums, some of them containing several hundreds of patients. Some examples of this kind are so much better than others, that it is not easy to find common characteristics which shall be true of the worst and not unjust to the best of them. Although institutions of this kind are conducted on the strictest business principles, and large profits made by small cconomies, the spirit of unjust detention does not predominate in them, it not being worth while to care much for the loss of a few patients paying small sums, whose vacant places would'soon be filled up by other patients of the same class. With a strange disregard for the requirements of large numbers of the insane when collected together, asylums of this kind 
are placed in the dingy suburban wilderness of brick and mortar, and the proprietors are unable to employ the potent tranquilizing influence of wide out-ofdoor space. Large numbers of lunatics have to be controlled in them under great disadvantage by attendants of low quality, and stinted in number by the economies of the place. The shabby and rickety buildings are enormously overcrowded, and the narrow grounds, with an air of Vauxhall by daylight, are utterly inadequate to the out-of-door enjoyment of the patients. It would be well, indeed, if the State were to gain possession of these places for the purpose of closing them. But, their existence being entirely caused by defect of hospital accommodation for the insane of small means, their abolition ought not to precede the erection of sufficient public hospitals for those who need them most; and the double expenditure of public money involved in the purchase of the old and the substitution of new buildings can scarcely be advocated.

Another kind of asylums having a distinct characteristic may be perceived in those houses licensed by the Commissioners themselves, or by Justices of the Peace under their recommendation, for the detention of "quiet and harmless cases only." By some persons it has been contended that no lunatics are really free from danger ; but the action of the Commissioners in licensing houses for harmless cases only, is a sufficient reply to this casuistical reason for placing restraint upon all insane persons. The reason why quiet and harmless cases should be confined and detained in asylums is not so apparent; and the position of the State in purchasing asylums licensed for such cases only might raise a curious question 
of ethics, if not of law. Common and case law declare that such persons ought not to be confined, while the statute law provides places in which they are confined; and therefore, if the State were to purchase the goodwill of such places, it would seem to purchase the proprietary right to break its own laws. The remark of course applies to the purchase of any private asylum in so far as it may contain patients who are not dangerous; but the perplexity is most cross-grained in the instance of the asylums licensed by the authorities of the State to confine and detain such cases only as the law of the State declares ought not to be confined at all. If while the common law made gaming an offence, the legislature were first to license and regulate gaming-houses, and then to purchase their goodwill, the inconsistency would not be greater.

There is a large remainder of asylums which have no characteristic features; poor places from which the owners, lay or medical, male or female, derive a livelihood in differing but not distinctive ways; they are too various in their peculiarities to be classed. As the trade or the medical spirit may predominate, the welfare of the patients is more or less submerged under the strong current of profit. 


\section{IX.}

"I DID STEER TOWARD THIS REMEDY."

By a most remarkable concurrence of opinion, which is evidently the result of independent conviction, all persons who have right to speak with authority on the best remedy for the evils of private trade in lunacy have advocated the extension of the system of public asylums for that purpose. The Lord Chancellor's Visitors, the Commissioners in Lunacy, the Royal Commissioners on Irish Asylums, and many other official and experienced persons, have with one accord fixed upon this remedy; and the Select Committee of 1877 , in its compromising report, endorsed this opinion by recommending to Parliament "that legislative facilities should be afforded by the enlargement of the powers of magistrates or otherwise for the extension of the system" "of public institutions for all classes, such as exist in Scotland, in Cornwall, and at Cheadle in Cheshire," so that eventually "there would be no demand for licensed houses for the upper and middle classes." Arguments may be advanced against making either the Scotch chartered asylums, the English hospitals for the insane, or the solitary 
instance of a county asylum for paying patients which exists in Cornwall, exact models for imitation of the new public asylums for paying patients which are now needed in this country. Excellent as all these institutions are in their own sphere of work, they none of them meet the requirements of the existing emergency; and there is no reason to believe that permissive " enlargement of the powers of magistrates," which is the project of Mr. Dillwyn's Bill, would not be that which the Select Committee of I859 declared it would be, namely, "inoperative." If so, therefore, a wise provision of public institutions for all classes must be "otherwise ;" and it is curious that the Committee should have omitted existing models which are far more to their purpose than those they have cited, although such models are plainly enough shown to be the right examples in an important paper printed by the Committee in the Appendix to their Report. This class of asylums are the State asylums, of which Broadmoor and the India Asylum at Ealing and the Naval Asylum at Yarmouth are excellent examples in this country, and of which the State asylums of the United States of America, accommodating patients of all classes, so that fewer than three hundred patients are confined in private asylums in all that vast community, are an example abroad.

The paper above referred to is a "Memorandum on the Establishment of Three State Asylums for the Chancery Lunatics," presented to the Lord Chancellor, and signed by Dr. Bucknill, Dr. Lockhart Robertson, and Dr. Crichton Browne; and it recommends that "three State asylums should be provided. for the care and treatment of the Chancery lunatics," and each with an accommodation for two hundred. 
patients, within fifty miles of London, each with an estate of one hundred acres, at a total estimated cost of $£ 300$ per patient." If the establishment of such State asylums for Chancery lunatics would be right, it is difficult to see on what principle such institutions should be confined to Chancery lunatics. Rather, it would seem that, as Chancery lunatics are already provided with costly and elaborate means of protection which are not enjoyed by ordinary lunatics, their further protection by means of separate State asylums for their use is less needful for them than for paying patients who are not under the care of the Court. All lunatics who either possess property or who have relatives possessing property who are bound to support them, ought to be under the protection of those to whom the Sovereign has deputed Her prerogative in this matter; while all lunatics maintained at the public cost may well be left under the protection of the Local Government Board. This is a social classification founded upon a real difference; but the accident of a lunatic's property being accessible or not, protected or not, being an artificial distinction upon which it is absurd to establish differences of jurisdiction, and still more so to arrange varieties of treatment, the logical division will no doubt at some time be recognized; and, meanwhile, it is desirable that State asylums should be founded upon the wide and reasonable basis of receiving all lunatics who pay for their maintenance. Probably the three physicians who signed the memorandum saw this clearly enough, but did not feel themselves justified in extending the scope of their recommendations beyond the borders of that which might seem to be their peculiar province; but it is most earnestly to be 
hoped that the Commissioners in Lunacy will adopt and endorse the recommendation with regard to all paying patients, and thus bring to a practical issue the general views they have so emphatically expressed as to the necessity of the establishment of public asylums for all classes.

The task is not tremendous. No one has proposed to establish State asylums for all paying patients, but only for so many as would enable the authorities to discontinue their licence to all owners of asylums who do not fulfil their implied contract between their patients, the public, and themselves, which is to give their patients the possession and enjoyment of all possible sources of comfort, security, and recovery. The total number of private patients in licensed houses on the Ist of January 1878 was 3,472 ; but from these ought to be deducted the soldiers at Bow Asylum and the imbecile children in the schools (which are only asylums in an official sense) of Normansfield, Kenton, Colchester, and Knowle, amounting to an aggregate of $66 \mathrm{I}$ patients, and leaving the total number of private patients, including Chancery patients in licensed houses, at only 2,8II. And this existing total is already on the wane from various causes, of which the steadily increasing preference of the public for the insane hospitals is the most observable. To what extent these admirable institutions, which are not likely to be increased in numbers, are likely to be increased in their capacity of accommodation, and to what extent the tranquil and slightly insane inmates of private asylums may, under a change of public and professional opinion, which may occur any day, pass into domestic care, it is impossible to estimate. But not forgetting the probable operation 
of these influences, it would seem fair and reasonable to leave half of the aggregate to be dealt with in the first instance by existing methods and the survival of the best proprietary asylums, and to make State provision for only $I, 450$ of the insane of the upper and middle classes at present confined in those proprietary asylums which ought to be speedily closed. Should the future management of the best asylums not justify the plea for their preservation which good authorities have urged, they also ought to be dealt with subsequently, and all insane persons be thus placed either under public or domestic care.

It would not be needful or right to estimate the cost for building and establishing new State asylums for paying patients of all classes so high as the Lord Chancellor's medical advisers have properly fixed their estimate for Chancery lunatics. The average payments of this latter class for mairtenance in proprietary asylums is $£ 253$ annually for each lunatic. But the large number of insane persons of small means who are confined in the worst proprietary asylums suffer more from the want of suitable accommodation than those who are comparatively opulent, and their claims for State interference and relief are more urgent ; and if $£ 300$ per patient would be an adequate sum for building State asylums for Chancery lunatics, who are paying an average of $£ 253$ a year for maintenance, the sum of $£ 200$ per patient would be a fair estimate for building State asylums for the paying insane of all classes, a large proportion of whom are comparatively poor. The estimate therefore would contemplate an expenditure of $£ 290,000$ for building State asylums for I,450 paying patients, far less than the sum which Colney Hatch asylum for 
paupers has cost, far less than one modern man-of-war has cost. And this money if advanced by the State could most certainly be repaid to the State, interest and capital, within the customary thirty years, out of the payments of the patients, and after they had received the most liberal treatment. If the owners of licensed houses calculate upon repayment of their purchase-money out of the profits of four years, the State, being owner, might very fairly arrange to repay itself within thirty years, unless, indeed, the State preferred to employ some of its receipts from the insane in the extension of its benevolent protection over this class of sufferers.

The most ready and efficient instrument by which these proposed State asylums could be established would seem to be a Parliamentary Commission, containing an independent medical and legal element and an efficient contingent from the existing boards of lunacy; and the main duties of such a Commission would be-

I. To enter into contracts for the purchase of sites and the erection and furnishing of buildings for State asylums, and to pay for the same with money advanced from the consolidated fund.

2. To repay interest and sinking fund for the debt so contracted from a percentage taken from the payments of patients received into such State asylums.

3. To make rules for the governance of such State asylums, and the payments of the patients.

4. To appoint the persons to form a governing body for each State asylum.

5. To determine what licensed houses for the reception of lunatics shall be closed, and upon what conditions. 
6. To summon and examine upon oath witnesses, and to require the production of documents relating to matters within the reference of the Commission.

7. To prepare statutory amendments on the lunacy laws and reports to Parliament.

Each State asylum should have a separate Governing Body, composed of gentlemen and professional men, ready and willing to discharge the unpaid duties of control, similar to those now discharged by the Committees of Management appointed by the Governors of Hospitals for the Insane, save and excepting one duty which some of these committees permit themselves to discharge in contravention of the original purpose of their institutions - namely, that of making a large profit. It is to be hoped that the contagion of the spirit of trade would find no entrance into the State asylums, and that there would be no rivalry between them except the generous rivalry of earnest endeavour to relieve the greatest amount of suffering. The Lord Chancellor's advisers recommend that each of the State asylums for Chancery lunatics should contain two hundred patients. (See note, p. 107.) This may be a good medium size; but State asylums on the wider basis should some of them be larger, and some perhaps smaller; some should be plain and economical, some more luxurious and costly. The present system of proprietary asylums, whereby under the same roof some wealthy patients are pampered and many poor patients are stinted, causes envious heart-burnings, which may most advantageously be avoided by the apportionment of payment to the variety of accommodation provided in different institutions. 
Carried out with wise forethought, and with the single purpose of benefiting a most suffering and pitiable class of the community, who are "so much at the mercy of. others," as Mr. Wilkes says, this scheme would seem to offer a thoroughly practical solution of a great social difficulty. Moreover, it promises to remove a great professional scandal; for there can be no room for doubt that the great and beneficent profession of medicine does suffer in its honour before the public, and in its self-respect before the tribunal of the corporate conscience, for the state of affairs into which it has unwittingly drifted in its relations to persons afflicted with mental disease. This position is most unjust to the profession at large, and even to that portion of the profession which has devoted itself to the study and relief of mental disease ; for, while there are fewer than one hundred medical men engaged in.what may, without injustice, be called the business of lunacy, there are "more than five hundred medical appointments held in the three kingdoms in connection with the treatment of mental diseases," and no doubt a much greater number of medical men engaged more or less in the private treatment of mental disease, not one of whom has ever touched one farthing of profit from the business of keeping lunatics. That the keeping of lunatics in licensed houses for profit is a business and not a profession, is at once obvious from an inspection of the names of the persons licensed to carry it on. It appears from the last report of the Commissioners in Lunacy that, out of the ninety-eight proprietary asylums in England and Wales, forty-nine are licensed to medical men alone, and twenty-one are licensed to medical men in partnership with laymen or women; 
and of the remainder, ten are licensed to laymen, and eighteen to women alone. But these figures, remarkable as they are, give a most inadequate idea of the inconsiderable amount of pecuniary interest which the medical profession possesses in the business of keeping lunatics. Few of the larger proprietary asylums which are licensed to medical men are in reality the property of the licensees. Large shares in them, and oftentimes the whole of the property, belong to laymen or to women, the medical licensee being a salaried person, with undefined powers and duties. Lord Shaftesbury said, in his evidence of 1859 , Question 82, "Medical men would be the fittest persons to be the proprietors of these houses, and to have the entire charge of them; but it often happens that the fittest medical men have no capital at all, and they have not the means of undertaking this charge, whereas other persons, who are not fit to have the charge themselves, have the capital."

It cannot be doubted, therefore, that this business of keeping diseased persons for profit in places of confinement is heterogeneous to the medical profession, except in so far as the medical profession is responsible to the community for abuses in the treatment of all diseased persons, that is to say, responsible to the extent of its power in amending such abuses ; and therefore it is that the medical profession has a duty to itself and a mission to society in the reform of a law which encourages a "vicious principle" of treatment of a most suffering and pitiable class of dișeased persons. To "minister to a mind diseased" is now as strictly within the scope of medical art as any ministrations to the diseased body; and the responsibility lies upon the whole medical profession, untainted with 
any indirect gains or advantages, to bring within its fold those most unhappy persons who, in the helplessness of their incompetence, lie " so much at the mercy of others," and have been too much sequestrated from the beneficent action of a profession which exists for the purpose of alleviating human suffering, and not for the purpose of keeping any people in safe custody; of a profession which subsists upon remuneration for services freely sought and accepted, and not upon payments by third parties for the board, lodging, and detention of unwilling captives.

\section{NOTE.}

P. ro4. Memorandum to the Lord Chancellor on the Establishment of Three State Asylums for the Chancery Lunatics. (See Appendix to Select Committee Report, 1877.)

I. There are 676 lunatics, wards of the Court of Chancery, now living, scattered in the several private asylums and registered hospitals in England and Wales, for whose maintenance upwards of roo, oool. a year is spent under the sanction of the Court. These patients are visited once a year by the Lord Chancellor's Visitors in Lunacy, who have however no voice in the selection of the asylum, nor do they exercise any control over its conduct and management.

2. It has been suggested to the Select Committee in evidence, that a more efficient supervision and control would be exercised by the visitors over the treatment of the Chancery lunatics in asylums if State asylums were provided for their reception under the control of the Board of Visitors. A precedent for this suggestion is given by the East India Asylum at Ealing, established by the Secretary of State and Council for India for the care and treatment of the insane officers and soldiers of the Indian army. Again, the Board of Admiralty have a similar asylum at Great Yarmouth for the insane officers and sailors of the Royal Navy.

3. It is suggested that three State asylums be provided for the care and treatment of the Chancery lunatics, each with accommodation for 200 patients. 
These asylums should be situated in the three several districts, north, south, and west, into which the visitation of the Chancery patients is by the Lord Chancellor divided, and each asylum should be within some fifty miles of London, for the greater facility of frequent visitation by the committees, visitors, and friends of the patients. Accommodation should be provided partly in the asylum and partly in detached villas in the grounds. Each asylum should have an estate of Ioo acres.

4. The total outlay for land, buildings, fitting, and furnishing, may, without any risk of error, be estimated at $300 l$. per patient. This sum, by a graduated annual payment (as in the case of the pauper county asylums), might be repaid to the Treasury, capital and interest, in thirty years.

The annual maintenance cost for each patient, including repairs of the fabric, may, with a wide margin, be stated at $\mathbf{1} 50 l$. a year. This sum would include the annual repayment of the capital.

The maintenance cost at Bethlehem Hospital-the inost costly of the lunatic hospitals -is only $77 l$. per patient. The estimate of $150 l$. per patient at the Chancery asylums leaves thus a wide margin for contingencies.

The average yearly payments now made by the Chancery lunatics in the several private asylums, is $253 l$, inclusive of extras, as carriage exercise, clothing, \&c. \&c. The sum necessary to meet the average annual estimate of $\mathbf{1 5 0 l}$. is thus already provided and sanctioned by the Court. No loss, therefore, would be entailed on the Treasury by the advance of the necessary capital.

5. It is suggested that, in the first instance, one State asylum for 200 Chancery lunatics be provided, at a total outlay not exceeding $60,000 \%$. This asylum should be built in the south district, in which there is now the largest number of Chancery lunatics in private asylums and where the want of such an establishment is most felt.

It may be situated in any of the southern (home) counties within fifty miles of London, on an estate of about 100 acres.

6. The India Asylum at Ealing is under the control of the Secretary of State and Council for India, and so likewise should this proposed Chancery asylum be placed under the control of the Lord Chancellor and of the Board of Visitors. . The detail government of the asylum would, as in the case of the lunatic hospitals and of the Ealing (India) Asylum, be in the hands of the physician and resident medical superintendent.

The financial detail would also be managed, as at Ealing, in the office at the asylum, and presents no unusual difficulties. 


\section{“I DID STEER TOWARD THIS REMEDY." IO9}

7. It is assumed that the medical visitors, with their great experience in lunacy, would not fail to place this State Chancery Asylum, as regards each detail of treatment and management, in the first rank of English public asylums, and afford to the lunatic wards of the Court every curative appliance known to science.

$$
\begin{aligned}
& \text { (Signed) J. C. Bucknill, M.D., F.R.S. } \\
& \text { C. Lockhart Robertson, M.D. } \\
& \text { J. Crichíon Browne, M.D. }
\end{aligned}
$$

London, IIth Aprit. 1877, 


\section{$\mathrm{X}$. \\ HOUSEHOLD HARMONI. \\ "After many moody thoughts, At last, by notes of household harmony, They quite forget their loss of liberty."}

THE domestic care and treatment of the insane is a subject well worthy of a treatise, and can only be briefly referred to in these pages. When a Commissioner in Lunacy in 1859 stated his opinion "that, as a general rule, persons who are of unsound mind and unfit, by reason of mental infirmity, to be at large, or to take care of themselves, ought to be in an asylum" [Question 2,243], he only expressed the thought accepted at the time, but of late more and more disputed. Yet as early as I 867 Dr. Maudsley, in his work on the Physiology and Pathology of the Mind, (p. 426), denounced "the system, which cannot be just, of indiscriminate sequestration-of locking up a person in an asylum simply because he is mad." Referring to the objection that the lunatic might be better treated there than in a private residence, he wrote-" "The quarter from which this objection is urged taints it with suspicion; I never heard it put forward but by those who are interested in the continuance of the 
present state of things-those who make it appear to fail entirely to appreciate the strength of the passion for liberty which there is in the human breast; and as I feel most earnestly that I should infinitely prefer a garret or a cellar for lodgings, with bread and water only for food, than to be clothed in purple and fine linen, and to fare sumptuously every day as a prisoner, I can well believe that all the comforts which the insane person has in his captivity are a miserable compensation for his entire loss of liberty, - that they are petty things which weigh not at all against the mighty suffering of a lifelong imprisonment. I would put it to those who lay stress on the comforts of asylums, whether they sufficiently consider the discomforts of them, apart from the imprisonment which they are by the nature of the case. Is it not a common thing to hear from an insane person bitter complaints of the associations which he has in the asylum, and of the scenes of which he is an unwilling witness-scenes which cannot fail to occur, notwithstanding the best classification, when all sorts and conditions of madness are congregated together? What can be conceived more affecting to a man who has any intelligence and sensibility left than the vulgar tyranny of an ignorant attendant-a tyranny which the best management cannot altogether prevent in a large asylum? And I might go on to enumerate many more of the unpreventible miseries of life in an asylum, which, when superintendent of one, forced themselves painfully upon my attention, and often made me sick at heart."

In 1871 Dr. Blandford said in his treatise on Insanity and its Treatment (p. 370)—“"There are patients with ample means, who make the fortunes of asylum 
proprietors, whose lives would be infinitely happier did they live beyond asylum walls." "How are you to know if a patient is capable of living beyond the walls of an asylum? The answer is simple: Give him a trial. Many unpromising cases I have known to benefit so much by the change that they would scarcely have been recognized. As the last generation did away with the fetters and mechanical restraints used in asylums, so let the present release from the restraints of an asylum all those capable of enjoying a larger amount of liberty and a freer atmosphere than that in which they now fret and chafe."

The late Dr. Alexander Sutherland, examined by the Select Committee in I 859 , said that he had had I 85 patients, as single patients, under attendants in private houses, and of the first 100 patients 74 had been cured, 20 had been uncured, and 6 had died; and of the last received 85 patients, more than 74 per cent. had been cured. The greater number of cures had been effected upon an average within the year. These patients had been of all classes, and he was sure that it was not only the most likely mode by which a cure could be effected, but that it was the kindest way of treatment. He visited these patients twice a week, and if the cases were acute, every day. Whenever he recommended such patients to be sent to an asylum the relations were very reluctant to agree to it; as there is a very great prejudice against the name of an asylum. These patients of Dr. Sutherland's were mostly treated in lodgings in St. John's Wood. [Questions 2,072 et seq.]

In 1878 the proportion of recoveries claimed to have taken place in licensed houses was 9.35 per cent. of the number under treatment. 
The opinion of the Secretary of the Lunatics' Friends' Association, expressed to the Select Committee in I860, is very decided:- "Are you not aware that there are many private houses where only one patient is kept, and that it is very desirable, on the score of humanity, to diminish the number of those private houses?-I am not of that opinion. I wholly disagree with Lord Shaftesbury in that respect, that confinement in single houses is generally to be deprecated. I am more of the opinion of Dr. Sutherland, that it is the best way of treating all patients." [Question 357.]

Lord Shaftesbury's disapproval of the single-patient system appears to have been founded upon his personal knowledge of the manner in which it was abused at a time when almost all lunatics were treated infamously. If he would investigate the mode of life of many Chancery single patients living in their own or their friends' houses, or with doctors and others, or even as lodgers with well-chosen companions, at the present time, he would change his opinion, as Dr. Lockhart Robertson was compelled to do by such an experience.

"Has the opinion you have formed, that it is desirable to remove as much as possible patients from asylums, been based upon the knowledge you have acquired since your appointment as a Lord Chancellor's Visitor ?-Most wonderfully. I could never have believed that patients who were such confirmed lunatics could be treated in private families in the way that Chancery lunatics are, if I had not personally watched their cases."

"Is your experience of private asylums corroborated by your experience of public asylums? Do you 
hold the same opinion with regard to them as to private patients?-I do; I think the patients are happier and better out of them if they can be removed out.-Happier ?-Certainly, happier.-Do you mean better behaved ?-Happier in the enjoyment of such pleasure and joy in life as is left to them." [Questions I,09I, et seq.]

But it is not merely the happy change which takes place in confirmed lunatics when they are judiciously removed from the dreary detention of the asylum into domestic life, it is the efficiency of the domestic treatment of lunacy during the whole course of the disease which constitutes its greatest value, and of this the Author's fullest and latest experience has convinced him that the curative influences of asylums have been vastly overrated, and that those of isolated treatment in domestic care have been greatly undervalued. It has long been the accepted doctrine that insanity can only be treated curatively in asylums. But it must not be forgotten that most of the works on the treatment of insanity have been written by medical men connected with asylums, who, without insincerity, might express opinions founded upon their own limited knowledge. A wider knowledge of insanity as it occurs among the upper and middle classes would have taught them that a very considerable number of cases of actual insanity run a short course and recover in domestic life with no great amount of treatment, and that not perhaps of a very scientific kind. As it is, the family doctor often treats and cures a case of lunacy almost without knowing it. Without paying that attention to the mental condition which he ought to do, he treats the failure of bodily health upon which it depends, and the patient 
frequently recovers in mind and body. In other cases, which are destined not to be transitory, the family doctor of necessity has to treat, and to treat at home, the disease in its most important phase-that of initiation and incubation. How little do the physicians of asylums know of the earliest stages of mental disease ; and yet it is frequently in those stages alone that the disease is curable. But it is in these stages that the general physician or the family doctor does treat the developing disease-treats it at home and cures it. He treats the young maid with her green and yellow melancholy; or the youth, pale, irritable and recluse, with averted eyes which speak of evil habits; or the desponding man with bile-poisoned blood; or the woman in her autumn days, for the first time losing her cheerfulness; and many other varieties of ailment becoming insanity; and the number of such cases which are cured under ordinary medical treatment bears no mean proportion to those which pass into the asylum and may be cured or confirmed according to the accidents of care, skill, and good fortune which no one can foresee or estimate. Some physician, with the garnered wisdom of many years, is not unfrequently able to say of a patient in whom mental changes have only been incidentally remarked as accompanying ill health, "This is a case which is likely to become insanity. I must not call it the fullydeveloped disease, for there are no facts on which I could sign a certificate." Nor will he wait until the disease is mature before he commences treatmentunder great difficulties, perhaps, for no control can be imposed at this stage; and yet the results of treatment are far more frequently successful than could by any means have been anticipated. 
But supposing that the patient has become unquestionably insane, what are the capacities of domestic treatment, and what are the exceptions in which it should never be resorted to? It has been laid down as a rule by good authorities, that homicidal and suicidal patients should always be sent to asylums, and it is worth quite as much as medical rules usually are: that is to say, it is properly applicable to the great majority of cases. It is needful to restrain the man with delusions of persecution and insane ideas of revenge within strict guard and narrow confines, because the overt act of such a man comes without warning; it is not always needful to imprison lunatics whose danger arises from ordinary violence accompanied by excitement which may come on with abundant warning and with long intervals of tranquillity. With regard to suicidal patients, it is right to place a lunatic with delusions leading to self-destruction in the greater security of an asylum; but it would be stupidly cruel to lock a man up in an asylum who had attempted his life under the depression caused by cholæmia or some other temporary influence, which medical treatment will remove in a few days or weeks.

Many a suicidal patient can live as safely with two faithful and skilful attendants in a villa or a cottage as in any asylum, and in the free air he will walk or drive, employ or amuse himself in various ways, and recover without the asylum brand or the asylum danger of falling more and more into subjective ways of thought, and shunting into the sad list of incurables.

There being few medical rules without exceptions, the rule against placing single patients with attendants 
only as companions is open to the important exception that when the conduct of the attendants is under the full supervision of a competent medical man, such a provision is often the most convenient and satisfactory one for the medical treatment of a recent case. No doubt such an arrangement may be abused if bad attendants are employed and are not properly looked after by the medical man in charge. But with skilful and faithful attendance and supervision, the plan "supplies at present a social want," which is as much as the Commissioners have to say for licensed houses. There can be no doubt that a great variety of cases of recent insanity may be treated, and frequently are treated, most successfully, in houses or apartments taken for the use of the patient in town or in country, according to the prevailing need for constant medical attendance and supervision, or for free air, space, and exercise. Asylum detention begets a routine life with a wonderful oblivion of medical resources. Narcotics and sedatives are used with more or less audacity now, as depressing medicines were used a generation ago; but the persistent efforts to relieve, by medicine, those bodily conditions upon which the morbid mental states depend, which were practised in asylums within even recent memory, have now gone out of vogue, and even the belief in them seems to be dead and gone. In many of the asylums now a patient may get well if he will under good hygienic influences; but as for any systematic attempts to aid nature by the resources of the medical art-except those in a few well-known institutions where the love of medical science survives-one would almost as soon expect to see them made as to meet with the older practices of mechanical restraint. Indeed it is not certain that to blister a patient's 
head in the hope of saving him from dementia would now be thought a cruelty. But in the treatment of single cases by any capable and conscientious physician it is quite different. Treatment is the physician's raison d'être, and even mad patients are very frequently intelligent enough to know whether efforts are or are not being made for their benefit. Discharged patients will tell you that they have been months in an asylum without having been spoken to by a medical man, but a single patient cannot escape the individual attention of the medical man in attendance whom the statute requires to visit once a fortnight, and who in recent cases may and does visit his patient as frequently as he thinks needful and right. Friends and relatives may and do reside with the single patient under active treatment, although their presence is often harmful, and then a well-chosen companion and trustworthy attendants must suffice; but in all varieties of circumstances the distinctive feature is medical treatment. A very different phase of lunacy life is that of the chronic single patient living in a family, his own or some other. There is no official record of lunatics living with their own families except of those upon whom inquisitions have been held; but from the frequent history of cases that have been living at home for years and years clearly enough insane, the number cannot be inconsiderable. They are not usually the best examples of home treatment, for relations are apt to be either too severe or too indulgent, and there may be no check or guidance, official or medical. Still every person whose knowledge of society is wide and varied must have known insane persons living with considerable enjoyment of life in the bosom of their own families. 
Another distinct class of single patients are those under the control of the Lord Chancellor and the inspection of his officers. Of these it has been truly said that "their condition is eminently satisfactory, and such as it is impossible it could be in the best asylums" (Maudsley, op. cit.). Many of them indeed are maintained in the position and habits of gentlemen, and in the enjoyment of the ordinary pleasures of life, whether in town or country.

Another distinct class of single patients are those fortunate lunatics whose friends have had the wisdom and the feeling to remove them from asylums and to place them "in private families, where after a time they truly become part of the family, and are considered in all its arrangements not otherwise than as a member of it afflicted with some incurable bodily disease would be." They are "happier amongst sane people, and under the circumstances of private life, than when surrounded by all degrees and kinds of lunacy, and subjected to the monotonous routine and oppressive regulations of an asylum" (Maudsley, op. cit.).

It is quite a mistake to suppose that the domestic care and treatment of the insane is necessarily costly. No doubt money removes difficulties, and many patients who are not tranquil or trustworthy enough for domestic life in a cottage could be thoroughly well taken care of with good attendants in the house of a doctor, or in an establishment of their own. But the experience of the Lord Chancellor's visitors proves that judiciously selected cases of tranquil lunacy may be made more comfortable and happy in very homely places of residence, and at a very moderate cost. Therefore the development of this system is not for 
the advantage of the rich alone, but for that of all lunatics who are easily manageable and are not dangerous, and it is in the development of this system of domestic treatment that the greatest promise lies of the largest possible amelioration of the unhappy lot of those afflicted with mental disease. 


\section{$\mathrm{XI}$.}

YOU MAY WEAR YOUR RUE WITH A DIFFERENCE. *

THE questions connected with this subject, which you have requested me to introduce to you, are so numerous and complicated, that I must attempt some delimitation of them by asking you to consider, in the -first place, on what grounds medical men generally are interested in the existence of proprietary lunatic asylums, and in the laws under which they are established and to some extent regulated. If it be true, as is maintained in the most recently published work on lunacy law, that "insanity is a purely relative term, at times employed to designate conditions of the mind which are only diseases in the same sense that general debility is a disease, or in the same sense that bodily fatigue or want of change of air are diseases, and that every passion and emotion may, in prolonged excess, be said to constitute a degree of mental disorder "-if this be true, I cannot claim for the medical profession the right to arrogate any

I This chapter was an Address given by the Author to the South Metropolitan Branch of the British Medical Association, February I 7 th, I880. 
authoritative judgment upon the manner in which such "conditions of the mind" should be dealt with. But if insanity be a bodily disease, then medical men have a clear right to discuss, and finally to decide upon, the proper manner of its treatment; and the necessity, utility, and management of proprietary lunatic asylums clearly come within the scope of such discussion. I think that not only the conviction of the profession, but the opinion of the public, will affirm the latter proposition, notwithstanding the operation of laws which have come down to us from times when insanity was thought to be something apart from disease-laws which have indeed been patched and enlarged as the crying needs of the time demanded, but which substantially deal with persons suffering from diseases affecting the mental powers in a different manner from that which is customary with regard to all other diseased persons.

The operation of these laws has tended, and still more and more tends, to sequester the insane from the care and treatment of the medical profession at large; to render more and more perplexing, dangerous, and difficult the medical treatment of any single case of lunacy; to herd lunatics together in special institutions where they can be inore easily visited and accounted for by the authorities, and to create a class of men whom these authorities can make responsible to themselve:; for the confinement and detention of the insane, according to certain regulations, but whom they do not and cannot make responsible for their proper medical treatment. It would, I think, be an excellent subject for one of our future discussions to inquire to what extent the herding together of lunatics is as beneficial as it is 
economical, even in those most creditably managed institutions for our destitute insane, which are more almshouses than hospitals - I mean the county asylums. But our present inquiry is restricted to institutions for the not destitute insane, institutions which certainly are not almshouses, and which, I am prepared to maintain, are not hospitals.' In what manner shall we regard these places for the confinement and detention of diseased persons, and to what degree are we called upon to extend our feelings of professional brotherhood and sympathy to the men who own them? Surely none of us can fail to feel and respond to the "strong claim on the kindly fellowship and protection of the whole profession" of all medical "practitioners" honourably engaged in the treatment of the insane, and surely we should deny and resent any "inconvenient and unfair aspersions which have been made upon their conduct." But surely, also, there is a line of distinction to be drawn between the practitioner and the proprietor; and although fairness is due to every one, I do not see, unless perchance I may be the proprietor of an asylum, why I should be bound to extend fellowship and protection to every one of that class. To take a parallel instance; say that I am a ship-doctor, one of a most useful class of practitioners, towards whom we all feel the fullest professional fellowship. But I am also owner of the ship, or of shares in shipping; surely I have no claim upon your fellowship as a shipowner. Doubtless the cause of the jumble of ideas on this subject which is entertained by the public, and from which the profession is not free, is, that doctors are generally associated with asylums, and asylums with doctors; but, in reality, the pecuniary interest of 
medical men in private asylums is much smaller than you would suppose to be possible. There are ninetyeight private asylums in England and Wales; and of these, forty-nine-being just one half-are licensed to medical men alone, the remaining half being licensed to laymen or to women, or to medical men in partnership for this purpose with laymen or with women. Moreover, of the asylums licensed to medical men, the proprietors of many of the most important ones are capitalists, or speculators, or trustees, or inheritors, or hilt-deep mortgagees to whom they are not licensed, and whose names do not appear.

There are, therefore, two classes of persons connected with private asylums who stand towards us in very different relations. First, there are the practitioners, whether paid by fee or by salary, to whom the whole profession owes kindly fellowship and protection; and secondly, there are the proprietors of asylums, who may or may not be medical men, and whom we may fairly be allowed to criticise-whom, indeed, it is our strict duty to criticise-in the interest of our profession, of the public, and of those diseased persons whom they are permitted to hold in confinement.

Now a great deal of misleading analogy has been drawn between the action of medical men, who in the ordinary practice of their profession receive payment in fees for their services, and that of the proprietors of lunatic asylums, who receive payment for the maintenance and detention of their inmates, which payment, in so far as it exceeds the cost of such maintenance, is their profit. I can perhaps scarcely do better, to illustrate this constantly recurring analogy, than by quoting two passages from recent works on the subject of lunacy law reform. Dr. William Wood, in 
his recent pamphlet on the Lunacy Law, expresses his opinion that "if care be taken that no patient shall be improperly placed in an asylum, there is no serious wrong inflicted on him if one who has been admitted under these precautions be kept for some time after his apparent recovery"; on the ground, as he explains, of the possibility of relapse. Dr. Wood proceeds to say: "Unworthy motives are not attributed to the surgeon who prolongs his attendance on a patient who has broken his leg, and who thinks it his duty to watch and guard against imprudence and premature use of the limb, though the bone has united. Why should not a physician in charge of an insane person, and why should not the friends of a patient, have the same measure of justice meted out to them as is without hesitation accorded to the surgeon?" (P. 57.)

Now, without commenting upon this justification of one of the peccadilloes of private lunatic asylums, the detention of patients after their apparent recovery, it must be observed that any surgeon who did act in the manner supposed would most certainly have unworthy motives attributed to him. Only, to make the analogy fit the case, this surgical patient must be put in such a condition that he can in no way help himself, and he must also be supposed to be incapable of saying to the surgeon that he had had enough of him, and also it should be assumed of him that his surgeon was paid by a third party, whose interest it might be that the bone should not speedily unite-of a child away from its parents, for instance, lying at an hotel. But, in reality, the fees of medical men, even under the old system of charging for medicines, are not profits. They are charges for work and skill made upon, and paid by,'voluntary agents, whereas 
the profit of a private asylum proprictor is that portion of the payment which is in excess of the cost, and which is great in proportion to the diminution of cost, and valuable in proportion to its continuance; and, in the well-considered words of Mr. Wilkes and Mr. Lutwidge, reporting to Her Majesty on this very question, "We fear it must be confessed by all that, where profit is the aim, it will too generally be pursued to the prejudice of those from whom it is derived." (Report of Royal Commission on Lunatic Asylums in Ireland, I 858, p. 32.) Or, in the vehement words of Lord Shaftesbury: "This vicious principle of profit runs through the whole." "I have no doubt that in the majority of instances, where they are acting on that abominable principle of profit, they screw them down to the lowest possible point." (P. Ico, Select Com. Report, I 859.)

I said that I should make two quotations to illustrate the analogy which is often drawn between the action of medical men in the open profession, and of men, medical or not medical, dealing with diseased persons in asylums. The second quotation is from a specch of the late Mr. Wakley. I quote from that work-full of information and suggestion in lunacy matters-The Care and Cure of the Insane, by Dr. J. Mortimer Granville, according to whose quotation from Hansard, 3rd series, vol. 59, Mr. Wakley, in August, I84I, said in the House of Commons: "I entreat the House to observe the operation of the law as regards lunatics. Suppose I have a relation who is possessed of a large fortune. I perceive certain eccentricities in the conduct 'of that individual. From the great affection I have for that relative, and the still greater affection I have for his property, I cause 
a commission of lunacy to be issued out, and, discovering him to be insane, place him in confinement. Then what motive of action is given, under the present system, to the person in whose charge the lunatic is placed? Why, it calls into operation the principle of selfishness common to human nature. The proprietor of the asylum will argue that he gets $£ 400$ a-year for the charge of the gentleman so long as he remains under that roof; and if he recovered, then he, the proprietor, would lose that annual amount. Suppose an honourable gentleman were to go to a doctor and say, "My liver is diseased, and so long as it remains so I will give you $£$ Ioo a-year!' What motive in such case would be given to the doctor?"

The quotation proves how forcibly the situation was even then comprehended by this "clear thinker and bold speaker," although, to construct his analogy, he was obliged to suppose the existence of such an agreement as is never made in the open medical profession. I have heard that, in China, medical men are paid salaries so long as their patients remain in good health; but a stated income received from a patient during the continuance of disease is, so far as I know, a thing unheard of out of asylums. I beg you to observe that all I have been saying has reference to the unchanging, and I fear unchangeable, principles which underlie human activities. I might have a good deal to say on the details of asylum management, if I thought it needful or desirable to do so; but I desire to put aside every word which may be construed to have a personal reference, and to ask your opinion, on the broad ground of principle, whether it is right that diseased and helpless persons should be detained and confined in asylums for the 
profit of private individuals; the amount of that profit depending upon what these individuals choose to expend upon the comfort and enjoyment of their inmates, and its continuance upon the duration of the disease, or what they choose to think its duration? May I not fairly ask you to consider what can possibly justify the existence of these institutions for private imprisonment, owned and kept by private people, lay and medical, male and female ; there being nothing like a parallel instance in which the liberty of Englishmen is submitted to such control ? In former times, indeed, debtors were permitted to be kept in durance by sheriff's officers; but a sheriff's officer was not quite a private individual, and the thing was felt to be a scandal, and was abolished. Control over the liberty of children is to a certain extent transferred from their natural guardians to schoolmasters; but this only lasts for a few months at a time, and the restraint imposed is a very different thing from the detention of a lunatic until he be discharged or die. But, the existence of these institutions being unquestionable, may I not further ask what good reasons can be given by medical men for sending patients to them? We know pretty well what the motives of relatives are for so doing: separation from and safe guarding of the patient, secrecy, and perhaps the hope of cure. But have we, as medical men, any clear knowledge of the medical treatment carried on for purposes of cure in these places? Have we, aś medical men, any assurance that secrecy will be observed when it is right, and not attempted when it is wrong? Above all, can we have any confidence that when, with or without medical treatment, our patients have recovered in 
these places, we shall be permitted to know the fact? or, if we should be so bold as to think that we have observed it for ourselves, are we sure that we shall not be contradicted and deceived? Are we sure that our recovered patients will not be indefinitely detained, under the supposition that they only appear to have recovered, and may possibly have a relapse? Perhaps I may be wrong in the opinion that, under the best treatment and the most auspicious circumstances, patients do not often attain to perfect recovery in asylums, any more than they do so in fever-hospitals ; the last touch of treatment wanted being the cordial restorative of home or the tonic of liberty. But do not the proprictors of asylums often recognize the persistence of symptoms of insanity in patients who appear to us to have recovered, which no one else can observe? If the matter were not too sad and serious, I could amuse you by descriptions of the manner in which I have myself been kept at bay in my diagnosis of recovery; for although, upon sufficient evidence, you may make up your mind with certitude as to the existence of mental disease, it requires great pains and patience and knowledge of your people to avoid being misled as to the possible existence of symptoms which you may not be capable of observing or of denying. Suppose, for instance, that the proprietor tells you that your patient, who appears to have recovered, has had a slight stroke, with a little facial palsy and some slight mental obfuscation, which passed off the day before yesterday; or that he has had two or three slight epileptic seizures, and has been a little fierce and angry just after them ; or that he hears voices at night and denies them in the morning,--upon what principles of diagnosis are you to 
determine that the gentleman is drawing upon his invention for his statements, and that he will not be inconsolable should the relapse occur which he assures you that he is anticipating?

But, as I have referred, however slightly, to my own unfavourable experience, let me also say that I have met with and had the pleasure of knowing some men who are the proprietors of asylums, who are as honourable and truthful and just as any men in existence; who forget their profits, and, as physicians, treat their patients with unfailing humanity and generosity and skill; whose doors are freely open for patients to leave with the earliest indication that change will be to the patients' advantage ; whose asylums are somewhat like lunatic clubs, in which the residence of patients is to a great extent voluntary; whose excellent practice, were it general, would go far to redeem a bad system; and whose active usefulness must survive any reasonable and beneficent change in the lunacy law. Of the present position of such men or of such a man in such a system, one can only say, "Que diable allait-il faire dans cette galère ?"

But what to do?

In the first place, I may broadly state my opinion that no change of the law can be satisfactory which does not contemplate the eventual abolition of all proprietary lunatic asylums. The deprivation of the personal liberty of any of the Queen's subjects is an affair of the State, and must only be undertaken by the State. From that axiom there must be no flinching. Such asylums as I have last described may survive, under some other name, as voluntary retreats for persons of defective or damaged mind. For lunatics who must be confined against their will, 
asylums ought to be provided by the State, and managed by boards of governors. Moreover, the care and treatment of quiet and harmless cases of insanity by the open medical profession in domestic life, as single, or double, or treble cases, ought to be encouraged by the law and its administrators, and not discouraged, as it is at present.

The discussion of the large question of certification may well be postponed to another opportunity; only I may observe that I think that no modification of the present certificate-system will suffice to make it safe to the practitioner or satisfactory to the public. The medical man ought to be put firmly upon his right footing as the exponent of scientific opinion; and the action taken upon evidence of that opinion in so grave a matter as that of depriving a man of his liberty ought to be no less than that of the civil power, whatever may be determined for the best as to the judge, or the court, or to the form of inquiry.

Moreover, great changes are needful in the administration of the lunacy laws. The Commissioners in Lunacy are administrators in the metropolitan district, and inspectors only in the remainder of England and Wales; and it is very certain that the worst asylums to be found in the country are under their immediate jurisdiction. If their Board is to survive a thorough reform of the lunacy laws, they ought at least to resign the control of the metropolitan asylums, and to install the justices of the peace of the counties of Middlesex, Surrey, Kent, and Essex in the same authority which the justices of the peace possess in all other counties, the Commissioners themselves exercising everywhere an uniform power of inspection, report, and superintendence. But a 
more extensive change is still more needful and important, which would render needless this local and partial change. There are socially and logically but two classes of lunatics in the community, those who are destitute and those who are not; and there ought, accordingly, to be only two authorities to administer the lunacy laws, and two laws for them to administer as they severally regard these two distinct classes of the insane. The present division of authority between the Lord Chancellor's Officers in Lunacy, the Commissioners in Lunacy, the Local Government Board and the Boards of Guardians, the Visiting Justices of County Asylums and the Visitors of Provincial Licensed Houses, the Boards of Cleveden and Caterham, \&c., is intricate, confused, and mischievous. Instead of this, the Local Government Board, or the Minister of Health, whenever he may be appointed, ought to be placed in authority over all subordinate authorities having control over the care and maintenance of all destitute lunatics; and the Lord Chancellor's Officers in Lunacy, or, to speak with more technical accuracy, the Lord Chancellor with all his subordinate officers in lunacy, under the Royal Prerngative, ought to have authority over all other lunatics and persons charged with their care and control. This change would leave no sphere of action for the present Board of. Commissioners in Lunacy, the members of which might well be distributed between the two new and enlarged authorities, half of them going to the Local Government Board, and half of them to the Lord Chancellor. Upon this broad basis, the details of lunacy law reform could be built up with symmetry, science, and effect; but, without some broad basis of this kind, 
founded upon a logical principle, any reform of the lunacy laws which we may expect will be but some tinkering of the old pot where the light of day most inconveniently shines through its rust-eaten sides. Be assured, however, that the longer reform is delayed the more comprehensive it will be when it does come; for the history of social policy is the opposite of that of the Sibylline leaves, and generally the longer you wait for it the larger it becomes. In the meanwhile, be it our duty, both collectively and individually, to strive that this most pitiable and helpless class of diseased persons, from whom the profits of proprietary lunatic asylums are derived, shall not suffer longer than we can help under the disadvantages of this worn-out old law. Sequestrated as they have been from our professional care, they are still, as diseased persons, the proper objects of our interest and regard; and we owe it to them, not less than to ourselves and to our profession, to strive that the law which governs their care and treatment shall be conceived and executed in the spirit of benevolence, of the scientific knowledge of disease, and of those relations which the ethics of our profession teach as being consistent with the true dignity and welfare of both medical practitioner and patient.

THE END. 
LONDON

R. Clay, SONS, and TAYlor, BREAD STREET HILI, E.C. 


\section{HABITUAL DRUNKENNESS}

AND

\section{INSANE DRUNKARDS.}

\section{Crown 8vo. 2s. 6d.}

"Whatever side we may take upon the question, there can be no doubt that Dr. Bucknill's volume is a valuable contribution to the discussion." - Spectator.

"Dr. Bucknill's criticism of the cruder notions of those who seek to restrain drunkards by forcible seclusion, was well-timed and has done a great deal of good."-Westminster Review.

"There is much that is sensible and judicious in Dr. Bucknill's suggestions, and we commend them to those who take an interest in this most important subject."-Morning Post.

"It is perhaps the greatest praise he could desire for the articles and speeches reprinted in the volume before us, that they have probably had no small share in compelling the promoters of the Habitual Drunkards' Bill, to modify that measure from its very objectionable original form to the much more modest and curtailed form in which it passed the second reading."-Medical Times.

"Dr. Bucknill has, in this republication of his remarks, addresses, and letters, upon the subject of habitual drunkenness, done a goorl service to social economy, as well as to the cause of psychological medicine."-American foumal of Insanity.

"We trust that all our legislators and social reformers who take up this question will study Dr. Buclnill's valuable work."-Court Circular. Post.

"Dr. Bucknill writes clearly and forcibly."-Birmingham Daily

"The vast experience which the author possesses, and the patient, extensive, and impartial investigations which he has made into the real facts of the case render this a. work of peculiar value."-Bumingham Daily Gazette. 


\section{MESSRS. MAGMILLAN AND CO.'S PUBLICATIONS.}

INSANITY IN ANCIENT AND MODERN LIFE, with Chapters on its Prevention. By D. HACI Tuke, M.D., F.R.C.P. Crown Svo. $6 s$.

"This work exhibits deep research in various directions, and teems with allusions and quotations which prove the auth $r$ to be not cnly an accomplished psychological physician, but a scholar of no mean order."-Medical Times.

\section{BY PROFESSOR MAUDSLEY, M.D.}

BODY AND MIND: An Inquiry into their Connection and Mutual Influence, specially in reference to Mental Disorders: being the Gulstonian Lectures for 1870. Delivered before the Royal College of Physicians. New Edition, with Psjchological Essays added. Crown Svo. 6s. 6d.

THE PHySIOLOGY OF MIND. Being the First Part of a Third Edition, revised, enlarged, and in great part re-written, of "The Physiology and Pathology of Mind." Crown Svo. 10s. $6 d$.

THE PATHOLOGY OF MIND. Being the Second Part of a Third Edition, revi-ed, enlarged, and in great part re-written, of "The Physiology and Pathology of Mind." Svo, I8s.

\section{By PROFESSOR CALDERWOOD, LL.D.} THE RELATIONS OF MIND AND BRAIN. Svo. izs.

\section{By DR, McCosH.}

THE EMIOTIONS. Sro. $9 s$.

\section{By DR. B. W. RICHARDSON, F.R.S.}

THE DISEASES OF MODERN LIFE. New Edition. Crown Sro. $6 s$.

ON ALCOHOL. Crown 8ro. is. TOTAL ABSTINENCE. Crown 8ro. 3s. 6d.

ON THE USE OF WINE IN HEALTH AND DISEASE.

By Fraxcis E. Axstie, M.D., F.R.S. Crown Sro. $2 s$. 


\section{MACMILLAN \& CO'S MEDICAL CATALOGUE.}

Works in Phystology, Anatomy, Zoology, Botany, Chemistry, PHYSICS, MIDWIFERY, MATERIA MEDICA, and other Professional Subjects.

ALLBUTT (T. C.) - ON THE USE OF THE OPHTHALMOSCOPE in Diseases of the Nervous System and of the Kidneys; also in certain othor General Disordérs. By Thomas Clifford Allbutr, M.A., M.D., Cantab., Physician to the Leeds General Infirmary, Lecturer on Practical Medicine, \&c., \&c. 8vo. 15s.

ANDERS0N.-Works by Dr. McCaLl Anderson, Professor of Clinical Medicine in the University of Glasgow, and Physician to the Western Infirmary and to the Wards for Skin Diseases.

ON THE TREATMENT OF DISEASES OF THE SKIN : with an Analysis of Eleven Thousand Consecutive Cases. Crown 8vo. $5 s$.

LECTURES ON CLINICAL MEDICINE. With Illustrations. 8vo. i0s. $6 d$.

ON THE CURABILITT OF ATTACKS OF TUBERCULAR PERITONITIS AND ACUTE PHTHISIS (Galloping Consumption). Crown Svo. 2s. $6 d$.

ANSTIE.-ON THE USE OF WINES IN HEALTH AND DISEASE. By F. E. Anstie, M.D., F.R.S., late Physician to Westminster Hospital, and Editor of The Practitioner. Crown 8vo. 2s.

BALFOUR.-Works by F.M. BALFour, M.A., F.R.S., Fellow ānd Lécturer of Trinity College, Cambridge.

ELASMOBRANCH FISHES; a Monograph on the Development of. With Plates. 8vo. $21 s$.

A TREATISE ON COMPARATIVE EMBRYOLOGY. With Illustrations. 8vo. [In the press.

BARWELL.-ON CURVATURES OF THE SPINE : their Causes and treatment. By RIĆA ARD BARWzLL, F.R.C.S., Surgeon and late Lecturer on Anatomy at the Charing Cross Hospital. Third Edition, with additional Illustrations. Crown 8vo. 5s.

BASTIAN.-Works by H. CharltoN Bastian, M.D., F.R.S., Professor of Pathological Anatomy in University College, London, \&c.:-

THE BEGINNINGS OF LIFE: Being some Account of the Nature, Nodes of Origin, and Transformations of Lower Organisms. In Two Volumes. With upwards of 100 Illustrations. Crown Svo. 2Ss.

EVOLUTION AND THE ORIGIN OF LIFE. Crown Svo, 6s. 6d.

ON PARALYSIS FROM BRAIN DISEASE IN ITS COMMON FORMS.

Illustrated. Crown Svo. 10s. $6 d$.

"It would be a good thing if all such lectures were as clear, as systematic, and as interesting. . . . . It is of interest not only to students but to all who make nervous diseases a study."-Journal of Mental Science.

BRUNTON.-PHARMACOLOGY AND THERAPEUTICS : or Medicine Past and Present. By T. LAUDER Brunton. M.D., F.R.S., Assistaut Physician and Lecturer on Materia Medica at St. Bartholomew's Hospital. Crown svo. 6s.

BUCKNILL.-HABITUAL DRUNKENNESS AND INSANE DRUNKARDS. By J. C. BucKNILL, M.D. Lond., F.R.S., F.R.C.P., late Lord Chancellor's Visitor of Lunatics. Crown 8vo. 2s. 6d.

CALDERW00D.-The Relations of Mind and Brain. By $\mathrm{H}$. CALDERWOOD, LL.D., Professor of Moral Philosophy in the University of Edinburgh. 8vo. $12 s$.

CARTeR.-Works by R. BRudeneli Cakter, F.R.C.S., Ophthalmic Surgeon to St. George's Hospital, \&c.

3,000.2.80. 
CARTER-continued.

A PRACTICAL TREATISE ON DISEASES OF THE EYE. With Illustrations. 8vo. $16 s$.

"No one will read Mr. Carter's book without having both his special and general knowledge inereased."-Laneet.

ON DEFECTS OF VISION WHICH ARE REMEDIABLE BY OPTICAT, APPIIANCES. Lectures at the Royal College of Surgeons. With numerous Illustrations. Svo. $6 s$.

EYESIGHT, GOOD AND BAD : a Treatise on the Exercise and Preservation of Vision. With Illustrations. Crown 8vo. $6 s$.

CHRISTIE.-CHOLERA EPIDEMICS IN EAST AFRICA. An Account of the several Diffusions of the Disease in that country from 1821 till 1872, with an Outline of the Geography. Ethnology, and Trade Connections of the Recrions through which the Epidemies passed. By J. CHRIstie, M.D., late Physician to H.H. the Sultan of Zanzibar. With Maps. 8vo. 15s.

COOKE (JOSIAH P., Juu.).-FIPST PRINCIPLES OF CHEMICAL PHILOSOPHY. By JosiaH P. Cooke, Jun., Ervine Professor of Chemistry and Mineralogy in Harvard College. Third Edition, revised and corrected. Crown 8vo. 12s.

CREIGHTON - CONTRIBUTIONS TO THE PHYSIOLOGY AND PATHOLOGY OF THE BREAST AND ITS LYMPHATIC GLANDS. By Charles Creighton, M.D., Demonstrator of Anatomy in the University of Cambridge. With Iilustrations. Svo. $9 s$.

"It is impossible not to see at once that the work is deserving of all praise, hoth from the originality and from the care which has been bestowed upon it." Practitioner.

FLOWER (W. H.).-AN INTRODUCTION TO THE OSTEOLOGY OF THE MAMMALIA. Being the substance of the Course of Lectures delivered at the Royal College of Surgeons of England in 1870 . ' $\mathrm{By}$ W. $\mathrm{H}$. Flower, F.R.S., F.R.C.S., Hunterian Professor of Comparatire Ánatomy and Physiology. With numerous Illustrations. Second Edition, revised and enlarged. Crown 8vo. 10s. $6 d$.

FLÜCKIGER and HANBURY.-Pharmacographia : a History of the Prineipal Drugs of Vegetable Origin met with in Great Blitain and India. By F. A. FLÜCKIGER, MI.D., and D. HANBURY, F.R.S. Second Edition, rerised. Sro. $21 s$.

FOSTER.-Works by Michael Foster, M.D., F.R.S. :-

A TEXT BOOK OF PHYSIOLOGY, for the use of Medical Students and others. Third Edition, revised with Plates. 8vo. $21 s$.

"Dr. Foster has combined in this work the conflicting desiderata in all textbooks-comprehensiveness, brevity, and clearness. After a careful perusal of the whole work we can confidently recommend it, both to the student and the practitioner as being one of the best text-books on physiology extant."-Lancet.

A PRIMER OF PAYSIOLOGY. Illustrated. 15mo. 1s.

FOSTER and I.ANGLEY.-AN ELEMENTARY COURSE OF PRACTICAL PHYSIOLOGY. BY MICHAEL FUSTER, M.D., F.R.S., assisted by J. N. Langley, B.A. Third Edition, enlarged. Crown Svo. $6 s$.

"Equipped with a text-book such as this .... the beginner cannot fail to acquire a real, though of course elementary, knowledge of the leading facts and principles of Physiology."-Academy.

FOSTER and BAIFOUR.-ELEMENTS OF EMBRYOLOGY.

By MFichael Foster, M.D., F.R.S., and F. M. Batfour, M.A., Fellow of Trinity College, Cambridge. With numerous Illustrations. Part I. Crown Sro. $7 s .6 d$.

"Both text and illustrations are alike remarkable for their clcarness and freedom from error, indicatiug the immense amount of labour and care expended in the production of this most valuable addition to scientific literature."-Medical Press and Circular. 
FOTHERGILL. - Works by J. Milner Fothergill, M.D., M.R.C.P., Assistant Plysician to the Victoria Park Chest Hospital, and to the West London Hospital :-

THE PRACTITIONER'S HANDBOOK OF TREATMENT : or, THE PRINCIPLES OF RATIONAL THERAPEUTICS. S\%o. $14 s$.

"We have every reason to thank the author for a practical and suggestive work. - Lancet.

THE ANTAGONISI OF THERAPEUTIC AGENTS, AND WHAT IT TEACHES. The Essay to which was awarded the Fotliergillian Gold Medal of the Medical Society of London for 1S7S. Crown Svo. 6s.

FOX.-Works by Wilson Fox, M.D. Lond., F.R.C.P., F.P.S., Holme Professor of Clinical Meclicine, University College, London, Physician Extraordinary to her Majesty the Queen, \&c. :-

DISEASES OF THE STOMACH: being a new and revised Edition of "THE Diagnosis and Treatment of the Virintiks of Dyspepsia." Svo. 8s. $6 d$. ON THE ARTIFICIAL PRODUCTION OF TUBERCLE IN THE LOWER ANIMALS. With Colnured Plates. 4to. 5s. 6d.

ON THE TREATMENT OF HYPERPYREXIA, as Illustrated in Acute Articular Rheumatism by means of the External Application of Cold. 8vo. 2.s. $6 d$.

GALTON (D.).-AN ADDRESS ON THE GENERAL PRINCIPLES WHICH SHOULD BE OBSERVED IN THE CONSTRUCTION of hospitals. By Dovglas Galton, C.B., F.R.S. Crown 8vo. 3s. $6 d$.

GEGPNBAUR.-ELEMENTS OF COMPARATIVE ANATOMY. By Carl Gegenbaur, Professor of Anatomy and Director of the Anatomical Institute, Heidelberg. A translation by F. JEFFkEY BeLL, B.A., revised, with Preface by E. Ray Lankester, M.A., F.R.S., Professor of Zoology and Comparative Anatomy in University College, London. With numerous Illustrations. Medium Svo. 21s.

\section{GRIFFITHS.-LESSONS ON PRESCRIPTIONS AND THE} ART OF PRESCRIBING. By T. Hassel GrifftThs, Ph.D., L.R.C.P.E. New Edition. 18mo. 3s. 6 .

"We recommend it to all students and junior members of the profession who desire to understand the art of preseribing. "-Medical Fress.

HANBURY.-SCIENCE PAPERS, chiefly Pharmacological and Botanical. By Daniel HaNedry, F.R.S. Edited with Mlemoir by JosepH INCE, F.L.S.. F.C.S. 8vo. 14s.

HOOD (Wharton.).- ON BONE-SETTING (so-called), and its Relation to the Treatment of Joints Crippled by Injury, Rheumatisn, Intiammation, dece, \&c. By Wharion P. Hoov, M.D., M.R.C.S. Crown 8vo. Illustrated. 4s. $6 d$.

"Dr. Hood's book is full of instruction, and should be read by all surgeons."Medical Times.

HOOKER (Dr:).-THE STUDENT'S FLORA OF THE BRITISH ISLANDS. By Sir J. D. IJooker, K.C.S.I., C.B., M.D., D.C.L., President of the Royal Society. Second Edition, revised and corrected. Globe 8vo. 10s. $6 d$.

HUMPHRY.-Works by G. M. Humphry, M.D., F.R.S., Professor of Anatomy in the University of Cambridge, and Honorary Fellow of Downing College :-

THE HUMAN SKELETON (including the Joints). With 260 Illustration drawn from Nature. Medium Svo. 28 s.

OBSERVATIONS IN MYOLOGY. Illustrated. 8vo. $6 s$.

THE HUMAN FOOT AND HAND. Illustrated. Fcap. 8vo. 4s. $6 d$.

THE HUNTERIAN ORATION, 1879. 8vo. 2s. $6 d$. 
HUXLEY and MARTIN. - A COURSE OF PRACTICAL INSTRUCTION IN ELEMENTARY BIOLOGY. BY T. H. HUXLEY, LL.D: Sec. R.S., assisted by H. N. Martra, M.B., D.Sc. New Edition, revised. Crown 8vo. $6 s$.

“To intending medical students this book will prove of great value."-Lancet.

HUXLEY (Professor).-LESSONS IN ELEMENTARY PHY. SIOLOGY. BY T. H. HUXLEY, LL.D., F.R.S. With numerous Illustrations. New Edition. Feap. 8vo. 4s. 6d.

KEETLEY,-THE STUDENT'S GUIDE TO THE MEDICAL PROFESSION. By C. B. KEFTLEX, F.R.C S., Assistant Surgeon to the West London Hospital. With a Chapter for Women Students. By Mrs. GarretT ANDERSON. Crown Svo. 2s. $6 d$.

KÜHNE.-ON THE PHOTOCHEMISTRY OF THE RETINA AND ON VISUAL PURPLE. Translated from the German of Dr. KÜHNE, and Edited, with Notes, by Michael Foster, M.D., F.R.S. 8vo. 3s. $6 d$.

LANDAUER.-Blowpipe Analysis. By J. Landauer, Authorised English Edition by JAMES TAYLOR, and W. E. KAY of the Owens College, Manchester. With Illustrations. Extra fcap. 8vo. 4s. 6d.

LANKESTER.-COMPARATIVE LONGEVITY IN MAN AND THE LOWER animals. By E. Ray Lankester B.A. Crown 8vo. 4s. $6 d$.

LEISHMAN.-A SYSTEM OF MIDWIFERY, inclnding the Diseases of Pregnancy and the Puerperal State. By William Leishmax. M.D., Regius Professor of Midwifery in the University of Glasgow: Physician to the University Lying-in Hospital : Fellow and late Vice-President of the Obstetrical Society of London, \&c., \&c. Illustrated. Third Edition, rerised, 8vo. $21 s$.

MACLAGAN. - THE GERM THEORY APPLIED TO THE EXPLANATION OF THE PHENOMENA OF DISEASE. By T. MaclagaN, M.D. 8 vo. $10 s, 6 d$.

"We think it well that such a book as this should be written. It places before the rearler in clear and unmistakable language what is meant by the germ theory of disease."-Lancet.

MACNAMARA.-Works by C. Macnamara, F.C.U., Surgeon to Westminster Hospital :-

A HISTORY OF ASIATIC CHOLERA. Crown 8vo. 10s. 6d.

"A very valuable contribution to medical literature, and well worthy of the place which it is sure to assume as the standard work on the subject."-Medical Examiner.

DISEASES OF BONE.-CLINTCAL LeGTURES. Crown 8vo. 5s.

MACPHERSON.-Works by JoHN Macpherson, M.D. :-

THE BATHS AND WELLS OF EUROPE: their Action and Uses. With Notices of Climatic Resorts and Diet Cures. With a Map. New Edition, revised and enlarged. Extra fcap. 8vo. 6s. 6d.

OUR BATHS AND WELLS: The Mineral Waters of the British Islands. With a List of Sea-Bathing Places. Extra fcap. 8vo. 3s. $6 d$.

MANSFIELD (C. B.).-A THEORY OF SALTS. A Treatise on the Constitution of Bipolar (two-membered) Chemical Compounds. By the late Charles Blachford Mansfield. Crown 8vo. 14s.

MAUDSLEY.-Works by Henry MaUdsley, M.D., Professor of Medical Jurisprudence in Unirersity College, London:-

BODY AND MLND : An Jnquiry into their Connection and Mutnal Influence, specially in reference toMental Disorders: being the Gulstonian Lectures for 1S70. Delivered before the Royal College of Physicians. New Edition, with Psyehological Essays added. Crown 8vo. 6s. 6d.

THE PHYSIOLOGY OF MIND. Being the First Part of a Third Edition, revised, enlarged, and in great part re-written, of "The Physiology and Patbology of Mind." Crown Svo. 10s. $6 d$.

THE PATHOLOGY OF MIND. Being the Third Edition of the Second Part of "The Physiology and Pathology of Mind," recast, enlarged, and re-written. 8vo. 18s. 
MIALI,-STUDIES IN COMPARATIVE ANATOMY.

No. I. -The Skull of the Crocodile. By L. C. MIALL, Professor of Biology in the Yorkshire College of Science. 8vo, 2s. $6 d$.

No. II.-The Anatomy of the Indian Elephant. By L. C. Miall and F. Greenwood, Curator of the Leeds School of Medicine, Illustrated. 8vo. 5s. .

MIVART (St. George).-Works by Sr. George Mivart, F.R.S., \&c., Lecturer in Comparative Anatomy at St. Mary's Hospital :-

ON THE GENESIS OF SPECIES. Second Edition, to which notes have been aclded in reference and reply to Darwin's "Descent of Man." With numerous Illustrations. Crown 8vo. $9 s$.

LFSSONS IN ELEMENTARY ANATOMT. With upwards of 400 Illustrations. New Edition. Fcap. Svo. 6s. $6 d$.

"It may be questioned whether any other work on anatomy contains in like compass so proportionately great a mass of information."-Lancet.

M'KENDRICK.-OUTLINES OF PHYSIOLOGY IN ITS RELA. TIONS TO MAN. By JohN GRAY M'Kendrick, M.D., F.R.S.E., Professor of the Institute of Medicine and Physiology in the University of Glasgow. Illustrated. Crown sto. 12s. $6 d$.

MUIR.-PRACTICAL CHEMISTRY FOR MEDICAL STUDENTS. Specially arranged for the first. M. B. Course. By M. M. Patrison Murr, F.R.S.E., Prælector in Chemistry, Caius College, Cambridge. Fcap. 8vo. 1s.6d.

"This little book will aid the student not only to pass his professional examination in practical Chemistry unore easily, but will give him such an insight into the subject as will enable him readily to extend his knowledge of it should time and inclination permit."-Practitioner.

OLIVER.-LESSONS IN ELEMENTARY BOTANY. By DANIEL Oulver, F.R.S., F.L.S., Professor of Botany in University College, London, and Keeper of the Herbarium and Library of the Royal Gardens, Kew. With nearly 200 Illustrations. New Edition. Fcap. 8vo. 4.s. 6 d.

PARKER and BETTANY.-THE MORPHOLOGY OF THE SKULL. By W. K. PARKer, F.R.S., Hunterian Professor, Royal College of Surgeons, and G. T. Bettany, M.A., B.Sc., Lecturer on Botany in Guy's Hospital Medical School. Crown 8vo. 10s. 6d.

PETTIGREW.-THE PHYSIOLOGY OF THE CIRCULATION IN PLANTS, IN THE LOWER ANIMALS, AND IN MAN. By J. BELL Petrigrew, M.D.. F.R.S., etc. Illustrated by 150 Woodeuts. 8vo. 12s.

"A more original, interesting, exhaustive, or comprehensive treatise on the eirculation and the circulatory apparatus in plants, animals, and man, has never, we are certain, been offered for the acceptance of the anatomist, physiologist, or student of medicine."-Veterinary Journal.

PIFFARD.-AN ELEMENTARY TREATISE ON DISEASES OF THE SKIN, for the Use of Students and Practitioners. By H. G. Piffard, M.D., Professor of Dermatology in the University of the City of New York, \&c. With Illustrations. 8vo. 16 s.

RADCLIFFE.-Works by Charles Bland Radclifee, M.D., F. R.C.P., Physician to the Westminster Hospital, and to the National Hospital for the Paralysed and Epileptic:-

VITAL MOTION AS A MODE OF PHYSICAL MOTION. Crown 8vo. 8s. $6 d$. PROTEUS : oR UNITY IN NATURE. Second Edition. 8vo. 7s.6d.

RANSOME.-ON STETHOMETRY. Chest Examination by a more Exact Method with its Results. With an Appendix on the Chemical and Microscopical Exanination of Respired Ajr. By Arthur Ransome, M.D. With Illustrations. 8vo. 10s. 6d,

"We can recommend his book not only to those who are interested in the graphic method, but to all who are specially concerned in the treatment of diseases of the chest."-British Medical Journal. 
REYNOLDS (J. R.).-A SYSTEM OF MEDICINE. Edited by J. RUSSELL ReYNolns, M.D., F.R.S. London. In 5 Vols. Vols. I. to III., 25s. each ; Vol. IV., 21s.; Vol. V., 25 s.

Vor. I.-Part I. General Diseases, or Affections of the Whole System. Part II. Local Diseases, or Affeetions of Particular Systems. \$I.-Diseases of the Skin.

VoL. II.--Part II. Local Diseases (continued). \& I.-Diseases of the Nervous System. § II.-Diseases of the Digestive System.

Vol. III.-Part II. Local Diseases (continued). § II.-Diseases of the Digestive System (continued). \& III.-Diseases of the Respiratory System.

VoL. IV.-Diseases of the Heart. Part II. Local Diseases (cuntinued). §IV -Diseases of the Organs of Circulation.

VoL. V.-Diseases of the Organs of Circulation.-Diseases of the Vessels.Diseases of the Blood-Glandniar System.-Diseases of the Urinary Organs. -Diseases of the Female Reprodactive Organs.-Diseases of the Cutaneous System.

Also, now publishing in MONTHLY PARTS, Price 5s. each, to be completed in 24 Parts. (Part 1, April 1st, 1879.)

RICHARDSON.--Works by B. W. RichaRDSON, M.D., F.R,S. :DISEASES OF MODERN LIFE. Fifth and Cheaper Edition. Crown 8vo. $6 s$. ON ALCOHOL. New Edition. Crown 8vo. $1 s$.

HYGEIA, A CITY OF HEALTH. Crown 8vo. Is.

THE FUTURE OF SANITARY SCIENCE. Crown 8vo. $1 s$.

TOTAL ABSTINENCE. A course of addresses. Crown 8vo. 3s. $6 d$.

PREVENTIVE MEDICINE. 8vo.

[In the Press.

ROSCOE.-Works by Henky Roscoe, F.R.S., Professor of Chemistry in Ow'ens College, Manchester :-

LESSONS IN ELEMENTARY CHEMISTRY, INORGANIC AND ORGANIC. With numerous Illustrations, and Chromolithographs of the Solar Spectrum and of the Alkalies and Alkaline Earths. New Edition. Feap. Svo. 4s. $6 d$.

CHEMICAL PROBLEMS, adapted to the above. By Professor T. E. Thorpe, M.D., F.R.S.E., with Preface by Professor Roscoe. Fifth Edition, with Key. Isino. $2 s$.

PRIMER OF CHEMISTRY. Illustrated. 18mo. Is.

ROSCOE and SCHORLEMMER-A TREATISE ON INORGANIC CHEMISTRY. By Professurs Roscoe and SCHORLgmmer. Vol. I. The Non-Metallic Elements. With Numerous Illustrations and Portrait of Dalton. 8vo. 21s. Vol. II. Metals. 2 Parts. With numerous Illustrations. Svo. 18s, each.

SCHORLEMMER.-A MANUAL OF THE CHEMISTRY OF THE CARBON COMPOUNDS, OR ORGANIC CHEMISTRY. By C. Schorlemmer, F.R.S., Lecturer in Organic Chemistry in Owens College, Manchester. 8vo. 14s.

SPATON.-A HANDBOOK OF VACCINATION. By EDWARD C. Sliaton, M.D., Medical Inspector to the Privy Council. Extra fcap. Svo. Ss. $6 d$.

SEILER.-MICRO-PHOTOGRAPHS IN HISTOLOGY, Normal and Pathological. By CARI. SEILler, M.D., in eonjunetion with J. GibBons HUNT, M.D., and J. G. RichaRdson, M.D. 4to. 31.s. 6d.

\section{SPRNDPR.-THERAPEUTIC MEANS FOR THE RELIEF OF}

PAIN. Being the Prize Essay for which the Medical Society of London awarded the Fothergillian Gold Medal in 1874. By JoHN KENT SpENDER, M.D. Lond., Surgeon to the Mineral Water Hospital, Bath. 8vo. 8s. $6 d$. 
STEWART (B.).-LESSONS IN ELEMENTARY PHYSICS. BV BatFotr STEWARt, F.R.S. Professor of Natural Philosopht in Orens Collere. Manchester. With Tumerons Inustrations and Chromolithograph of the Spectra of the Sun, Stars, and Nebulx. Ner Edition. Fcap. Sro. 4s. 6 d. PRIMER OF PHISICS. Br the same Author. Innstrated. 13mo. 1 s.

TUKE,-INSAYITY IN ANCIENT AND MODERA LIFE, with Chapters on its Prerention. B! D. HAck ItKe, M. D., F.R.C.P. Crown Sro. $6 s$.

"This work exhibits deep research in rarious directions, and teems with allusions and quotations which prove the author to be not onle an accomplished psrchoIozical phrsician, but a scholar of no mean order." - Meaical Times.

WEST.-HOSPITAL ORGANISATIOX. With special reference to the orzanisation of Hospitals for Children. Br Charles West, M.D. Founder of, and for twentr-three years Physician to, the Hospital for Sick Children. Cromn Sro. $2 s, \dot{0} \vec{a}$.

WURTZ.-A HISTORY OF CHEYICAT THEORY from the Age of Laroisier domn to the present time. BT AD. Wertz. Translated by Hexis WATTS, F.R.S. Crown Sro. Bंs.

\section{IIANUALS FOR STUDENTS.}

A TEXT BOOK OF PHYSIOLOGY. BY MichaEL FOSTER, ML., F.R.S. Third Edition, revised, with Piates. Éro. 2is.

ELEMENTS OF COMPARATIVE ANATOMY. BY CARL GEGEXBACR, Professor of Anatoms and Director of the Anatomical institute, Heidelberg. A translation br F. JeFFrer BeLL. B.A, revised, with Preface by E. RAr LANkester, M.A., F.R.S., Professor of Zoologr and Comparatire Anatons in University College, London. With namerous Illastrations. Medium 8ro. 218.

A TREATISE 0N INORGANIC CHRMISTRY. By Professors Roscoe and Sceoriemure. Fol. I. The Non-Jietallic Elements. With Numerous Illastrations and Portrait of Dalton. 5re. 21s. Vol. II. Metals. 2 Parts. With numerous Illustrations. Sro. 18s. each.

THE MORPHOLOGY OF THE SKUJI. Br T. K. PAREER, F.R.S., Hunterian Protessor, Roral College of Surzeons, and G. T. Bertart, B.Sc., Lecturer on Botany in GuY S Hospital Medical School. Illustrated. Cromn sro. 10: 6 d.

THE OSTEOLOGY OF THE MAMMALIA: A Series of Lectures or Prot. $\Pi$. H. Flower. F.R.S., F.R.C.S. With numerocis Illustrations. New Edition, en'arged. Crom sro. 103. 6 .

THE ELEMENTS OF EMBRYOLOGY. By Michael Foster, M.D., F.R.S., and F. M. BALFOCR, MI.I. Part I. Ts. 6 .

PRACTICAL PHYSIOLOGY : an Elementart Course of. By Dr. 3. Foster, assisted bJ J. Lasgler. Jer Edition. Crown Ero. 6s.

ELEMENTARY BIOLOGY : a Course of Practical Instruction in. By Prof Hexles and H. X. Mstris. New Edition. Cromsio. bis.

PHYSIOGRAPHY: an Introduction to the Study of Tature. $\mathrm{By}$ Pme Hislrs, F.R.S. With Coloured Plates and Toodeuts. New Edition. Croxas $8: 0$. 7. 6 . 
PRICE EIGHTEENPENCE, MONTHLY,

\section{THE PRACTITIONER ;}

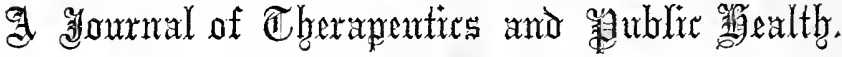

EDITED BY

T. LAUDER BRUNTON, MI.D., F.R.S.,

Fellow of the Royal College of Physicians;

Assistant Physicion to St. Bartholomew's Hospital; and Lecturer on Materia Ifedica and Therapeutics in St. Bartholomew's Hospital Sehool.

CONTENTS.

Original Communications-Reviews of Books-Clinic of the Month-Extracts from British and Foreign Journals-Notes and Queries-Bibliography-and the Public Health Department.

In Quarterly Parts, price 3s. 6d., and Yearly Volumes, 15 s.

\section{B R A I N :}

\section{A JOURNAL OF NEUROLOGY.}

EDITED BY

J. C. BUCENILL, M.D., M.R.C.P., F.R.S.

J. CRICHTON-BROW NE, M.D., F.R.S.E.

D. FERRIER, M.D., F.R.C.P., F.R.S.

J. HUGHLINGS-JACKSON, M.D., F.R.C.P.

Contents-Original Articles, cousisting mainly of Clinical and Pathólogical Records and Anatomical and Physiological Researches, Human and Comparative, on the Nervous System. Signed Critical Digests and Reviews of Clinical, Experimental and other Researches in this department of science, both at home and abroad. Foreign Correspondence. It will be the object of "BraIN" to keep its readers well abreast of modern progress in Neurology, and to advance the knowledge of a class of disease respecting which it is universally admitted that much has yet to be learnt.

\section{THE JOURNAL OF PHYSIOLOGY.}

\section{EDITED}

(With the co-operation in England of Prof. A. GAMGEE; F.R.S., of Manchester; Prof. W. RUTHERFORD, F.R.S.. of Edinburgh; Prof. J. B. SANDERSON, F.R.S., of London; and in America of Prof. H. P. BOWDITCH, of Boston; Prof. H. N. MARTIN, of Baltimore; and Prof. H. C. WOOD, of Philadelphia) by

$$
\begin{gathered}
\text { DR. MICHAEL FOSTER, F.R.S., } \\
\text { Of Trinity College, Cambridge. }
\end{gathered}
$$

It is proposed to publish it in parts, not at rigidly fixed times, but according to the supply of material. Every effort, however, will be made to prevent any unnecessary irregularity in the appearance of the successice parts. About four or six parts, the exact number depending on the size of the several parts, will form a volume of about 500 pages. The volume will not necessarily coincide with the year; its jssue, like that of the constituent parts, will depend on the abundance of contributions.

The snbscription-price for the volnme, post free, will be, when paid in advance-

For Great Britain or America $\quad \ldots \quad \ldots \quad \ldots \quad \ldots 11$ s., or $\$ 5,25$ (gold).

Each part, as well as each volume, may also be obtained in the usual way through the trade, at the rate of $£ 111 s .6 d$. per volume, the exact price of each part, being dependent on its size, \&c. 


$R C \times 40$

385

Buokrill

Care of truizsare 
